NASA/TM-2000-209891, Vol. 207

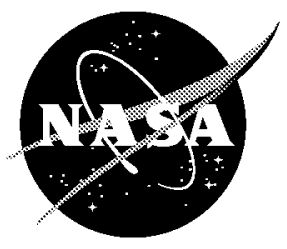

Technical Report Series on the Boreal Ecosystem-Atmosphere Study (BOREAS)

Forrest G. Hall and Karl Huemmrich, Editors

\title{
Volume 207 \\ BOREAS TF-10 NSA-Fen Tower Flux and Meteorological Data
}

J. Harry McCaughey and Dennis E. Jelinski

Queen's University, Kingston, Ontario

National Aeronautics and

Space Administration

Goddard Space Flight Center

Greenbelt, Maryland 20771 
The NASA STI Program Office ... in Profile

Since its founding, NASA has been dedicated to the advancement of aeronautics and space science. The NASA Scientific and Technical Information (STI) Program Office plays a key part in helping NASA maintain this important role.

The NASA STI Program Office is operated by Langley Research Center, the lead center for NASA's scientific and technical information. The NASA STI Program Office provides access to the NASA STI Database, the largest collection of aeronautical and space science STI in the world. The Program Office is also NASA's institutional mechanism for disseminating the results of its research and development activities. These results are published by NASA in the NASA STI Report Series, which includes the following report types:

- TECHNICAL PUBLICATION. Reports of completed research or a major significant phase of research that present the results of NASA programs and include extensive data or theoretical analysis. Includes compilations of significant scientific and technical data and information deemed to be of continuing reference value. NASA's counterpart of peer-reviewed formal professional papers but has less stringent limitations on manuscript length and extent of graphic presentations.

- TECHNICAL MEMORANDUM. Scientific and technical findings that are preliminary or of specialized interest, e.g., quick release reports, working papers, and bibliographies that contain minimal annotation. Does not contain extensive analysis.

- CONTRACTOR REPORT. Scientific and technical findings by NASA-sponsored contractors and grantees.
- CONFERENCE PUBLICATION. Collected papers from scientific and technical conferences, symposia, seminars, or other meetings sponsored or cosponsored by NASA.

- SPECIAL PUBLICATION. Scientific, technical, or historical information from NASA programs, projects, and mission, often concerned with subjects having substantial public interest.

- TECHNICAL TRANSLATION. English-language translations of foreign scientific and technical material pertinent to NASA's mission.

Specialized services that complement the STI Program Office's diverse offerings include creating custom thesauri, building customized databases, organizing and publishing research results ... even providing videos.

For more information about the NASA STI Program Office, see the following:

- Access the NASA STI Program Home Page at http://www.sti.nasa.gov/STI-homepage.html

- E-mail your question via the Internet to help@sti.nasa.gov

- Fax your question to the NASA Access Help Desk at (301) 621-0134

- Telephone the NASA Access Help Desk at (301) 621-0390

- Write to:

NASA Access Help Desk

NASA Center for AeroSpace Information 7121 Standard Drive Hanover, MD 21076-1320 
NASA/TM-2000-209891, Vol. 207

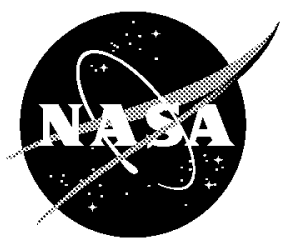

Technical Report Series on the Boreal Ecosystem-Atmosphere Study (BOREAS)

Forrest G. Hall and Karl Huemmrich, Editors

\section{Volume 207 \\ BOREAS TF-10 NSA-Fen Tower Flux and Meteorological Data}

J. Harry McCaughey and Dennis E. Jelinski

Queen's University, Kingston, Ontario

National Aeronautics and

Space Administration

Goddard Space Flight Center

Greenbelt, Maryland 20771 


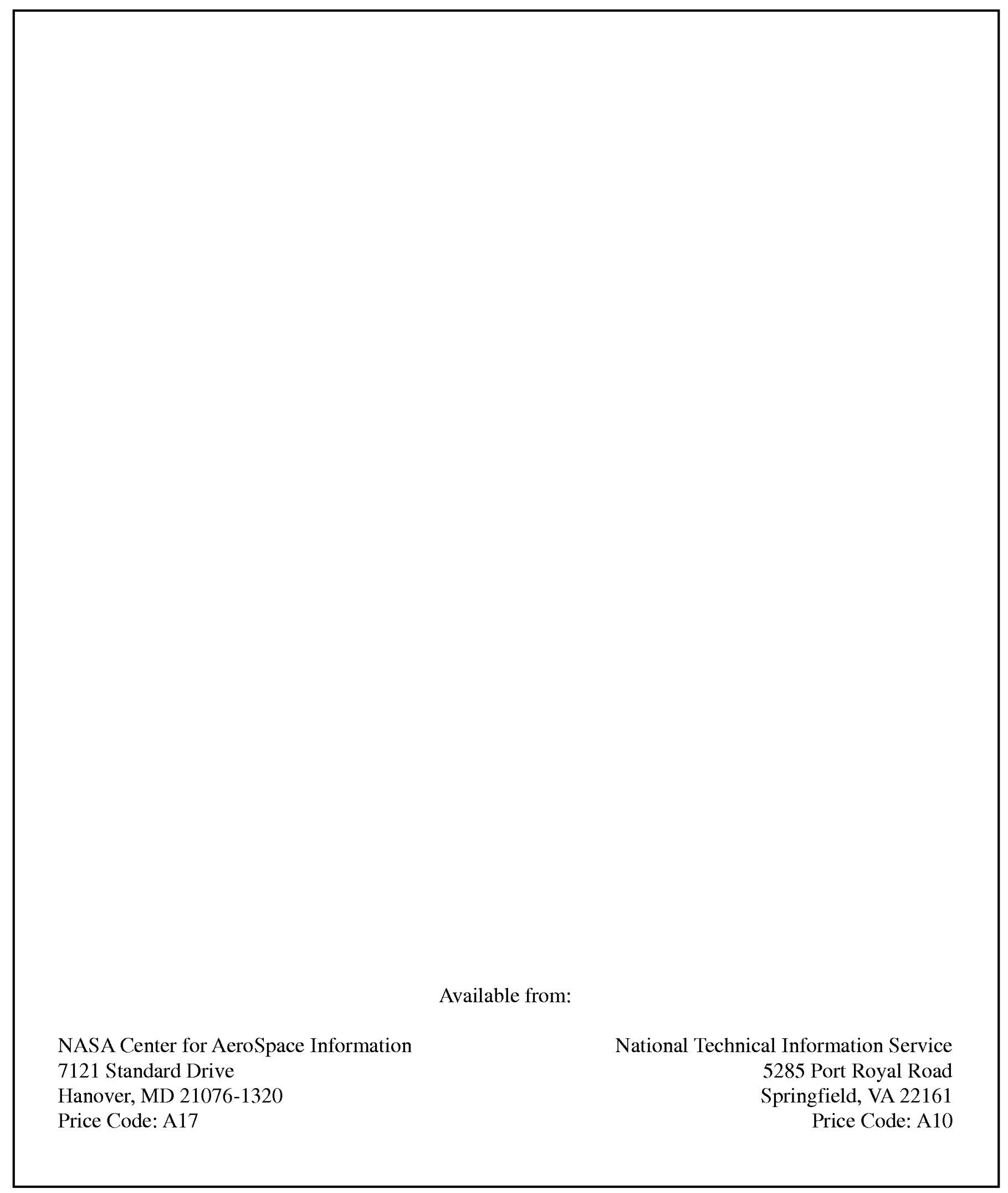




\title{
BOREAS TF-10 NSA-Fen Tower Flux and Meteorological Data
}

\author{
J. Harry McCaughey, Dennis Jelinski
}

\section{Summary}

The BOREAS TF-10 team collected tower flux and meteorological data at two sites, a fen and a young jack pine forest, near Thompson, Manitoba, Canada, as part of BOREAS. A preliminary data set was assembled in August 1993 while field testing the instrument packages, and at both sites data were collected from 15-Aug to 31-Aug. The main experimental period was in 1994, when continuous data were collected from 08-Apr to 23-Sep at the fen site. A very limited experiment was run in the spring/summer of 1995, when the fen site tower was operated from 08-Apr to 14-Jun in support of a hydrology experiment in an adjoining feeder basin. Upon examination of the 1994 data set, it became clear that the behavior of the heat, water, and carbon dioxide fluxes throughout the whole growing season was an important scientific question, and that the 1994 data record was not sufficiently long to capture the character of the seasonal behavior of the fluxes. Thus, the fen site was operated in 1996 in order to collect data from spring melt to autumn freeze-up. Data were collected from 29-Apr to 05-Nov at the fen site. All variables are presented as 30-minute averages. The data are stored in tabular ASCII files.

\section{Table of Contents}

1) Data Set Overview

2) Investigator(s)

3) Theory of Measurements

4) Equipment

5) Data Acquisition Methods

6) Observations

7) Data Description

8) Data Organization

9) Data Manipulations

10) Errors

11) Notes

12) Application of the Data Set

13) Future Modifications and Plans

14) Software

15) Data Access

16) Output Products and Availability

17) References

18) Glossary of Terms

19) List of Acronyms

20) Document Information

\section{Data Set Overview}

\subsection{Data Set Identification}

BOREAS TF-10 NSA-Fen Tower Flux and Meteorological Data

\subsection{Data Set Introduction}

The meteorological data collected from the fen and Young Jack Pine (YJP) towers represent, in some sense, polar opposites of the range of surface climate conditions expected in the boreal forest. The fen is normally characterized by abundant water close to, or located at, the surface, whereas the 
YJP site can be one of the driest surfaces in the boreal forest. Jack pine generally inhabit well-drained, sandy soils where, in the absence of regular precipitation, a significant water deficit can develop. The data presented here bear out the contrast in the surface climate conditions experienced by the two sites. For example, in the driest periods in the summer of 1994 it was common to measure mid-afternoon Bowen ratios in the range of 10 to 15 , leading to the characterization of the site as a "Green Desert"; at the same time, the typical Bowen ratio at the fen seldom exceeded 1.0, and was usually closer to 0.8 .

The YJP site can be fairly described as a fast response surface in that there were major and rapid changes in flux behavior, especially in evaporation, as the site was wetted or when it dried down. No such behavior could be ascribed to the fen because of the steadier supply of surface water.

A broad array of supporting data was also collected to describe the surface's state and to provide the information, in association with the flux data, to build Soil-Vegetation-Atmosphere-Transfer (SVAT) models. At the fen, our ancillary data collection focused upon the spatial pattern of vegetation present on the fen. These ancillary data are available upon request from the Principal Investigator (PI) for the fen site, Dr. D. Jelinski.

\subsection{Objective/Purpose}

This project is concerned with the spatial heterogeneity of surface energy fluxes in the northern boreal forest. The study was designed to compare surface radiation, energy, water, $\mathrm{CO}_{2}$ fluxes, and their biophysical controls at both wetland and upland forest sites within the northern boreal forest. Specific objectives of the study were as follows:

- To quantify the differences between surface-atmosphere interactions between the sites.

- To compare hydrological estimates of basin evaporation to modeled water loss values (computed from knowledge of the vegetational composition of homogeneous landscape units and their ecotones, and the functional response of these units to climatic forcing.

- To provide continuous tower fluxes of water, sensible heat, $\mathrm{CO}_{2}$ in support of the development of SVAT models at the stand and regional scales.

Data for this study were collected on two sites in the BOReal Ecosystem-Atmosphere Study (BOREAS) Northern Study Area (NSA) at Thompson, Manitoba: a young jack pine forest (YJP), and a fen wetland.

\subsection{Summary of Parameters}

The following variables were measured at the fen: net radiation, incoming and reflected solar radiation, incoming and outgoing longwave radiation, incoming and reflected photosynthetic photon flux density (PPFD), wind speed, wind direction, wet- and dry-bulb temperature, soil temperature, soil heat flux, sensible heat flux, latent heat flux, $\mathrm{CO}_{2}$ flux, rainfall, and water level.

\subsection{Discussion}

The primary objective of this project was to develop a full suite of radiation, energy, and $\mathrm{CO}_{2}$ flux measurements for the two flux tower sites. At both towers, identical instrumentation was used for data collection. The measurement systems used can be briefly summarized as follows:

- $\quad$ Radiation balance fluxes, including PPFD, were monitored using standard instrumentation mounted near the top of the flux towers.

- $\quad$ Soil heat flux $(\mathrm{G})$ was measured using soil heat flux plates combined with calorimetric calculations of heat storage (see Sections 4.1 and 9.1).

- Convective fluxes of latent (LE) and sensible (H) heat were measured directly via the eddy covariance technique.

- $\quad$ Net $\mathrm{CO}_{2}$ flux ( $\left.\mathrm{Fe}_{\mathrm{CO} 2}\right)$ was measured using an eddy covariance system; this system consisted of a single-axis sonic anemometer and a fast-response infrared $\mathrm{CO}_{2}$ gas analyzer. The air intake was located at the same level as the sonic anemometer, and air was drawn down to the gas analyzer at the base of the tower. Lag times between the gas analyzer signal and the sonic anemometer signal were included in the online processing of the flux; offline processing included heat flux density corrections (Webb et al., 1980) and $\mathrm{CO}_{2}$ storage in the air layer between the intake and the surface. 
Flux data were supported with accompanying meteorological measurements. At each site, profiles of wind speed, temperature, and humidity were measured in the lower boundary layer. In addition, soil and biomass temperatures, wind direction, and rainfall were monitored.

Tower data at both sites were collected from 15-Aug to 31-Aug-1993. In 1994, the YJP tower was operational almost continuously from 23-May to 30-Sep, and the fen tower was operational from 08-Apr to 23-Sep. Before 01-Jun, only convective energy fluxes and the supporting profile data were measured at the fen to support an associated hydrological study of snowmelt in an adjoining basin during the Focused Field Campaign (FFC) from 12-Apr to 02-May. $\mathrm{CO}_{2}$ flux data came online at the fen by 01-Jun-1994. In 1995, only the fen was operational to support the continuation of the hydrological experiment; data were collected from the tower from 15-Apr to 10-Jun. In 1996, the measurement period at the YJP extended from 08-May to 07-Nov at the fen, data were collected from 29-Apr to 05-Nov.

\subsection{Related Data Sets}

BOREAS AFM-07 SRC Surface Meteorological Data

BOREAS HYD-01 Volumetric Soil Moisture Data

BOREAS TGB-01/TGB-03 NEE Data over the NSA Fen

BOREAS TF-11 SSA-Fen Tower Flux and Meteorological Data

BOREAS TF-10 NSA-YJP Tower Flux, Meteorological, and Porometry Data

\section{Investigator(s)}

\subsection{Investigator(s) Name and Title}

Dr. J. Harry McCaughey

(Principal Investigator at NSA-YJP)

Department of Geography

Queen's University

Dr. Dennis E. Jelinski

(Principal Investigator at NSA-Fen)

Department of Geography

Queen's University

Two PIs were associated with the Tower Flux (TF)-10 group: Harry McCaughey and Dennis Jelinski. Harry McCaughey oversaw the tower fluxes at both the NSA-YJP and the NSA-Fen sites. Dennis Jelinski was responsible for the vegetation work at the NSA-Fen site. Peter Lafleur shared responsibility for measurements at both sites. David Fitzjarrald (Principal Investigator for the TF-08 group) kindly loaned the TF-10 team a sonic anemometer and associated equipment that were used at the NSA-Fen site in 1996. The TF-10 team is grateful for Dr. Fitzjarrald's contribution, his help with field deployment of the equipment, and his advice at all stages of the work. As well, the TF-10 team acknowledges the help and advice of Kathy Moore and R.K. Sakai, members of the TF-08 team.

In addition, a large group of very competent graduate students, field assistants, and technicians contributed to the overall success of the work. Special mention goes to David Joiner and Paul Bartlett

(Queen's University). David developed and built the $\mathrm{CO}_{2}$ measurement system. Paul started work as a technician in the group and later stayed at Queen's University as a doctoral student. He made many contributions, but special mention must go to his work on assembling and organizing the deployment of equipment in 1993 and to his porometry work at the YJP site in 1994 and 1996. Andrew Costello (Queen's University), helped in the field setup in 1993 and did most of the initial stand measurements on the YJP canopy. He was assisted by Blair Mantha from Trent. Bob Metcalfe, Queen's and Trent, worked on an associated hydrology project focused upon the feeder basin north of the fen. He was supervised jointly by Jim Buttle, Trent University, and Harry McCaughey. Mike Skarupa and Greg Bryant, Trent, assisted in the data collection efforts at both sites. Kristan Boudreau was an outstanding field assistant and she performed excellent work in 1994 in all facets of the experiments at both sites. 
Bruce Robertson and Derek Mueller were able field assistants in 1996.

Finally, a special thanks to Laura Liblik, who did the majority of the work associated with the preparation of the data before its submission to the BOREAS Information System (BORIS). Her attention to detail, her writing, and her editorial skills are much appreciated.

\subsection{Title of Investigation}

Surface Energy and Water Balances of Forest and Wetland Subsystems in the Boreal Forest Surface Atmosphere Links and Ecological Controls

\subsection{Contact Information}

\section{Contact 1:}

Dr. J. Harry McCaughey

Dept. of Geography

Queen's University

Kingston, ON

CANADA

K7L 3N6

(613) 545-6035

(613) 545-6122 (fax)

mccaughe@post.queensu.ca

\section{Contact 2:}

Dr. Peter M. Lafleur

Dept. of Geography

Trent University

Peterborough, ON

CANADA

K9J 7B8

(705) $748-1487$

(705) 748-1205 (fax)

plafleur@trentu.ca

\section{Contact 3:}

Dr. Dennis Jelinski

School of Environmental Studies

Queen's University

Kingston, Ontario

CANADA

K7L 3N6

(613) 545-6875

(613) 545-6617 (fax)

dj4@qsilver.queensu.ca

\section{Contact 4:}

K. Fred Huemmrich

Code 923

NASA GSFC

Greenbelt, MD 20771

(301) 286-4862

(301) 286-0239 (fax)

Karl.Huemmrich@gsfc.nasa.gov 


\section{Theory of Measurements}

Many of the individual measurements made during the study involved routinely collected data obtained with a single instrument (e.g., incoming solar radiation and temperature measurement with thermocouples). Such measurements represent standard data collection techniques, and specific, detailed elaboration is not provided in this report. However, there is discussion of some limited aspects of these routine measurements where such detail is required for a complete understanding. Readers are referred to the manufacturers' specifications for details on the theory of measurement and operation of individual instruments.

The following section describes only the measurement method used for the fluxes.

Sensible (H) and latent (LE) heat fluxes, and the net flux of $\mathrm{CO}_{2}\left(\mathrm{Fe}_{\mathrm{CO} 2}\right)$ (net ecosystem exchange, NEE) were found using the eddy covariance technique (Campbell and Unsworth, 1979; Tanner et al., 1993). Fluxes are computed as the time-averaged product of the fluctuations of vertical wind velocity $\left(w^{\prime}\right)$ and fluctuations of the appropriate scalar (the covariance). For example, fluctuations of temperatures $\left(\mathrm{T}^{\prime}\right)$ for $\mathrm{H}$, water vapor density $\left(\mathrm{q}^{\prime}\right)$ for $\mathrm{LE}$, and $\mathrm{CO}_{2}$ concentration $\left(\mathrm{C}^{\prime}\right)$ for $\mathrm{Fe}_{\mathrm{CO} 2}$, give:

$$
\begin{aligned}
& \mathrm{LE}=\mathrm{L}<\mathrm{w}^{\prime} \mathrm{q}^{\prime}> \\
& \mathrm{H}=\operatorname{rho} \mathrm{Cp}<\mathrm{w}^{\prime} \mathrm{T}^{\prime} \\
& \mathrm{Fe}_{\mathrm{CO} 2}=\operatorname{rho}(\mathrm{c})<\mathrm{w}^{\prime} \mathrm{C}^{\prime}
\end{aligned}
$$

where $\mathrm{L}$ is the latent heat of vaporization of water $(\mathrm{J} / \mathrm{kg})$, rho is the density of air $\left(\mathrm{kg} / \mathrm{m}^{3}\right), \mathrm{Cp}$ is the specific heat of air at constant pressure $\left(\mathrm{J} / \mathrm{kg} /{ }^{\circ} \mathrm{C}\right)$, $\mathrm{rho}(\mathrm{c})$ is the density of $\mathrm{CO}_{2}\left(\mathrm{~kg} / \mathrm{m}^{3}\right)$, and the $<>$ symbol represents a time averaged product or covariance.

In practical terms, the eddy covariance technique is very sensitive to site conditions and instrument response. For one-dimensional measurements the site is assumed to be perfectly flat. This eliminates net positive or negative horizontal advection. Ideally, the response time of the instrument should be fast enough to monitor the complete spectrum of frequencies occurring in the turbulent flow. However, the total response is determined by the response time of the individual sensor, the instrument size and orientation, and the capacity to monitor the signal. Where two sensors are required, one to monitor $w^{\prime}$ and the other to monitor the appropriate scalar variable ( $T^{\prime}, q^{\prime}$, or $\left.C^{\prime}\right)$, then separation of the instruments in horizontal space introduces a possible error of mismatched frequencies sensed by the two systems. It is desirable to have the instruments as close together as possible; however, this can result in distortion of the wind field of one instrument by the presence of the other. A compromise is needed to overcome these two opposing problems, and sensors are typically placed $0.30 \mathrm{~m}$ to $0.40 \mathrm{~m}$ apart. Given the current status of data logging capacity, eddy covariance instruments are usually sampled at a rate of $10 \mathrm{~Hz}$ or greater.

\section{Equipment}

\subsection{Sensor/Instrument Description}

\section{Micrometeorological Instruments}

Meteorological and flux data at both sites were collected with similar instrumentation. Instruments were mounted on towers as described in Section 4.1.2. A listing of instrumentation follows.

- $\quad$ Net radiation was measured with a net pyrradiometer (model CN-1 Middleton, Carter-Scott Design, Victoria, Australia) aspirated with dry nitrogen gas.

- Incoming and outgoing solar radiation was measured with pyranometers (model 8-48, Eppley Laboratories Inc., Newport, RI, USA). 
- $\quad$ Outgoing longwave radiation was measured with a pyrgeometer (model PIR, Eppley Laboratories Inc., Newport, RI, USA).

- Incoming and outgoing PPFD were measured with quantum sensors (model LI-Q190SA, LI-COR, Inc., Lincoln, NE, USA).

- Absolute wet- and dry-bulb temperatures were measured with psychrometers constructed from PVC tubing covered with reflective tape. Ventilation was supplied by a 12 -volt DC fan that gave an air flow between 4-6 m/s across the sensor. The sensors were single-junction 24 a.w.g. copper-constantan thermocouples sealed with epoxy in stainless steel tubing $(250 \mathrm{~mm}$ in length, $3.5 \mathrm{~mm}$ in diameter). The wet-bulbs were covered with cotton wicking to a length of $150 \mathrm{~mm}$.

- Wind speeds were measured with 3-cup anemometers (model 12102, R.M. Young Co., Traverse City, MI, USA). The anemometers contained a DC generator that produced an analog signal proportional to wind speed.

- Wind direction was measured with a vane (model 12302, R.M. Young Co., Traverse City, MI, USA) containing a potentiometer that designated direction as proportional to the voltage output.

- $\quad$ Rainfall was measured with tipping bucket gauges (model TE252M, Campbell Scientific, Inc., Logan, UT, USA).

- $\quad$ Soil temperatures were measured with single-junction copper-constantan thermocouples (24 a.w.g.) fixed into a 3.18 -cm-diameter wooden dowel inserted into the soil. Two soil temperature rods were installed at each site in order to sample soil temperatures below different cover types.

At the fen, one soil temperature rod was installed in a moss hummock where the zero level (effectively the surface of the moss) was, on average, $25-30 \mathrm{~cm}$ above the water table. The second rod was placed in an adjacent hollow, where zero was effectively at the mean water table level. In each location, temperatures were measured at depths of 1, 5, 10, 25, 50, 75, 100, 150, and $200 \mathrm{~cm}$ during both 1993 and 1994.

- Soil heat flux was measured at each site with two soil heat flux plates (model HFT-3, Radiation Energy Balance Systems, Inc. (REBS), Seattle, WA, USA). Values from these instruments, combined with the soil temperature profiles, were used to calculate soil heat flux at each site as follows.

At the fen, measurements were taken at a depth of $2 \mathrm{~cm}$ below the moss surface at a hummock and at a depth of $7.5 \mathrm{~cm}$ below the surface water in a hollow, which corresponded to a depth of $17 \mathrm{~cm}$ below the moss surface of the hummock. Heat flux plates, traditionally used to measure the soil heat flux, are known to perform poorly in organic (peat) soils. This may occur because the thermal conductivity of the plate is usually much greater than that of organic material and/or because it is difficult to get good thermal contact between the plate and the surrounding soil. For these reasons, it is recommended that heat flux plate readings be adjusted with a correction factor determined from calorimetric calculations of total heat storage (Halliwell and Rouse, 1987). According to this technique, heat storage in distinct soil layers is calculated from soil heat capacity and measured temperatures. Heat storage in each layer is accumulated, and conduction beneath the lowest layer is added to compute total heat storage. This value is then divided by the heat flux value measured from the plate to give a correction factor. The calculations are usually done over periods of several days, and the correction factor is applied to the half-hourly heat flux plate measurements (see Section 9.1). We divided that it was necessary to use a correction factor only for the 1994 data set. In 1996, the values of soil heat flux measured by the plates in the hummock and hollow were reasonable, and applying a correction similar to that used in 1994 would have produced values of flux that were unreasonably high. It was concluded that the thermal contact between the plates was better in 1996 than in 1994. However, it must be acknowledged that the measurement of heat storage in a fen remains a scientific concern.

- Data Logging: All tower variables (except eddy covariance) were recorded on data loggers (model CR7X, Campbell Scientific, Inc., Logan, UT, USA). The eddy covariance signals were recorded on data loggers (model 21X, Campbell Scientific, Inc., Logan, UT, USA). 
- $\mathrm{CO}_{2}$ concentration and flux densities were measured with a system designed at Queen's University by D. Joiner. It consisted of a single-axis sonic anemometer (mentioned above) and a fast response infrared gas analyzer (IRGA) (model LI-6252, LI-COR, Inc., Lincoln, NE, USA).

Air is drawn by an AC pump from the intake of a tube (1/4" i.d. Bev-a-line IV) situated on the sonic anemometer arm to the IRGA at the base of the tower. The flow is split before reaching the IRGA, and the line to the IRGA passes through a fine particle filter. Air from the IRGA passes a pressure transducer (model PX142, Omega Engineering, Stamford, CT, USA) and a mass flow sensor (model 5860E, Brooks Instruments Division, Hatfield, PA, USA).

Cross-correlation analysis was used to determine the travel time of the air from the tube inlet to the gas analyzer. The $\mathrm{CO}_{2}$ flux density was then determined with the eddy covariance technique by finding the covariance of the $10-\mathrm{Hz}$ direct output from the gas analyzer with time-lagged vertical wind velocity measured with a one-dimensional sonic anemometer (model CA-27, Campbell Scientific, Inc., Logan, UT, USA).

The direct output from the IRGA was calibrated once a day using calibration gases flowing through the gas analyzer at the same pressure as that of the air down the tower. These field calibrations, linear over the range of ambient $\mathrm{CO}_{2}$ concentrations and unchanging with temperature, were constantly corrected for pressure changes recorded with the gauge pressure transducer.

Data processing and storage were done on data loggers (model 21X, Campbell Scientific, Inc., Logan, UT, USA), using the covariance at $10-\mathrm{Hz}$ data and a $15-$ minute averaging subinterval. The $\mathrm{CO}_{2}$ flux data were corrected for fluctuations of temperature and water vapor density during postseasonal analysis (Webb et al., 1980).

Absolute concentrations of $\mathrm{CO}_{2}$ were calculated using the factory calibration equation supplied with the LI-6252 and were corrected for air pressure fluctuations. Station values for air pressure (obtained from the Thompson airport) were entered daily as a constant into the data loggers. Daily field calibration of the IRGA showed that the absolute concentration may exhibit a drift of up to 3 ppmv over a 24-hour period.

Final $\mathrm{CO}_{2}$ flux density values combine the contributions from both the eddy flux and the changes in $\mathrm{CO}_{2}$ storage for the volume of air beneath the eddy covariance instruments.

\section{Biophysical Instruments}

Water level in the fen was monitored continuously at the tower with an electronic water level recorder, which consisted of a weighted float connected to a potentiometer. The continuous output of the potentiometer is proportional to the relative water level in the fen. Water level is reported as a relative height in $\mathrm{mm}$ from an arbitrary datum. The datum zero represented the water level on the first day/hour of measurements: day of year (DOY) 230 at 1800 Universal Time Code (UTC) in 1993, DOY 127 at 1030 UTC in 1994, and DOY 140 at 2300 UTC in 1995.)

\subsubsection{Collection Environment}

The instruments were operated mainly under summer conditions with maximum temperatures around $35^{\circ} \mathrm{C}$. Data were collected over the growing season of 1994 , the spring of 1995 , and the spring through fall/winter of 1996. In the spring and fall/winter seasons, more extreme low temperatures were experienced. During these periods, the environment was more severe, and freezing temperatures were common; the lowest temperatures experienced were around $-30^{\circ} \mathrm{C}$.

\subsubsection{Source/Platform}

The towers erected at the YJP and fen sites were 12-meter-tall triangular communications type, guyed on three sides, and anchored into the mineral soil. At the fen, the mineral soil was approximately $6 \mathrm{~m}$ below the mean surface. A floating boardwalk was constructed from the shore to the tower, and a $2.44-\mathrm{m}$ by $2.44-\mathrm{m}$ platform was built at the base of the tower. 
At both sites, all sensors were mounted on the towers with fixed aluminum $(3.18 \mathrm{~cm}$ diameter $)$ extension arms, with the exception of the eddy covariance equipment, which was mounted on a swivel system, allowing for orientation of the instruments into the wind. Sensor height above the surface, distance from the tower, and orientation (degrees from magnetic north) are given in Table 1.

Table 1. Sensor heights on the flux tower at the fen in 1993, 1994, 1995, and 1996. The orientation of the arm holding the sensor is given in degrees measured from magnetic north, and the distance $(\mathrm{m})$ from the tower is given. The symbol n/a, indicating "not applicable," means that no measurements were taken. The orientation of the arm holding the sonic anemometer and the krypton hygrometer was variable on a swivel mount that could be set anywhere from $150^{\circ}$ from magnetic north through $360^{\circ}$ to $55^{\circ}$ from magnetic north.

\begin{tabular}{|c|c|c|c|c|c|c|}
\hline \multirow[t]{2}{*}{ Variable [Sensor] } & \multicolumn{4}{|c|}{ Height(m) } & \multirow{2}{*}{$\begin{array}{l}\text { Distance } \\
\quad(\mathbf{m})\end{array}$} & \multirow{2}{*}{$\begin{array}{l}\text { Orientation } \\
\text { (degrees) }\end{array}$} \\
\hline & 1993 & 1994 & 1995 & 1996 & & \\
\hline Incoming Solar Radiation [pyranometer] & 10.47 & 10.47 & 10.47 & 10.47 & 1.5 & 135 \\
\hline Outgoing Solar Radiation [pyranometer] & 10.23 & 10.23 & 10.23 & 10.23 & 1.5 & 135 \\
\hline $\begin{array}{l}\text { Outgoing Longwave Radiation } \\
\text { [pyranometer] }\end{array}$ & 10.33 & 10.33 & 10.33 & 10.33 & 1.5 & 265 \\
\hline Net Radiation [net pyrradiometer] & 10.45 & 10.45 & 10.45 & 10.45 & 2.3 & 155 \\
\hline Incoming PPFD [quantum sensor] & 10.49 & 10.49 & 10.49 & 10.49 & 1.5 & 145 \\
\hline Outgoing PPFD [quantum sensor] & 10.31 & 10.31 & 10.31 & 10.31 & 1.5 & 145 \\
\hline \multicolumn{7}{|l|}{$\begin{array}{l}\text { Wet- and Dry-bulb Temperatures } \\
\text { [thermocouples] }\end{array}$} \\
\hline $\begin{array}{l}\text { Level } 1 \\
\text { Level } 2 \\
\text { Level } 3 \\
\text { Level } 4 \\
\text { Level } 5 \\
\text { Level } 6\end{array}$ & $\begin{array}{l}2.57 \\
3.59 \\
4.65 \\
5.75 \\
6.55 \\
7.65\end{array}$ & $\begin{array}{l}2.50 \\
3.25 \\
4.00 \\
5.00 \\
6.00 \\
7.50\end{array}$ & $\begin{array}{l}2.50 \\
3.25 \\
4.00 \\
5.00 \\
6.00 \\
7.50\end{array}$ & $\begin{array}{l}2.50 \\
\mathrm{n} / \mathrm{a} \\
\mathrm{n} / \mathrm{a} \\
\mathrm{n} / \mathrm{a} \\
6.00 \\
\mathrm{n} / \mathrm{a}\end{array}$ & $\begin{array}{l}0.6 \\
0.6 \\
0.6 \\
0.6 \\
0.6 \\
0.6\end{array}$ & $\begin{array}{l}295 \\
295 \\
295 \\
295 \\
295 \\
295\end{array}$ \\
\hline Wind Direction [vane] & 7.65 & 6.00 & 6.00 & 6.00 & 1.4 & 24 \\
\hline \multicolumn{7}{|l|}{ Wind Speed [cup anemometer] } \\
\hline $\begin{array}{l}\text { Level } 1 \\
\text { Level } 2 \\
\text { Level } 3 \\
\text { Level } 4 \\
\text { Level } 5\end{array}$ & $\begin{array}{l}3.59 \\
4.65 \\
5.75 \\
6.55 \\
7.65\end{array}$ & $\begin{array}{l}2.50 \\
3.25 \\
4.00 \\
5.00 \\
6.00\end{array}$ & $\begin{array}{l}2.50 \\
3.25 \\
4.00 \\
5.00 \\
6.00\end{array}$ & $\begin{array}{l}2.50 \\
\mathrm{n} / \mathrm{a} \\
4.00 \\
\mathrm{n} / \mathrm{a} \\
6.00\end{array}$ & $\begin{array}{l}1.4 \\
1.4 \\
1.4 \\
1.4 \\
1.4\end{array}$ & $\begin{array}{l}24 \\
24 \\
24 \\
24 \\
24\end{array}$ \\
\hline Vertical Wind Speed [sonic anemometer] & 6.00 & 4.50 & 4.50 & 4.50 & 1.0 & $150-360-55$ \\
\hline Vapor Density [krypton hygrometer] & 6.00 & 4.50 & 4.50 & 4.50 & 1.0 & $150-360-55$ \\
\hline Relative Humidity [T/RH sensor] & $\mathrm{n} / \mathrm{a}$ & $\mathrm{n} / \mathrm{a}$ & $\mathrm{n} / \mathrm{a}$ & 4.00 & 0.2 & 25 \\
\hline
\end{tabular}




\subsubsection{Source/Platform Mission Objectives}

The primary objective of the towers was to support the needed instrumentation.

\subsubsection{Key Variables}

The key meteorological variables are incoming and reflected solar radiation, PPFD, outgoing terrestrial radiation, net radiation, wet- and dry-bulb temperatures, wind speed, wind direction, latent and sensible heat fluxes, net $\mathrm{CO}_{2}$ flux, soil temperature, biomass temperature, rainfall, and water level.

\subsubsection{Principles of Operation}

\section{Sonic Anemometer}

The sonic anemometer system (model CA27, Campbell Scientific, Inc., Logan, UT, USA) obtains the velocity fluctuations of vertical wind speed from the measured Doppler shift induced by the wind velocity on an ultrasonic frequency pulse broadcast across a $10-\mathrm{cm}$ path. The effect of temperature on sound velocity is eliminated by determining the Doppler frequency from the difference between forward and reverse path observations. Electronic processing of the signals from the ultrasonic transducers produces a real-time analog output voltage in the range $\pm 4.0 \mathrm{~V} \mathrm{DC}$.

Air temperature fluctuations for the Campbell Scientific eddy covariance system are measured with a fine-wire thermocouple mounted about $4 \mathrm{~cm}$ from the anemometer sound path. The thermocouple output is amplified to a $\pm 4.0 \mathrm{~V} \mathrm{DC}$ signal. The thermocouple temperature is referenced to the instrument case, which is thermally lagged and responds slowly to temperature changes.

\section{Absorption Hygrometer}

The absorption hygrometer (model KH20, Campbell Scientific, Inc., Logan, UT, USA) measures the ultraviolet light transmission across a nominal $1-\mathrm{cm}$ path in a water vapor absorption band corresponding to a krypton emission line (Campbell and Tanner, 1985). Instrument response is at least sufficient to resolve fluctuations of $80 \mathrm{~Hz}$. The instrument output is a voltage in the range 0 to $4 \mathrm{~V} \mathrm{DC}$. The signal strength may be subject to gradual diminution as a result of scale accumulation on the optical surfaces.

\section{Longwave Radiation Measurement}

The sensing surface of a pyrgeometer (model PIR, Eppley Laboratories, Inc., Newport, RI, USA) consists of a differential thermopile that measures net longwave radiation fluxes between itself and the sky or ground (depending on orientation). The dome of the pyrgeometer is composed of silicon with a vacuum-deposited interference filter on its inner surface. The composite dome transmission shows an abrupt transition between approximately 3 and 4 micrometers from complete opaqueness to maximum transparency.

The outgoing longwave radiation from the instrument is calculated using the temperature of its blackbody cavity and the Stefan-Boltzmann equation. This flux is added to the thermopile signal to get the total incoming flux. The temperature of the blackbody radiator can be measured using a thermistor.

The thermopile output signal is measured as a single-ended voltage in the Campbell Scientific CR7X data logger. The case thermistor is not polarized and is connected between an analog input channel and ground. A 1000-ohm resistor is connected between the analog input channel and a switched analog output channel (725 card). The thermistor is excited with $1350 \mathrm{mV}$ across the 1000 -ohm resistor, and the thermistor (pyrgeometer) temperature is calculated as a function of the thermistor voltage (a function of its resistance). This method corresponds to the protocol for using the Eppley pyrgeometer proposed by the National Atmospheric Radiation Center (NARC). This method does not use the pyrgeometer's battery-powered temperature compensation circuit, and no battery should be installed when using the pyrgeometer in this manner.

\subsubsection{Sensor/Instrument Measurement Geometry}

See Table 1 in Section 4.1.2. 


\subsubsection{Manufacturer of Sensor/Instrument}

Mass flow sensor and control unit for eddy covariance system:

Brooks Instruments Division

Emmerson Electric Co.

407 W Vine St.

Hatfield, PA 19440

USA

(215) 362-3500

Sonic anemometer; krypton hygrometer; fine-wire thermocouple; CR7X and 21X data loggers; rain gauge (fen):

Campbell Scientific, Inc.

P.O. Box 551

Logan, UT, 84321

USA

(519) 354-7356

Sonic anemometer:

Applied Technologies, Inc.

Boulder, CO

USA

Pyranometer; pyrgeometer:

Eppley Laboratories, Inc.

P.O. Box 419

Newport, RI -2840

USA

(401) 847-1020

Quantum sensor; CO2 IRGA:

LI-COR, Inc.

4421 Superior Street

P.O. Box 4425

Lincoln, NE 68504

USA

(402) 467-3576

Net pyrradiometer:

Carter-Scott Design

22 Ailsa Street

Box Hill

Victoria, 3128

AUSTRALIA

+61-3-9899-4277

Pressure transducer; thermocouple wire:

Omega Engineering

One Omega Drive

P.O. Box 4047

Stamford, CT 06907

USA

(203) 359-1660 
Soil heat flux plate:

Radiation Energy Balance Systems Inc. (REBS)

P.O. Box 15512

Seattle, WA 98115-0512

USA

(206) 624-7221

Cup anemometer; wind vane:

R.M. Young Co.

2801 Aero Park Drive

Traverse City, MI 49648

USA

(616) 946-3980

All other instruments were produced in the climate laboratories at either Queen's University or Trent University.

\subsection{Calibration}

Pyranometers, pyrgeometers, and net pyrradiometers used at both sites were calibrated at NARC, Atmospheric Environment Service (AES), Downsview, Ontario.

In addition, following the intersite calibration on net pyrradiometers performed in the field in 1994 with the roving REBS 6-net pyrradiometer (Hodges and Smith, 1997; Smith et al., 1997), a corrected set of net radiation data was calculated for the 1994, 1995, and 1996 experimental periods for both the fen and the YJP. The corrected net radiation data will potentially facilitate the intercomparison of flux behavior between the tower flux sites.

$\mathrm{CO}_{2}$ concentrations for high- and low-span calibration gases were determined at the Carbon Cycle Research Section, AES, Downsview, Ontario, Canada.

Factory calibrations were used for several instruments, and the recalibration details for individual sensors are given below.

- $\quad$ Quantum sensors and porometer (LI-COR, Inc., Lincoln, NE, USA)

- Cup anemometers and wind vane (R.M. Young Co., Traverse City, MI, USA)

Following the 1993 field experiment, each individual calibration for the group of cup anemometers was checked using the wind tunnel at Trent University, and no changes were needed to the original factory calibrations. Because the potentiometer on the two wind vanes was set in the field each time the instruments were deployed, both can be considered to have had regular field calibration checks.

- $\quad$ Soil heat flux plates (REAS, Seattle, WA, USA)

The factory calibrations were accepted for all four transducers, two at each site.

- $\quad$ Rain gauges (Campbell Scientific, Inc., Logan, UT, USA, and Weathermeasure Corporation, Sacramento, CA, USA)

Routine calibration checks were done on all rain gauges by pouring a known amount of water into the gauge and noting the response. In all cases, the gauges were within the manufacturer's specification.

- Sonic anemometers and krypton hygrometers (Campbell Scientific, Inc., Logan, UT, USA)

The hygrometers at both the fen and the YJP sites were recalibrated in March 1994 following the 1993 experiment and before redeployment for the 1994 experiment. Minor changes resulted, but they were not large enough to require correction to the 1993 data.

\section{Thermocouples}

- For all thermocouples, the appropriate calibration equation available in the data loggers (Campbell Scientific, Inc., Logan, UT, USA) was used. 


\subsubsection{Specifications}

Whenever a new calibration was determined for an instrument, the new calibration was applied from the time of the recalibration. There was no attempt to blend the calibrations before and after the recalibration. Any step-up or step-down in the data values as a result of recalibration was accepted. For all instruments, the calibration changes were minor, and there were no instances where a blending of the calibrations was necessary.

\subsubsection{Tolerance}

The precision of the measured meteorological variables and the corresponding transducers are summarized below.

\begin{tabular}{||l|l|l||}
\hline Variable & Transducer & Precision \\
\hline solar radiation & Eppley pyranometer & $1 \mathrm{~W} / \mathrm{m}^{2}$ \\
\hline longwave radiation & Eppley pyrgeometer & $1 \mathrm{~W} / \mathrm{m}^{2}$ \\
\hline PPFD & Middleton net pyrradiometer & $1 \mathrm{~W} / \mathrm{m}^{2}$ \\
\hline carbon dioxide concentration & LI-COR quantum sensor & $1 \mu \mathrm{mol} / \mathrm{m}^{2} / \mathrm{s}$ \\
\hline soil heat flux & LI-COR IRGA & $1 \mathrm{ppmv}$ \\
\hline air, soil, and biomass temperature & REBS heat flux plate & $1 \mathrm{~W} / \mathrm{m}^{2}$ \\
\hline horizontal wind speed & R.M. Young cup anemometer & $0.1{ }^{\circ} \mathrm{C}$ \\
\hline wind direction & R.M. Young wind vane & $0.1 \mathrm{~m} / \mathrm{s}$ \\
\hline relative humidity & R.M. Young T/RH sensor & $1^{\circ}$ \\
\hline vertical wind speed & Campbell Scientific sonic anemometer & $1 \%$ \\
\hline rainfall & Campbell Scientific tipping bucket & $0.1 \mathrm{~m} / \mathrm{s}$ \\
\hline rainfall & Weathermeasure tipping bucket & $0.254 \mathrm{~mm}$ \\
\hline \hline
\end{tabular}

\subsubsection{Frequency of Calibration}

All radiometers used in the study were on a regular, 2-year calibration cycle. This calibration frequency was increased during BOREAS, and each radiometer was calibrated before each major field experiment. Full calibrations were done in April 1994, October 1994, and March 1996.

One sonic anemometer (model CA27, Campbell Scientific, Inc., Logan, UT, USA) was recalibrated by the manufacturer in May 1995 following water damage to the instrument in September 1994 at the fen.

The krypton hygrometers from the YJP and fen were calibrated in 1993 before deployment in the field and were recalibrated in March 1994.

Calibrations were determined on all $\mathrm{CO}_{2}$ reference gas tanks prior to both major field seasons in March 1994 and March 1996.

Routine calibration checks were made on the rain gauges, following the protocol suggested by the manufacturers, prior to their deployment in all field experiments. No calibration change was necessary to either gauge. 


\subsubsection{Other Calibration Information}

A summary follows of the instruments used at each site along with their calibration histories.

Solar Radiation was measured using Eppley pyranometers. The instruments, identified by serial number, used at both sites for each experiment are given in Table 2.

Table 2. Eppley pyranometers used at the fen in all experimental years. Each pyranometer is identified by its serial number.

Table 2. Eppley pyranometers used at the Fen

\begin{tabular}{||l|l|l|l|l||}
\hline \hline Variable & Year & $\mathbf{1 9 9 4}$ & $\mathbf{1 9 9 5}$ & $\mathbf{1 9 9 6}$ \\
\hline $\mathrm{Kd}$ & $\mathbf{1 9 9 3}$ & 13762 & 13762 & 13762 \\
\hline $\mathrm{Ku}$ & 15889 & 13855 & 13855 & 13855 \\
\hline \hline
\end{tabular}

The calibration histories of the pyranometers are shown in Table 3 . All calibrations remained stable through the BOREAS field periods, and the largest change in any calibration was $-0.57 \%$.

Table 3. Calibration history of the Eppley pyranometers used in all experimental years. The change in calibration is given as a percentage from the previous value. The units of calibration are microvolts/( $\left.\mathrm{Wm}^{2}\right)$.

Table 3. Calibration history of the Eppley pyranometers

\begin{tabular}{||l|l|l|l||}
\hline \hline Serial number & Year & Calibration & $\begin{array}{l}\text { \%change in } \\
\text { calibration }\end{array}$ \\
\hline 13762 & 1992 & 12.21 & -1.12 \\
\cline { 2 - 4 } & 1994 & 12.14 & -0.57 \\
\cline { 2 - 4 } & 1996 & 12.20 & 0.49 \\
\hline \multirow{3}{*}{13855} & 1992 & 10.92 & -0.55 \\
\cline { 2 - 4 } & 1994 & 10.89 & -0.27 \\
\cline { 2 - 4 } & 1996 & 10.92 & 0.28 \\
\hline \multirow{3}{*}{15889} & 1992 & 11.17 & -0.62 \\
\cline { 2 - 4 } & 1994 & 11.14 & -0.27 \\
\cline { 2 - 4 } & 1996 & 11.14 & 0.00 \\
\hline & 1992 & 11.09 & -1.10 \\
\cline { 2 - 4 } & 1994 & 11.05 & -0.36 \\
\cline { 2 - 4 } & 1996 & 11.06 & 0.09 \\
\hline
\end{tabular}

Longwave radiation was measured using Eppley pyrgeometers. 
Eppley pyrgeometer (serial number 29583F3) was used at the fen from 1993 to 1996 . The calibration history of the instrument is given in Table 4. The first calibration of instrument $29583 \mathrm{~F} 3$ in 1994 proved to be wrong because of a malfunctioning reference temperature bath at NARC. This was corrected by a recalibration of the instrument the same year, and all of the data were corrected in postprocessing.

Table 4. Calibration history of the Eppley pyrgeometers used in all experimental years. The change in calibration is given as a percentage from the previous value. The units of calibration are microvolts $/ \mathrm{W} / \mathrm{m}^{2}$.

Table 4. Calibration history of the Eppley pyrgeometers

\begin{tabular}{||l|l|l|l||}
\hline \hline Serial number & Year & Calibration & \%change in calibration \\
\hline $29583 \mathrm{~F} 3$ & 1993 & 3.97 & - \\
\cline { 2 - 5 } & 1994 & 3.62 & -8.82 (calibration is suspect) \\
\cline { 2 - 4 } & 1994 & 3.83 & -3.53 (recalibration for 1994) \\
\cline { 2 - 4 } & 1996 & 3.83 & 0.00 \\
\hline
\end{tabular}

Net radiation was measured using Middleton net pyrradiometers. The instruments used are listed in Table 5.

Table 5. Middleton net pyrradiometers used in the field experiments. Each instrument is identified by serial number.

Table 5. Middleton net pyrradiometers

\begin{tabular}{||l|l||}
\hline \hline Serial number & Site \\
\hline 1330 & Fen in 1993, and from DOY 97-145 in 1996 \\
\hline 1333 & $\begin{array}{l}\text { Fen in 1994, and 1995, and from DOY 146 in } \\
1996\end{array}$ \\
\hline
\end{tabular}

The calibration histories of the net pyrradiometers are given in Table 6 . For all net pyrradiometers, the calibration values are given separately for shortwave (SW), longwave (LW), and combined the arithmetic average of SW and LW. The combined value was used for all times of the day, including the nighttime, when only longwave radiation is present. All instruments had two calibrations in 1994. The first calibration proved to be wrong because of a malfunctioning reference temperature bath at NARC. This was corrected by a recalibration of the instrument the same year, and all of the data were corrected in postprocessing. With the exception of the aberrant first calibration in 1994, all instruments remained stable for the duration of the experiments; changes were normally less than $1 \%$ and the largest was less than $4 \%$.

Table 6. Calibration history of the Middleton net pyrradiometers used in all experimental years. The change in calibration is given as a percentage from the previous value. The units of calibration are microvolts $/ \mathrm{W} / \mathrm{m}^{2}$. Separate calibrations are given for shortwave (SW), longwave (LW), and combined the arithmetic average of the SW and LW values. The calibration constant (cal. constant) is the ratio of the SW to LW calibration. 
Table 6. Calibration history of the Middleton net pyrradiometers

\begin{tabular}{||l|l|l|l|l|l|l|l|l||}
\hline $\begin{array}{l}\text { Serial } \\
\text { number }\end{array}$ & Year & SW & $\begin{array}{l}\text { \% } \\
\text { change } \\
\text { SW }\end{array}$ & LW & $\begin{array}{l}\text { \% } \\
\text { change } \\
\text { LW }\end{array}$ & combined & $\begin{array}{l}\text { \% change } \\
\text { combined }\end{array}$ & $\begin{array}{l}\text { cal. } \\
\text { constant }\end{array}$ \\
\hline \multirow{3}{*}{1330} & 1992 & 37.52 & -0.87 & 35.18 & -3.98 & 36.35 & -2.42 & 1.07 \\
\cline { 2 - 10 } & 1994 & 38.16 & 1.17 & 32.40 & -7.90 & 35.28 & -2.94 & 1.18 \\
\cline { 2 - 10 } & 1994 & 37.55 & 0.08 & 34.82 & -1.02 & 36.19 & -0.44 & 1.08 \\
\cline { 2 - 10 } & 1996 & 35.54 & -5.35 & 34.13 & -1.98 & 34.84 & -3.73 & 1.04 \\
\hline \multirow{3}{*}{1333} & 1992 & 37.74 & -2.15 & 34.90 & -6.46 & 36.32 & -4.27 & 1.08 \\
\cline { 2 - 10 } & 1994 & 38.41 & 1.78 & 32.85 & -5.87 & 35.63 & -1.90 & 1.17 \\
\cline { 2 - 10 } & 1994 & 38.17 & 1.14 & 34.62 & -0.80 & 36.39 & 0.22 & 1.10 \\
\cline { 2 - 9 } & 1996 & 38.12 & -0.13 & 35.17 & 1.59 & 36.64 & 0.69 & 1.08 \\
\hline
\end{tabular}

PPFD was measured using LI-COR quantum sensors. Table 7 shows the instruments used at each site in each experimental year, and Table 8 gives the calibration constants.

Table 7. Quantum sensors used at the experimental sites and the variables measured: PPFDd is incoming PPFD, and PPFDu is reflected PPFD. Instruments are identified by serial number.

Table 7. Quantum sensors used

\begin{tabular}{||l|l|l||}
\hline \hline Serial number & Site & Variable \\
\hline Q17605 & Fen 1993 to 1996 & PPFDd \\
\hline Q16754 & Fen 1993 to 1996 & PPFDu \\
\hline
\end{tabular}

Table 8. Calibration constants in units of $\mu$ mole $/ \mathrm{s} / \mathrm{m}^{2} / \mathrm{mv}$ for the quantum sensors used in the experiments. The instruments are identified by serial number.

Table 8. Calibration constants

\begin{tabular}{||l|l||}
\hline \hline Serial & Calibration \\
\hline Q17605 & 293.25 \\
\hline Q16754 & 355.87 \\
\hline
\end{tabular}

$\mathrm{CO}_{2}$ concentration and $\mathrm{CO}_{2}$ flux density were measured using an IRGA (model LI-6252, LI-COR, Inc., Lincoln, NE, USA) and a sonic anemometer (model CA27, Campbell Scientific, Inc., Logan, UT, USA). Table 9 lists the IRGAs and the sonic anemometers used at both sites. Sonic 1353 was damaged by water seeping into the lower arm at the conclusion of the 1994 experiment. This instrument was repaired and recalibrated before being deployed again in 1996.

Table 9. The sonic anemometers and IRGAs used at the fen. The instruments are identified by serial number. No $\mathrm{CO}_{2}$ flux was measured at the fen in 1995; the sonic anemometer measured the convective fluxes only. 
Table 9. The sonic anemometers and IRGAs

\begin{tabular}{||l|l|l||}
\hline \hline \multirow{2}{*}{ Sonic anemometer } & Serial number & Site \\
\hline \multirow{2}{*}{ IRGA } & 1201 & Fen in 1995, YJP in 1993, 1994, and 1996 \\
\cline { 2 - 4 } & 1353 & Fen in 1993, 1994, and 1996 \\
\hline \hline
\end{tabular}

Soil heat flux was measured using REBS soil heat flux plates. The calibrations of the plates and the sites where they were deployed are given in Table 10.

Table 10. Calibrations for the soil heat flux plates, in units of $\mathrm{W} / \mathrm{m}^{2} / \mathrm{mV}$, and the sites where they were deployed. Individual plates are identified by serial number.

Table 10. Calibrations for the soil heat flux plates

\begin{tabular}{||l|l|l||}
\hline \hline Serial number & Calibration & Site \\
\hline 933060 & 40.0 & Fen in 1993, 1994, 1995, and 1996 \\
\hline 933061 & 38.7 & Fen in 1993, 1994, 1995, and 1996 \\
\hline
\end{tabular}

Horizontal wind speed was measured using 3-cup anemometers (model 12102, R.M. Young Co., Traverse City, MI, USA). These instruments have calibrations in units of mv at $1800 \mathrm{rpm}$, and this is combined with a second general calibration equation to convert $\mathrm{rpm}$ to $\mathrm{m} / \mathrm{s}$. The calibrations of the anemometers are given in Table 11.

Table 11. Calibration of the 3-cup anemometers used at each site for horizontal wind speed measurement at the levels identified; e.g., U1 is the anemometer at level 1. The units of the calibration are $\mathrm{mv}$ at $1800 \mathrm{rpm}$.

Table 11. Calibration of the 3 -cup anemometers

\begin{tabular}{||l|l|l|l|l||}
\hline \hline Site: Fen & \multicolumn{3}{|l||}{} & \multicolumn{2}{||}{} \\
\hline \multicolumn{1}{||l|l||}{ Year } & $\mathbf{1 9 9 3}$ & $\mathbf{1 9 9 4}$ & $\mathbf{1 9 9 5}$ & $\mathbf{1 9 9 6}$ \\
\hline U1 & 2400 & 2400 & 2400 & - \\
\hline U2 & 2397 & 2397 & 2397 & 2397 \\
\hline U3 & 2396 & 2396 & 2401 & 2395 \\
\hline U4 & 2401 & 2401 & 2401 & - \\
\hline U5 & 2399 & 2399 & 2399 & 2401 \\
\hline \hline
\end{tabular}

Relative humidity was measured using a combination temperature/relative humidity probe (model 41372VC, R.M. Young Co., Traverse City, MI, USA) at each site in 1996 (Table 12). The temperature is measured with an RTD sensor, and the relative humidity is measured with a capacitance element. This probe was ventilated naturally and shielded by a 12-level plate shield. Each probe has the same calibration and specifications (Table 13). 
Table 12. Temperature/relative humidity sensors used at the sites in 1996.

Table 12. Temperature/relative humidity sensors used at the sites in 1996.

\begin{tabular}{|l|l|l||}
\hline \hline Model & Serial number & Site \\
\hline $41372 \mathrm{VC}$ & 1762 & Fen \\
\hline \hline
\end{tabular}

Table 13. Calibration and specifications for the temperature/relative humidity sensor (model 41372VC, R.M. Young Co., Traverse City, MI, USA).

\begin{tabular}{|c|c|}
\hline \multirow[t]{8}{*}{ Relative humidity: } & operating temperature: $-10^{\circ} \mathrm{C}$ to $60^{\circ} \mathrm{C}$ \\
\hline & measuring range: 0 to $100 \%$ \\
\hline & accuracy at $20{ }^{\circ} \mathrm{C}: 2 \%$ from $0-90 \% \mathrm{RH}$ \\
\hline & $3 \%$ from $90-100 \% \mathrm{RH}$ \\
\hline & stability: better than $\pm 2 \% \mathrm{RH}$ for 2 years \\
\hline & response time: $15 \mathrm{sec}$ \\
\hline & sensor element: Vaisala intercap \\
\hline & output signal: $0-1$ volt DC \\
\hline \multirow[t]{3}{*}{ Temperature: } & calibrated measuring range: $-50^{\circ} \mathrm{C}$ to $50^{\circ} \mathrm{C}$ \\
\hline & accuracy at $20^{\circ} \mathrm{C}: \pm 0.3^{\circ} \mathrm{C}$ \\
\hline & output signal: $0-1$ volt $\mathrm{DC}$ \\
\hline
\end{tabular}

Rainfall was measured using tipping bucket rain gauges at both sites in all years at the fen. The gauge (model TE525, Texas Instruments, supplied by Campbell Scientific, Inc., Logan, UT, USA) was at a height of 1 meter above the surface, and 1 tip of the gauge represented $1 \mathrm{~mm}$ of rain.

Atmospheric pressure was measured at each site in 1996 using a Vaisala pressure transmitter (model PTB 101B, Vaisala, Oy, Finland, and supplied by Campbell Scientific, Inc., Logan, UT, USA). Each instrument had been calibrated against a working standard in February 1996. The instrument at the fen was S/N R0940004.

\section{Data Acquisition Methods}

The outputs from all instruments producing voltages were recorded on data loggers. Data from the loggers' memories were downloaded at regular intervals to either cassette tape or electronic storage module, and all data were transferred in the field to microcomputers and backed up on either floppy diskette or 1-GB Jaz drives (Iomega Corporation, Fenton, MO, USA).

Specific details for each major system are given below.

- $\quad$ Tower data (except eddy covariance) -- All signals were recorded on data loggers (model CR7X, Campbell Scientific, Inc., Logan, UT, USA) at a scan rate of once per 10 seconds. Output was processed every 3,15 , and 30 minutes depending on the variable. Only 30-minute data are reported in the BORIS data base. 
- $\quad$ Eddy covariance -- All signals were recorded on data loggers (model 21X, Campbell Scientific, Inc., Logan, UT, USA) at a scan rate of once per 0.1 seconds. Intermediate processing was done every 15 minutes, and output data were processed every 30 minutes.

\section{Observations}

\subsection{Data Notes}

See Section 6.2.

\subsection{Field Notes}

\section{SPECIAL NOTES: 1993}

All data were averaged over thirty minutes, starting on the hour and half-hour, and ending thirty minutes later. Sampling was continuous and each day's data is from 0600 UTC to 0600 UTC the next day.

- $\quad$ LONGWAVE_IN_1033CM was calculated as a residual.

- Small nighttime values for SOLAR_RAD_IN_1047CM, SOLAR_RAD_OUT_1023CM, PPFD_IN_1049CM, and PPFD_OUT_1031CM were set to zero to account for very slight zero depressions and elevations in the radiometers.

- HEAT_STORAGE_TOTAL is the sum of HEAT_STORAGE_LATENT_AIR, HEAT_STORAGE_SENSIBLE_AIR, and SOIL_HEAT_FLUX_HOLLOW_10CM.

\section{Data Period: August 15/93 (DOY 227)}

- Data collection began on DOY 228 at 0000.

- All wet bulb temperatures are flagged DOY 227-228(2015).

Data Period: August 16 - August 29/93 (DOY 228-241)

- WET_BULB_TEMP_465CM is flagged DOY 228(2030)-229(730), and 229(1830-2130).

\section{SPECIAL NOTES: 1994}

All data were averaged over thirty minutes, starting on the hour and half-hour, and ending thirty minutes later. For example, data tagged at 0630, were collected between 0600 and 0630. Sampling was continuous and each day's data is from 0600 UTC to 0600 UTC the next day.

- $\quad$ LONGWAVE_IN_1033CM was calculated as a residual.

- $\quad$ SOIL_HEAT_FLUXX_FEN was calculated by multiplying SOIL_HEAT_FLUX_HOLLOW_10CM by a correction factor of 3.04 for DOY 132 through DOY 262 (see documentation for details).

- $\quad$ R_NET_1035CM_CORRECTED was calculated using day and night time equations developed by Hodges and Smith (1997) (see documentation for details).

- Small nighttime values for SOLAR_RAD_IN_1023,SOLAR_RAD_OUT_1045CM, PPFD_IN_1049CM, and PPFD_OUT_1031CM were set to zero to account for very slight zero depressions and elevations in the radiometers.

- HEAT_STORAGE_TOTAL is the sum of HEAT_STORAGE_LATENT_AIR, HEAT_STORAGE_SENSIBLE_AIR, and SOIL_HEAT_FLUX_FEN.

\section{Data Period: April 8 - April 11/94 (DOY 098-101)}

- PPFD_OUT_1031CM sensor installed on DOY 105 at 0030.

- $\quad$ SOIL_HEAT_FLUX_HOLLOW_10CM sensor installed on DOY 122 at 1900.

- WATER_LEVEL_DEPTH sensor installed on DOY 127 at 630.

- $\quad$ LATENT_HEAT_FLUX_450CM, SENSIBLE_HEAT_FLUX_450CM, and H2O_FLUX_450CM installed on DOY 101 at 630.

- $\quad$ SPECIFIC_HUMIDITY_450CM sensor installed on DOY 107 at 1700. 
- CO2_FLUX_450CM, CO2_CONC_450CM, SPECIFIC_HUMIDITY_STDEV_450CM, W_MEAN_450CM and W_STDEV_450CM sensors installed on DOY 151 at 1800.

- SOLAR_RAD_IN_1047CM, SOLAR_RAD_OUT_1023CM, NET_SOLAR_RAD_1035CM, LONGWAVE_IN_1033CM, LONGWAVE_OUT_1033CM TOTAL_RAD_IN_10 $\overline{4} 1 \mathrm{CM}$, TOTAL RAD_OUT 1028CM, R_NET_1035CM, PPFD_IN_1049CM, PPFD_OUT_1031CM, SURFACE_ALBEDO,SOIL_TEMP_HUMMOCK_1CM, SOIL_TEMP_HUMMOCK_5CM,SOIL_TEMP_HUMMOCK_10CM, SOIL_TEMP_HUMMOCK_25CM, SOIL_TEMP_HUMMOCK_50CM, SOIL TEMP_HUMMOCK_75CM, SOIL_TEMP_HUMMOCK_100CM, SOIL_TEMP_HUMMOCK_150CM, SOIL_TEMP_HUMMOCK_200CM, SOIL_TEMP_HOLLOW_1CM,SOIL_TEMP_HOLLOW_5CM, SOIL_TEMP_HOLLOW_10CM, SOIL_TEMP_HOLLOW_25CM, SOIL_TEMP_HOLLOW_50CM, SOIL_TEMP_HOLLOW_75CM, SOIL_TEMP_HOLLOW_100CM, SOIL_TEMP_HOLLOW SOIL_TEMP_HOLLOW_200CM, DRY_BULB_TEMP_250CM,

DRY_BULB_TEMP_325CM, DRY_BULB_TEMP_400CM, DRY_BULB_TEMP_500CM, DRY_BULB_TEMP_600CM, DRY_BULB_TEMP_750CM, WET_BULB_TEMP_250CM, WET_BULB_TEMP_325CM,WET_BULB_TEMP_400CM,WET_BULB_TEMP_500CM, WET_BULB_TEMP_600CM, WET_BULB_TEMP_750CM, VAPOUR_PRESSURE_250CM, VAPPUR_PRESSURE_325CM, VAPOUR_PRESSURE_400CM, VAPOUR_PRESSURE_500CM, VAPOUR_PRESSURE_600CM, VAPOUR_PRESSURE_750CM, RAINFALL_100CM and WATER_LEVEL_DEPTH values are missing on DOY 098 from 630-1700 and 1830 (start of field season) and on DOY 100 from 1700-1730 due to programming.

- $\quad$ SOIL_HEAT_FLUX_HOLLOW, all wet bulb temperatures, and all vapor pressures are missing DOY 98-131.

- WIND_SPEED_250CM is not available until DOY 98 at 1900 due to programming.

- WIND_SPEED_325CM is not available until DOY 103 at 0000.

- WIND_SPEED_400CM is not available until DOY 103 at 0030.

- WIND_SPEED_500CM is not available until DOY 103 at 1930.

- WIND_SPEED_600CM is not available until DOY 105 at 1530.

- WIND_DIR_600CM and WIND_DIR_STDEV_600CM are not available until DOY 104 at 220.

- $\quad$ SOIL_HEAT_FLUX_FEN, SOIL_HEAT_FLUX_HOLLOW_10CM, HEAT_STORAGE_TOTAL,HEAT_STORAGE_SENSIBLE_AIR, and HEAT_STORAGE_LATENT_AIR values are missing on DOY Ys 098 through 101.

- DRY_BULB_TEMP_250CM,DRY_BULB_TEMP_325CM, DRY_BULB_TEMP_400CM, DRY_BULB_TEMP_500CM, DRY_BULB_TEMP_600CM, DRY_BULB_TEMP_750CM, WET_BULB_TEMP_250CM, WET_BULB_TEMP_325CM, WET_BULB_TEMP_400CM, WET_BULB_TEMP_500CM, WET_BULB_TEMP_600CM and

WET_BULB_TEMP_750CM sensors are frozen on DOYs 099 through 101.

Data Period: April 12 - April 25/94 (DOY 102-115)

- $\quad$ PPFD_OUT_1031CM sensor installed on DOY 105 at 0030.

- SOIL_HEAT_FLUX_HOLLOW_10CM sensor installed on DOY 122 at 1900.

- WATER_LEVEL_DEPTH sensor installed on DOY 127 at 630.

- $\quad$ SPECIFIC_HUMIDITY_450CM sensor installed on DOY 107 at 1700.

- CO2_FLUX_450CM, CŌ2_CONC_450CM, SPECIFIC_HUMIDITY_STDEV_450CM, W_MEAN_450CM and W_STDEV_450CM sensors installed on DOY 151 at 1800 .

- $\quad$ SPECIFIC_HUMIDITY_450CM values missing on DOYs 107 through 115.

- $\quad$ LATENT_HEAT_FLUX_450CM, and H2O_FLUX_450CM values are missing on DOY 107 from $1600-600$ and on DOY 108 from $630-600$ due to weather. 
- $\quad$ LATENT_HEAT_FLUX_450CM, SENSIBLE_HEAT_FLUX_450CM, and

H2O_FLUX_450CM values are missing on DOYs 110 from 2230-600, on DOY 111 from

630-1430, on DOY 112 from 1930-2030 and 2230-600, on DOY 113 from 630-600, on DOY 114 from 630-1600 and from 2100-600 and on DOY 115 from 630-1530 and 1730-600 due to weather.

- $\quad$ SOIL_HEAT_FLUX_HOLLOW_10CM,SOIL_HEAT_FLUX_FEN, HEAT_STORAGE_TOTAL,HEAT_STORAGE_SENSIBLE_AIR, and HEAT_STORAGE_LATENT_AIR values are missing on DOYs 104, 105, 110, 111 and 114.

- DRY_BULB_TEMP_250CM,DRY_BULB_TEMP_325CM, DRY_BULB_TEMP_400CM, DRY_BULB_TEMP 500CM, DRY_BULB_TEMP_600CM, DRY_BULB_TEMP 750CM, WET_BULB_TEMP_250CM, WET_BULB_TEMP_325CM, WET_BULB_TEMP_400CM, WET_BULB_TEMP_500CM,WET_BULB_TEMP_600CM and WET_BULB_TEMP_750CM sensors are frozen on DOYs 102 through 115.

- WIND_SPEED_325CM is not available until DOY 103 at 0000.

- WIND_SPEED_400CM is not available until DOY 103 at 0030 .

- WIND_SPEED_500CM is not available until DOY 103 at 1930.

- WIND SPEED 600CM is not available until DOY 105 at 1530.

- WIND_DIR_600CM and WIND_DIR_STDEV_600CM are not available until DOY 104 at 220.

Data Period: April 25 - May 9/94 (DOY 116-129)

- DOY127(1800) RAINFALL_100CM and WATER_LEVEL_DEPTH are interpolated.

- $\quad$ SOIL_HEAT_FLUX_HOLLOW_10CM sensor installed on DOY 122 at 1900.

- $\quad$ WATER_LEVEL_DEPTH sensor installed on DOY 127 at 630.

- CO2_FLUX_450CM, CO2_CONC_450CM, SPECIFIC_HUMIDITY_STDEV_450CM, W_MEAN_450CM and W_STDEV_450CM sensors installed on DOY 151 at 1800 .

- $\quad$ SPECIFIC_HUMIDITY_450CM values are missing on DOY 116 through 129.

- $\quad$ LATENT_HEAT_FLUX_450CM,SENSIBLE_HEAT_FLUX_450CM, and H2O_FLUXX_450CM values are missing on DOYs 116 from $630-1600$ and from $2230-600$, on DOY 117 from 630-1600, on DOY 119 from 2300-600, on DOY 120 from 630-1430, on DOY 121 from 2000-600, on DOY 122 from 630-2030 and from 2200-600, on DOY 123 from 630-600, on DOY 124 from 630-1530, on DOY 126 from 1600-600, on DOY 127 from 1830-600, on DOY 128 from 630-600 and on DOY 129 from 630-1500 due to weather.

- $\quad$ SOIL_HEAT_FLUX_HOLLOW_10CM, SOIL_HEAT_FLUX_FEN, HEAT_STORAGE_TOTAL,HEAT_STORAGE_SENSIBLE_AIR, and HEAT_STORAGE_LATENT_AIR values are missing on DOYs 117 and 118 .

- SOIL_HEAT_FLUX_HOLLOW_10CM sensor had instrument malfunction on DOY 128 from $1400-600$.

- DRY_BULB_TEMP_250CM, DRY_BULB_TEMP_325CM, DRY_BULB_TEMP_400CM, DRY_BULB_TEMP_500CM, DRY_BULB_TEMP_600CM, DRY_BULB_TEMP_750CM, WET_BULB_TEMP_250CM, WET_BULB_TEMP_325CM, WET_BULB_TEMP_400CM, WET_BULB_TEMP_500CM, WET_BULB_TEMP_600CM and WET_BULB_TEMP_750CM sensors are frozen on DOYs 116 through 124, 126 and 129.

- $\quad$ SOIL_HEAT_FLUX_HOLLOW, all wet bulb temperatures, and all vapor pressures are missing DOY 98-131

Data Period: May 10 - May 23/94 (DOY 130-143)

- CO2_FLUX_450CM, CO2_CONC_450CM, SPECIFIC_HUMIDITY_STDEV_450CM, W_MEAN_450CM and W_STDEV_450CM sensors installed on DOY 151 at 1800.

- $\quad$ SPECIFIC_HUMIDITY_450CM values are missing on DOYs 130 through 143. 
- $\quad$ LATENT_HEAT_FLUX_450CM, SENSIBLE_HEAT_FLUX_450CM, and

$\mathrm{H} 2 \mathrm{O}$ FLUX 450CM values are missing on DOYs 130 from 1830-600, on DOY 131 from 630-1430, on DOY 132 from 2030-600, on DOY 133 from 630-600, on DOY 134 from 630-1630 and from 2030-600, on DOY 135 from 630-1500, and from 200-600, on DOY 136 from 630-1100 and from 1830-600, on DOY 137 from 630-1530 and from 1830-600, on DOY 138 from 630-1530 and from 2100-600, on DOY 139 from 630-1430, on DOY 140 from 1600-600 and on DOYs 141 through 143 due to weather.

- $\quad$ LATENT_HEAT_FLUX_450CM, SENSIBLE_HEAT_FLUX_450CM, and H2O_FLUX_450CM values are missing on DOY 132 from $1600-1630$ and on DOY 135 at 1630 due to instrument adjustment.

- SOIL_TEMPERATURE_HUMMOCK_50CM sensor was broken from DOYs 135 at 1600 through to 147 at 2100 . Reinstalled on DOY 147 at 2130.

- WIND_SPEED_600CM sensor had incorrect offset from DOYs 131 through 142. Correct offset used on DOY 142 at 1500.

- DRY_BULB_TEMP_250CM, DRY_BULB_TEMP_325CM, DRY_BULB_TEMP_400CM, DRY_BULB_TEMP_500CM, DRY_BULB_TEMP_600CM, DRY_BULB_TEMP_750CM, WET_BULB_TEMP_250CM, WET_BULB_TEMP_325CM, WET_BULB_TEMP_400CM, WET_BULB_TEMP_500CM, WET_BULB_TEMP_600CM and

WET_BULB_TEMP_750CM sensors are frozen on DOYs 130 through 136, and 139-141.

- $\quad$ SOIL_HEAT_FLUX_HOLLOW, all wet bulb temperatures, and all vapor pressures are missing DOY $98-131$.

\section{Data Period: May 24 - June 6/94 (DOY 144-157)}

- CO2_TOTAL_FLUX_450CM, CO2_CONC_450CM, SPECIFIC_HUMIDITY_STDEV_450CM, W_MEAN_450CM and W_STDEV_450CM sensors installed on DOY 151 at 1800 .

- $\quad$ SPECIFIC_HUMIDITY_450CM values missing on DOYs 144 and 145.

- $\quad$ LATENT_HEAT_FLUX_450CM, SENSIBLE_HEAT_FLUX_450CM, and H2O_FLUX_450CM values are missing on DOY 144 from $630-1530$.

- $\quad$ LATENT_HEAT_FLUX_450CM, SENSIBLE_HEAT_FLUX_450CM, H2O_FLUX_450 $\bar{C}$ M and SPECIFIC_HUMIDITY_450CM values are missing on DOY 148 from 500-600, on DOY 149 from 630-600 and on DOY 150 from 630-600 due to weather.

- $\quad$ LATENT_HEAT_FLUX_450CM, SENSIBLE_HEAT_FLUX_450CM, H2O_FLUX_450CM, CO2_TOTAL_FLUX_450CM, $\bar{C} O 2$ CONC_450CM, and SPECIFIC_HUMIDITY_450CM values are missing on DOY 151 from 630-600 and on DOY 152 from $630-1530$ due to weather.

- $\quad$ SPECIFIC_HUMIDITY_STDEV_450CM, W_MEAN_450CM and W_STDEV_450CM values are missing on DOY 151 from $630-1730$.

- $\quad$ LATENT_HEAT_FLUX_450CM, SENSIBLE_HEAT_FLUX_450CM, H2O_FLUX_450CM, CO2_TOTAL_FLUX_450CM, CO2_CONC_450CM, SPECIFIC_HUMIDITY_450CM and SPECIFIC_HUMIDITY_STDEV_450CM values missing on DOY 153 from 1500-2000 due to instrument replacement.

- $\quad$ LATENT_HEAT_FLUX_450CM, SENSIBLE_HEAT_FLUX_450CM,

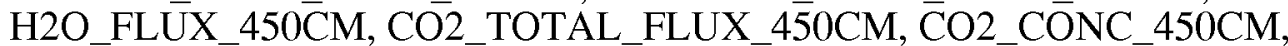
SPECIFIC_HUMIDITY_450CM, SPECIFIC_HUMIDITY_STDEV_450CM,

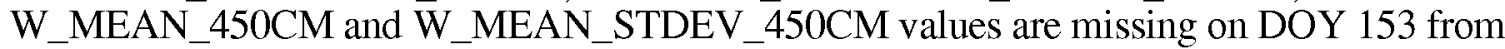
2330-600 due to instrument failure.

- $\quad$ SPECIFIC_HUMIDITY_STDEV_450CM, W_MEAN_450CM and W_STDEV_450CM values are missing on DOY 154 at 1930 due to lag tests.

- $\quad$ LATENT_HEAT_FLUX_450CM, SENSIBLE_HEAT_FLUX_450CM, H2O_FLUX_450त्CM, CO2_TOTAL_FLUX_450CM, and SPECIFIC_HUMIDITY_450CM values are missing on DOY 157 from $450-600$ due to weather. 
- $\quad$ SOIL_HEAT_FLUX_HOLLOW_10CM,SOIL_HEAT_FLUX_FEN, HEAT_STORAGE_TOTAL, HEATT_STORAGE_SENSIBLE_ATIR, and HEAT_STORAGE_LATENT_AIR values are missing on DOY 147.

- $\quad$ SOIL_TEMPERATURE_HUMMOCK_50CM sensor was broken from DOYs 135 at 1600 through to 147 at 2100. Reinstalled on DOY 147 at 2130.

- DRY_BULB_TEMP_250CM, DRY_BULB_TEMP_325CM, DRY_BULB_TEMP_400CM, DRY_BULB_TEMP_500CM, DRY_BULB_TEMP_600CM, DRY_BULB_TEMP_750CM, WET_BULB_TEMP_250CM, WET_BULB_TEMP_325CM, WET_BULB_TEMP_400CM, WET_BULB_TEMP_500CM,WET_BULB_TEMP_600CM and

WET_BULB_TEMP_750CM sensors are frozen on DOY 148.

- $\quad$ Changed hummock and hollow ground temperature rods on DOY 147 at approximately 2100.

- WET_BULB_TEMP_325CM sensor had a dry wick on DOY 155.

- WET_BULB_TEMP_400CM sensor had a dry wick on DOY 155.

- WET_BULB_TEMP_500CM sensor had a dry wick on DOY 156.

- $\quad$ DRY_BULB_TEMP_250CM sensor had inconsistent data on DOYs 155 and 156.

- $\quad$ DRY_BULB_TEMP_325CM sensor had inconsistent data on DOYs 154 and 156.

- $\quad$ DRY_BULB_TEMP_400CM sensor had inconsistent data on DOY 154.

- DRY_BULB_TEMP_600CM sensor had inconsistent data on DOYs 150 and 154.

\section{Data Period: June 7 - June 20/94 (DOY 158-171)}

- $\quad$ LATENT_HEAT_FLUX_450CM, H2O_FLUX 450CM, and SPECIFIC_HUMIDITY_450CM are missing on DOY 158 from $630-1200$ due to instrument failure.

- $\quad$ LATENT_HEAT_FLUX_450CM, SENSIBLE_HEAT_FLUX_450CM,

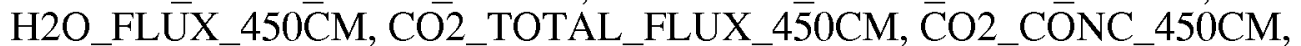
SPECIFIC_HUMIDITY_450CM, SPECIFIC_HUMIDITY_STDEV_450CM, W_MEAN_450CM and W_STDEV_450CM values are missing on DOY 162 from 1600-600, on DOY 163 from 1530-600 and on DOY 164 from 630-1700 due to weather.

- $\quad$ LATENT_HEAT_FLUX_450CM, SENSIBLE_HEAT_FLUX_450CM,

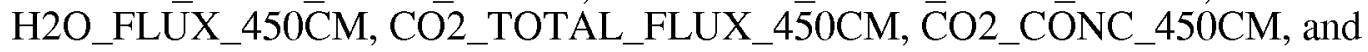
SPEC̄IFIC_HUMIDITY_450CM values are missing on DOY 162 from 630-1500 due to weather.

- $\quad$ LATENT_HEAT_FLUX_450CM, SENSIBLE_HEAT_FLUX_450CM, H2O_FLUX_450CM, CO2_TOTAL_FLUX_450CM and SPECIFIC_HUMIDITY_450CM values are missing on DOY 165 from $1130-600$, on DOY 166 from $630-600$, on DOY 167

- from 630-600, on DOY 168 from 630-1200, on DOY 169 from 330-600, on DOY 170 from 630-1630 and on DOY 171 from 730-600 due to instrument failure.

- CO2_CONC_450CM and SPECIFIC_HUMIDITY_STDEV_450CM values are missing on DOY 165 from $1500-600$ and on DOY 166 from $630-1600$ due to weather.

- $\quad$ CO2_CONC_450CM values are missing on DOY 171 from 2030-600 due to weather.

- WET_BULB_TEMP_400CM sensor had a dry wick on DOY 169.

- WET_BULB_TEMP_750CM sensor had a dry wick on DOY 168.

- $\quad$ DRY_BULB_TEMP_400CM sensor had inconsistent data on DOYs 169 and 170 .

- DRY_BULB_TEMP_600CM sensor had inconsistent data on DOY 170 and was rewicked on JDay 164 from 1800-2030.

Data Period: June 21 - July 4/94 (DOY 172-185)

- PPFD_OUT_1031CM sensor had instrument malfunctions on DOY 180 from 1900-600 and on DOY 181 from $1100-1400$.

- $\quad$ LATENT_HEAT_FLUX_450CM, SENSIBLE_HEAT_FLUX_450CM,

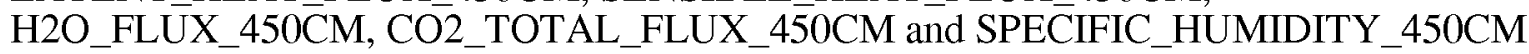
values are missing on DOY 174 from $2030-600$ due to weather. 
- $\quad$ LATENT_HEAT_FLUX_450CM, SENSIBLE_HEAT_FLUX_450CM,

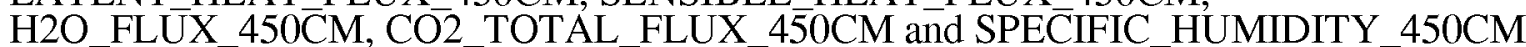
values are missing on DOY 175 from $630-600$, on DOY 176 from $630-1630$, on DOY 177 from 1800-600, on DOY 178 from 630-1730, on DOY 179 from 100-600 and on DOY 180 from 630-1800 due to instrument malfunction.

- $\quad$ LATENT_HEAT_FLUX_450CM, SENSIBLE_HEAT_FLUX_450CM, H2O_FLUX 450CM, CO2 TOTAL_FLUX 450CM, $\overline{\mathrm{CO}} 2$ CONC 450CM and SPECIFIC_HUMIDITY_450CM are missing on DOY 172 from 630-1800, on DOY 176 from 1700-600 and on DOY 177 from 630-1730, due to weather.

- $\quad$ LATENT_HEAT_FLUX_450CM, SENSIBLE_HEAT_FLUX_450CM, H2O_FLUX_450CM, CO2_TOTAL_FLUX_450CM, $\overline{\mathrm{CO}} 2$ _CONC_450CM and SPECIFIC_HUMIDITY_450CM are missing on DOY 180 from 200-600 and on DOY 184 from 1230-600 due to instrument malfunction.

- $\quad$ LATENT HEAT FLUX 450CM, SENSIBLE HEAT FLUX 450CM, H2O_FLUX_450CM and CO2_TOTAL_FLUX_450CM are missing on DOY 172 from 2200-600 due to weather.

- $\quad$ SPECIFIC_HUMIDITY_450CM values are missing on DOY 172 from 400-600 due to weather.

- CO2_TOTAL_FLUX_450CM values are missing on DOY 179 from 1730-1900 due to instrument calibration.

- CO2_TOTAL_FLUX_450CM and CO2_CONC_450CM values missing on DOYs 181 through 184 at 1200 due to instrument malfunction.

- $\quad$ LATENT_HEAT_FLUX_450CM and H2O_FLUX_450CM values are missing on DOY 184 at 630 due to instrument malfunction.

- $\quad$ SPECIFIC_HUMIDITY_STDEV_450CM values are missing on DOY 184 from 1700-600 due to instrument malfunction.

- $\quad$ LATENT_HEAT_FLUX_450CM, SENSIBLE_HEAT_FLUX_450CM, H2O_FLUX 450CM, CO2 TOTAL_FLUX 450CM, CO2_CONC 450CM, SPECIFIC_HUMIDITY_450CM and SPECIFIC_HUMIDITY_STDEV_450CM values are missing on DOY 185 from $630-600$ due to instrument malfunction.

- SOLAR_RAD_IN_1047CM, SOLAR_RAD_OUT_1023CM, NET_SOLAR_RAD_1035CM, LONGWAVE_IN_1033CM, LONGWAVE_OUT_1033CM TOTAL_RAD_IN_10 $\overline{4} 1 \mathrm{CM}$, TOTAL_RAD_OUT_1028CM, R_NET_1035CM, R_NET_1035CM_CORREC̄TED, PPFD_IN_1049 CM, PPFD_OUT_1031CM, SURFACE_ALBEDO, SOIL_TEMP_HUMMOCK_1CM, SOIL_TEMP_HUMMOCK 5CM, SOIL_TEMP_HUMMOCK_10CM, SOIL_TEMP_HUMMOCK_25CM, SOIL_TEMP_HUMMOCK_50CM, SOIL TEMP_HUMMOCK_75CM, SOIL_TEMP_HUMMOCK_100CM, SOIL_TEMP_HUMMOCK $150 \mathrm{CM}$, SOIL_TEMP_HUMMOCK_200CM, SOIL_TEMP_HOLLOW_1CM, SOIL TEMP HOLLOW 5CM, SOIL TEMP HOLLOW 10CM, SOIL_TEMP_HOLLOW_25CM, SOIL_TEMP_HOLLOW_50CM, SOIL_TEMP_HOLLOW_75CM, SOIL TEMP_HOLLOW 100CM, SOIL_TEMP_HOLLOW_150CM, SOIL_TEMP_HOLLOW_200CM, DRY_BULB_TEMP_250CM, DRY_BULB_TEMP_325CM, DRY_BULB_TEMP_400CM, DRY_BULB_TEMP_500CM, DRY_BULB_TEMP_600CM, DRY_BULB_TEMP_750CM, WET_BULB_TEMP_250CM, WET_BULB_TEMP_325CM, WET_BULB_TEMP_400CM,WET_BULB_TEMP_500CM,WET_BULB_TEMP_600CM, WET_BULB_TEMP_750CM, VAPOUR_PRESSURE_250CM, VAPÖUR_PRESSURE_325CM, VAPOÜR_PRESSURE_400CM, VAPOUR_PRESSURE_500CM, VAPOUR_PRESSURE 600CM, VAPOUR_PRESSURE_750CM, WIND_SPEED_250CM, WIND_SPEED_325CM, WIND_SPEED_400CM, WIND_SPEED_500CM, WIND_SPEED_600CM, WIND_DIR_600CM, WIND_DIR_STDEV_600CM, RAINFALL_100CM and WATER_LEVEL_DEPTH values are missing on DOYs 181 at 1450 through to DOY 186 at 1530 due to loss of generator power. 
- SOIL_HEAT_FLUX_HOLLOW_10CM, SOIL_HEAT_FLUX_HUMMOCK_10CM,

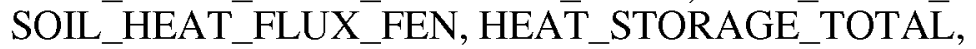
HEAT_STORAGE_SENSIBLE_AIR, and HEAT_STORAGE_LATENT_AIR values are missing on DOYs 181 through 185.

- WET_BULB_TEMP_600CM sensor had a dry wick on DOY 181.

- WET_BULB_TEMP_325CM, WET_BULB_TEMP_400CM,WET_BULB_TEMP_500CM, WET_BULB_TEMP_750CM had dry wicks from DOY 178 through to 180 at 1630.

- WET_BULB_TEMP_750CM and VAPOUR_PRESSURE_750CM sensors had data inconsistencies on DOY 175 from 1830-600 due to rewicking, and on DOYs 176 from 630-600 and 177 from 630-1900 due to instrument malfunctions.

- $\quad$ DRY_BULB_TEMP_400CM had data inconsistencies on DOYs 173 through 177.

- DRY_BULB_TEMP_750CM sensor had inconsistent data on DOY 175 from 1830-600 due to rewicking.

- WET_BULB_TEMP_325, 400, 500, and 600 had a dry wick on DOY 178

Data Period: July 5 - July 18/94 (DOY 186-199)

- LATENT_HEAT_FLUX_450CM, SENSIBLE_HEAT_FLUX_450CM, H2O_FLUX_450CM, CO2_TOTAL_FLUX_450CM, CO2_CONC_450CM, SPECIFIC_HUMIDITY_450CM and SPECIFIC_HUMIDITY_STDEV_450CM values are missing on DOYs 186 through 189 at 1930, on DOY 193 from 2300-600, on DOY 194 from 630-600 and on DOY 195 from 630-1830 due to instrument malfunction.

- LATENT_HEAT_FLUX_450CM, SENSIBLE_HEAT_FLUX_450CM,

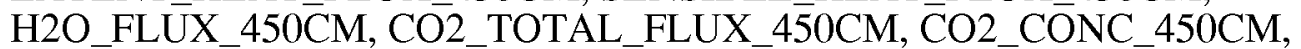
SPECIFIC_HUMIDITY_450CM and SPECIFIC_HUMIDITY_STDEV_450CM values are missing on DOY 191 from 2030-600 due to weather.

- $\quad$ LATENT_HEAT_FLUX_450CM, SENSIBLE_HEAT_FLUX_450CM, H2O_FLUX_450 $\bar{C} M, C O 2$ TOTAL_FLUX_450CM, SPECIFIC_HUMIDITY_450CM and SPECIFIC_HUMIDITY_STDEV_450CM values are missing on DOY 192 from 630-1600 due to weather.

- $\quad$ LATENT_HEAT_FLUX_450CM, SENSIBLE_HEAT_FLUX_450CM,

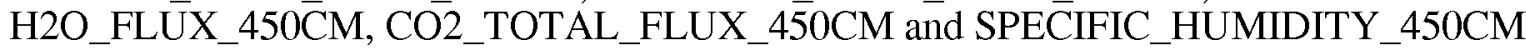
values are missing on DOY 196 from $1300-1900$ and from 300-600 and on DOY 197 from 630-1700 due to instrument malfunction.

- W_MEAN_450CM and W_MEAN_STDEV_450CM values are missing on DOY 192 at 1600 .

- SOLAR_RAD_IN_1047M, SOLAR_RAD_OUT_1023CM, NET_SOLAR_RAD_1035CM, LONGWAVE_IN_1033CM, LONGWAVE_OUT_1033CM TOTAL_RAD_IN_1041CM, TOTAL_RAD_OUT_1028CM, R_NET_1035CM, R_NET_1035CM_CORRECTED, PPFD_IN_1049CM, PPFD_OUT_1031CM, SURFACE_ALBEDO, SOIL_TEMP_HUMMOCK_1CM, SOIL_TEMP_HUMMOCK 5CM, SOIL_TEMP_HUMMOCK_10CM, SOIL_TEMP_HUMMOCK_25CM, SOIL_TEMP_HUMMOCK_50CM, SOIL TEMP_HUMMOCK_75CM, SOIL_TEMP_HUMMOCK_100CM, SOIL_TEMP_HUMMOCK_150CM, SOIL_TEMP_HUMMOCK_200CM, SOIL_TEMP_HOLLOW_1CM, SOIL_TEMP_HOLLOW_5 $\overline{\mathrm{CM}}$, SOIL_TEMP_HOLLOW_10CM, SOIL_TEMP_HOLLOW_25CM, SOIL_TEMP_HOLLOW_50CM, SOIL_TEMP_HOLLOW_75CM, SOIL_TEMP_HOLLOW_100CM, SOIL_TEMP_HOLLOW_150CM, SOIL_TEMP_HOLLOW_200CM, DRY_BULB_TEMP_250CM, DRY_BULB_TEMP_325CM, DRY_BULB_TEMP_400CM, DRY_BULB_TEMP_500CM, DRY_BULB_TEMP_600CM, DRY_BULB_TEMP_750CM, WET_BULB_TEMP_250CM, WET_BULB_TEMP_325CM, WET_BULB_TEMP_400CM,WET_BULB_TEMP_500CM,WET_BULB_TEMP_600CM, WET_BULB_TEMP_750CM, VAPOUR_PRESSURE_250CM, VAPŌUR_PRESSURE_325CM, VAPOUTR_PRESSURE_400CM, 
VAPOUR_PRESSURE_500CM, VAPOUR_PRESSURE_600CM,

VAPOUR_PRESSURE_750CM, WIND_SPEED_250CM, WIND_SPEED_325CM,

WIND_SPEED_400CM, WIND_SPEED_500CM, WIND_SPEED_600CM,

WIND_DIR_600CM, WIND_DIR_STDEV_600CM, RAINFALL_100CM and

WATER_LEVEL_DEPTH values are missing on DOYs 181 at 1450 through to DOY 186 at 1530 due to loss of generator power.

- $\quad$ SOIL_HEAT_FLUX_HOLLOW_10CM, SOIL_HEAT_FLUX_HUMMOCK_10CM, SOIL_HEAT_FLUX_FEN,HEAT_STORAGE_TOTAL,

HEAT_STORAGE_SENSIBLE_AIR, and HEAT_STORAGE_LATENT_AIR values are missing on DOYs 186 and 193.

- WET_BULB_TEMP_325CM sensor had a dry wick on DOY 190.

- WET_BULB_TEMP_500CM sensor had a dry wick on DOYs 189, 190 and 195 through 198.

- WET_BULB_TEMP_600CM sensor had a dry wick on DOYs 186 through 192.

- $\quad$ DRY_BULB_TEMP_400CM had data inconsistencies on DOYs 191 and 192.

Data Period: July 19 - August 1/94 (Julian Days 200-213)

- $\quad$ LATENT HEAT FLUX 450CM, SENSIBLE HEAT FLUX 450CM, H2O_FLUXX_450CM, CO2_TOTAL_FLUX_450CM, $\bar{C} O 2$ CONC_450CM, SPECIFIC_HUMIDITY_450CM and SPECIFIC_HUMIDITY_STDEV_450CM values are missing on 201 from $630-2000$ due to weather.

- $\quad$ LATENT_HEAT_FLUX_450CM, SENSIBLE_HEAT_FLUX_450CM, H2O_FLUXX_450CM, CO2_TOTAL_FLUX_450CM, and SPECIFIC_HUMIDITY_450CM values are missing on DOY 200 from $1330-600$ due to weather.

- $\quad$ CO2_CONC_450CM and SPECIFIC_HUMIDITY_450CM values are missing on DOY 200 from $1800-600$ due to weather.

- CO2_TOTAL_FLUX_450CM and CO2_CONC_450CM values are missing on DOY 205 from 1530-1730, on DOY 207 from 030-200 and on DOY 213 from 1930-2230 due to instrument calibration.

- $\quad$ LATENT_HEAT_FLUX_450CM and H2O_FLUX_450CM values are missing on DOY 206 from $1200-1500$ due to weather.

- $\quad$ LATENT_HEAT_FLUX_450CM, H2O_FLUX_450CM,CO2_TOTAL_FLUX_450CM and SPECIFIC_HUMIDITY_ $450 \mathrm{CM}$ values are missing on DOY 203 from $1230-14 \overline{50}$ and from 230-330 due to weather.

- $\quad$ LATENT_HEAT_FLUX_450CM, H2O_FLUX_450CM and SPECIFIC_HUMIDITY_450CM values are missing on DOY 211 from 1030-1130 due to instrument malfunction.

- SOLAR_RAD_IN_1047CM, SOLAR_RAD_OUT_1023CM, NET_SOLAR_RAD_1035CM, LONGWAVE_IN_1033CM, LONGWAVE_OUT_1033CM TOTAL_RAD_IN_10 $\overline{4} 1 \mathrm{CM}$, TOTAL_RAD_OUTT_1028CM, R_NET_1035CM, R_NET_1035CM_CORREC̄TED, PPFD_IN_1049CM, PPFD_OUT_1031CM, SURFACE_ALBEDO, SOIL_TEMP_HUMMOCK_1CM, SOIL_TEMP_HUMMOCK_5CM, SOIL_TEMP_HUMMOCK_10CM, SOIL_TEMP_HUMMOCK_25CM, SOIL_TEMP_HUMMOCK_50CM, SOIL TEMP_HUMMOCK_75CM, SOIL_TEMP_HUMMOCK_100CM, SOIL_TEMP_HUMMOCK_150CM, SOIL_TEMP_HUMMOCK_200CM, SOIL_TEMP_HOLLOW_1 $\overline{\mathrm{C} M}$, SOIL_TEMP_HOLLOW_5CM, SOIL_TEMP_HOLLOW_10CM, SOIL_TEMP_HOLLOW_25CM, SOIL_TEMP_HOLLOW_50CM, SOIL_TEMP_HOLLOW_75CM, SOIL_TEMP_HOLLOW_100CM, SOIL_TEMP_HOLLOW_150CM,SOIL_TEMP_HOLLOW_200CM, DRY_BULB_TEMP_250CM, DRY_BULB_TEMP_325CM, DRY_BULB_TEMP_400CM, DRY_BULB_TEMP_500CM, DRY_BULB_TEMP_600CM, DRY_BULB_TEMP_750CM, WET_BULB_TEMP_250CM, WET_BULB_TEMP_325CM, WET_BULB_TEMP_400CM, WET_BULB_TEMP_500CM, WET_BULB_TEMP_600CM, WET_BULB_TEMP_750CM, 
VAPOUR_PRESSURE_250CM, VAPOUR_PRESSURE_325CM,

VAPOUR_PRESSURE_400CM, VAPOUR_PRESSURE_500CM,

VAPOUR_PRESSURE_600CM, VAPOUR_PRESSURE_750CM,

WIND_SPEED_250CM, WIND_SPEED_325CM, WIND_SPEED_400CM,

WIND_SPEED_500CM, WIND_SPEED_600CM, WIND_DIR_600CM,

WIND_DIR_STDEV_600CM, RAINFALL_100CM and WATER_LEVEL_DEPTH values are missing on DOYs 202 from 2030-2200 due to psychrometer work and on DOYs 211 from 2030-600 and DOY 212 from 630-1530 due to instrument repair.

- $\quad$ SOIL_HEAT_FLUX_HOLLOW_10CM, SOIL_HEAT_FLUX_FEN, HEAT_STORAGE_TOTAL,HEATT_STORAGE_SENSIBLE_ĀIR, and

HEAT_STORAGE_LATENT_AIR values are missing on DOYs 202, 211 and 212.

- WET_BULB_TEMP_250CM sensor had a dry wick on DOY 204 and was subsequently rewicked.

- WET_BULB_TEMP_325CM sensor had a dry wick on DOYs 202, 203 and 204.

- WET_BULB_TEMP_600CM sensor had a dry wick on DOYs 201, 202, 203 through 207, and on 209.

- $\quad$ WET_BULB_TEMP_750CM sensor had a dry wick on DOYs 204 and 208.

\section{Data Period: August 2 - August 15/94 (DOY 214-227)}

- $\quad$ PPFD_OUT_1031CM sensor is broken on DOY 216 through 217 from 630-2230.

- $\quad$ LATENT_HEAT_FLUX_450CM, SENSIBLE_HEAT_FLUX_450CM, H2O_FLUX_450CM and SPECIFIC_HUMIDITY_450CM values are missing on DOY 214 from $1800-600$ and on DOY 218 from $630-1730$ due to weather.

- $\quad$ CO2_TOTAL_FLUX_450CM and CO2_CONC_450CM values are missing on DOY 214 from $1600-600$ due to weather.

- $\quad$ LATENT_HEAT_FLUX_450CM, SENSIBLE_HEAT_FLUX_450CM, H2O_FLUX _450CM, CO2_TOTAL_FLUX_450CM, CO2_CONC_450CM and SPEC̄IFIC_HUMIDITY_450CM values are missing on DOY 215 from 630-1600 due to weather.

- $\quad$ LATENT_HEAT_FLUX_450CM, SENSIBLE_HEAT_FLUX_450CM, H2O_FLUX_450CM, CO2_TOTAL_FLUX_450CM, CO2_CONC_450CM and SPECIFIC_HUMIDITY_450CM values are missing on DOY 224 from 630-600 and on DOY 225 from $630-1600$ due to instrument malfunction.

- $\quad$ LATENT_HEAT_FLUX_450CM, SENSIBLE_HEAT_FLUX_450CM, H2O_FLUX_450 $\bar{C} M, C O 2$ TOTAL_FLUX_450CM and SPECIFIC_HUMIDITY_450CM values are missing on DOY 217 from $2330-600$, on DOY 218 from $630-1730$ and on DOY 223 from 2200-600 due to weather.

- $\quad$ LATENT_HEAT_FLUX_450CM, H2O_FLUX_450CM and SPECIFIC_HUMIDITY_450CM values are missing on DOY 216 from 900-1230 due to instrument malfunction.

- WET_BULB_TEMP_600CM sensor had a dry wick on DOYs 221 through 227.

Data Period: August 16 - August 29/94 (DOY 228-241)

- $\quad$ LATENT_HEAT_FLUX_450CM, SENSIBLE_HEAT_FLUX_450CM, H2O_FLUX_450CM, CO2_TOTAL_FLUX_450CM, SPECIFIC_HUMIDITY_450CM, values are missing on DOY 234 from $130-600$, on DOY 235 from $630-1530$, on DOY 240 from 300-600, and on DOY 241 from 630-1730 due to weather.

- $\quad$ LATENT_HEAT_FLUX_450CM, SENSIBLE_HEAT_FLUX_450CM, H2O FLUX 450CM, CO2 TOTAL FLUX 450CM, $\overline{\mathrm{CO}} 2$ CONC 450CM and SPECIFIC_HUMIDITY_450CM values are missing on DOY 240 from $630-1530$ and on DOY 241 from $1800-600$ due to weather.

- $\quad$ LATENT_HEAT_FLUX_450CM and H2O_FLUX_450CM values are missing on DOY 228 from 630-1130 due to instrument malfunction. 
- $\quad$ LATENT_HEAT_FLUX_450CM, SENSIBLE_HEAT_FLUX_450CM, H2O_FLUX_450 CM and SPECIFIC_HUMIDITY_450CM values are missing on DOY 239 from $2200-600$ due to weather.

- CO2_TOTAL_FLUX_450CM and CO2_CONC_450CM values are missing on DOY 239 from $1730-600$ due to weather.

- WET_BULB_TEMP_600CM sensor had a dry wick on DOYs 228 through 239.

- WET_BULB_TEMP_750CM sensor had a dry wick on DOY 240.

- $\quad$ DRY_BULB_TEMP_750CM sensor had data inconsistencies on DOY 240.

Data Period: August 30 - September 12/94 (DOY 242-255)

- $\quad$ LATENT_HEAT_FLUX_450CM, SENSIBLE_HEAT_FLUX_450CM, H2O_FLUXX_450C̄M, CO2_TOTAL_FLUX_450CM, $\overline{\mathrm{CO}} 2$ _CONC_450CM and SPECIFIC_HUMIDITY_450CM values are missing on DOY 242 from 630-1450, due to instrument malfunction.

- $\quad$ LATENT_HEAT_FLUX_450CM,SENSIBLE_HEAT_FLUX_450CM, H2O_FLUX_450CM, CO2_FLUX_450CM and SPECIFIC_HUMIDITY_450CM values are missing on DOY 243 from $630-1330$, on DOY 254 from $400-600$ and on DOY 255 from 630-730 due to instrument malfunction.

- $\quad$ LATENT_HEAT_FLUX_450CM, SENSIBLE_HEAT_FLUX_450CM,

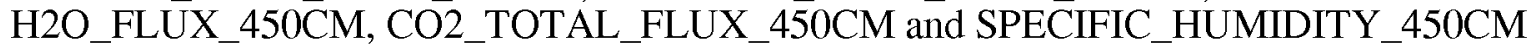
values are missing on DOY 246 from 830-1300, on DOY 247 from 1400-600, and on DOY 248 from $630-1700$ and from $2030-600$ due to weather.

- $\quad$ LATENT_HEAT_FLUX_450CM,H2O_FLUX_450CM and SPECIFIC_HUMIDITY_450CM values are missing on DOY 244 from 900-1400 due to instrument malfunction.

- CO2_TOTAL_FLUX_450CM and CO2_CONC_450CM values are missing on DOY 249 from $1730-600$ due to instrument malfunction.

- $\quad$ LATENT_HEAT_FLUX_450CM, SENSIBLE_HEAT_FLUX_450CM, H2O_FLUX_450CM and SPECIFIC_HUMIDITY_450CM values are missing on DOY 249 from $2200-600$ due to instrument malfunction.

- CO2_TOTAL_FLUX_450CM values are missing on DOY 250 from 530-630 and on DOY 251 from $630-800$ due to instrument malfunction.

- $\quad$ LATENT_HEAT_FLUX_450CM, SENSIBLE_HEAT_FLUX_450CM and H2O_FLUX_450CM values are missing on DOY 251 at 630 due to instrument malfunction.

- WET_BULB_TEMP_500CM sensor had a dry wick on DOY 254

- WET_BULB_TEMP_600CM sensor had a dry wick on DOYs 245 through 255.

- WET_BULB_TEMP_750CM sensor had a dry wick on DOY 255.

Data Period: September 13 - September 19/94 (DOY 256-262)

- SOLAR_RAD_IN_1047CM, SOLAR_RAD_OUT_10323M, NET_SOLAR_RAD_1035CM, LONGWAVE_IN_1033CM, LONGWAVE_OUT_1033CM TOTAL_RAD_IN_1041CM, TOTAL_RAD_OUT_1028CM, R_NET_1035CM, R_NET_1035CM_CORREC̄TED, PPFD_IN_1049CM, PPFD_OUT_1031CM, SURFACE_ALBEDO, SOIL_TEMP_HUMMOCK_1CM, SOIL_TEMP_HUMMOCK_5CM, SOIL_TEMP_HUMMOCK_10CM, SOIL_TEMP_HUMMOCK_25CM, SOIL_TEMP_HUMMOCK_50CM, SOIL TEMP_HUMMOCK_75CM, SOIL_TEMP_HUMMOCK_100CM, SOIL_TEMP_HUMMOCK_150CM, SOIL_TEMP_HUMMOCK_200CM, SOIL_TEMP_HOLLOW_1CM, SOIL_TEMP_HOLLOW_5 $\overline{C M}$, SOIL_TEMP_HOLLOW_10CM, SOIL_TEMP_HOLLOW_25CM,SOIL_TEMP_HOLLOW_50CM, SOIL_TEMP_HOLLOW_75CM, SOIL_TEMP_HOLLOW_100CM, SOIL_TEMP_HOLLOW_150CM, SOIL_TEMP_HOLLOW_200CM, DRY_BULB_TEMP_250CM, DRY_BULB_TEMP_325CM, DRY_BULB_TEMP_400CM, DRY_BULB_TEMP_500CM, DRY_BULB_TEMP_600CM, DRY_BULB_TEMP_750CM, 
WET_BULB_TEMP_250CM, WET_BULB_TEMP_325CM, WET_BULB_TEMP_400CM, WET_BULB_TEMP_500CM, WET_BULB_TEMP_600CM, WET_BULB_TEMP_750CM, VAPOUR_PRESSURE_250CM, VAPPOUR_PRESSURE_325CM,

VAPOUR_PRESSURE_400CM, VAPOUR_PRESSURE_500CM,

VAPOUR PRESSURE 600CM, VAPOUR PRESSURE 750CM,

WIND_SPEED_250CM, WIND_SPEED_325CM, WIND_SPEED_400CM,

WIND_SPEED_500CM, WIND_SPEED_600CM, WIND_DIR_600CM,

WIND_DIR_STDEV_600CM, RAINFALL_100CM and WATER_LEVEL_DEPTH values

are missing on DOY 262 from 1500-600 (end of field season).

- $\quad$ LATENT_HEAT_FLUX_450CM, SENSIBLE_HEAT_FLUX_450CM,

H2O_FLUX_450CM, CO2_TOTAL_FLUX_450CM, $\overline{\mathrm{CO}} 2 \_\mathrm{CONC} 4450 \mathrm{CM}$ and

SPECIFIC_HUMIDITY_450CM values are missing on DOY 256 from 630-1700 and on

DOY 258 from $2200-600$ due to weather.

- $\quad$ LATENT_HEAT_FLUX_450CM, SENSIBLE_HEAT_FLUX_450CM,

H2O_FLUX_450CM, CO2_TOTAL_FLUX_450CM, $\overline{\mathrm{CO}} 2 \_\mathrm{CONC} 4450 \mathrm{CM}$ and

SPECIFIC_HUMIDITY_450CM values are missing on DOY 258 on $630-1700$ and on DOY 259 from 630-600, on DOYY 260 from 630-1530 and from 2200-600 and on DOY 261 from 630-1530 due to instrument malfunction.

- $\quad$ LATENT_HEAT_FLUX_450CM, SENSIBLE_HEAT_FLUX_450CM,

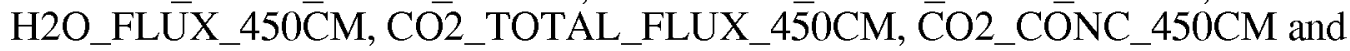
SPECIIFIC_HUMIDITY_450CM values are missing on DOY 256 from 1800-1830 due to instrument calibration.

- $\quad$ LATENT_HEAT_FLUX_450CM, SENSIBLE_HEAT_FLUX_450CM, H2O_FLUX_450CM, CO2_TOTAL_FLUX_450CM, CO2_CONC_450CM, SPECIFIC_HUMIDITY_450CM and SPECIFIC_HUMIDITY_STDEV_450CM values are missing on DOY 257 from 1530-1730 due to weather.

- $\quad$ LATENT_HEAT_FLUX_450CM, SENSIBLE_HEAT_FLUX_450CM, H2O_FLUXX_450CM, CO2_TOTAL_FLUX_450CM, CO2_CONC_450CM, SPECIFIC_HUMIDITY_450CM, SPECIFIC_HUMIDITY_STDEV_450CM, W_MEAN_450CM and $\bar{W} \_$MEAN_STDEV_450CM are missing on DOY 262 from 1530-600 due to the end of the field season.

- $\quad$ LATENT_HEAT_FLUX_450CM, H2O_FLUX_450CM, SPECIFIC_HUMIDITY_450CM and SPECIFIC_HUMIDITY_STDEV_450CM values are missing on DOY 257 from 900-1300 due to weather.

- SOIL_HEAT_FLUX_HOLLOW_10CM, SOIL_HEAT_FLUX_HOLLOW_10CM, SOIL_HEAT_FLUX_FEN, HEAT_STORAGE_TOTAL, HEAT_STORAGE_SENSIBLE_AIR, and HEAT_STORAGE_LATENT_AIR values are missing on 262 (end of field season).

- DRY_BULB_TEMP_500CM sensor had inconsistent data on DOY 261.

\section{SPECIAL NOTES: 1995}

All data were averaged over thirty minutes, starting on the hour and half-hour, and ending thirty minutes later. Sampling was continuous and each day's data is from 0600 UTC to 0600 UTC the next day.

- $\quad$ LONGWAVE_IN_1033CM was calculated as a residual.

- Small nighttime values for SOLAR_RAD_IN_1047CM, SOLAR_RAD_OUT_1023CM, PPFD_IN_1049CM, and PPFD_OUT_1031CM were set to zero to account for very slight zero depressions and elevations in the radiometers.

- $\quad$ R_NET_1035CM_CORRECTED was calculated from day and night time equations developed by Hodges and Smith (1997) (see documentation for details).

- HEAT_STORAGE_TOTAL is the sum of HEAT_STORAGE_LATENT_AIR, HEAT_STORAGE_SENSIBLE_AIR, and SOIL_HEAT_FLUX_HOLLOWW_10CM 
Data Period: April 8 - April 11/95 (DOY 098-101)

- $\quad$ R_NET_1035CM sensor installed on DOY 098 at 1830.

- WIND_SPEED_250CM sensor installed on DOY 098 at 2000.

- WIND_SPEED_325CM sensor installed on DOY 098 at 2030.

- WIND_SPEED_400CM and WIND_SPEED_500CM sensors installed on DOY 098 at 2100.

- DRY_BULB_TEMP_250CM,DRY_BULB_TEMP_325CM, and

DRY_BULB_TEMP_400CM sensors installed on DOY 099 at 2000.

- SOLĀR_RAD_IN_1047CM and SOLAR_RAD_OUT_1023CM sensors installed on JDay 099 at 2000 .

- $\quad$ LONGWAVE_RAD_OUT_1033CM sensor installed on DOY 099 at 2200.

- $\quad$ LATENT_HEAT_FLUX_450CM, SENSIBLE_HEAT_FLUX_450CM,

H2O_FLUX_450CM, SPECIFIC_HUMIDITY_450CM and

SPECIFIC_HUMIDITY_STDEV_450CM not installed until DOY 100 at 630.

- WIND_SPEED_600CM, WIND_DIR_600CM and WIND_DIR_STDEV_600CM sensors installed on DOY 100 at 2200.

- $\quad$ PPFD_IN_1049CM and PPFD_OUT_1031CM sensors installed on DOY 101 at 2000.

- DRY_BULB_TEMP_250CM, DRY_BULB_TEMP_325CM, DRY_BULB_TEMP_400CM, DRY_BULB_TEMP_500CM, DRY_BULB_TEMP_600CM, DRY_BULB_TEMP_750CM, WET_BULB_TEMP_250CM, WET_BULB_TEMP_325CM, WET_BULB_TEMP_400CM, WET_BULB_TEMP_500CM, WET_BULB_TEMP_600CM and WET_BULB_TEMP_750CM sensors are intermittently frozen on DOYs 098 through 101.

- $\quad$ LATENT_HEAT_FLUX_450CM, SENSIBLE_HEAT_FLUX_450CM,

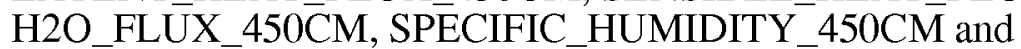
SPECIIFIC_HUMIDITY_STDEV_450CM are missing on DOY 101 from 1630 to 1930 due to programming error.

Data Period: April 12 - April 25/95 (DOY 102-115)

- DRY_BULB_TEMP_250CM, DRY_BULB_TEMP_325CM, DRY_BULB_TEMP_400CM, DRY_BULB_TEMP_500CM, DRY_BULB_TEMP_600CM, DRY_BULB_TEMP_750CM, WET_BULB_TEMP_250CM, WET_BULB_TEMP_325CM, WET_BULB_TEMP_400CM, WET_BULB_TEMP_500CM, WET_BULB_TEMP_600CM and

WET_BULB_TEMP_750CM sensors are intermittently frozen on DOYs 102 through 115 .

- $\quad$ SENSIBLE_HEAT_FLUX_450CM value is missing on DOY 116 from 130 to 600 due to broken thermocouple wire.

Data Period: April 25 - May 9/95 (DOY 116-129)

- DRY_BULB_TEMP_250CM, DRY_BULB_TEMP_325CM, DRY_BULB_TEMP_400CM, DRY_BULB_TEMP_500CM, DRY_BULB_TEMP_600CM, DRY_BULB_TEMP_750CM, WET_BULB_TEMP_250CM, WET_BULB_TEMP_325CM, WET_BULB_TEMP_400CM, WET_BULB_TEMP_500CM,WET_BULB_TEMP_600CM and

WET_BULB_TEMP_750CM sensors are intermittently frozen on DOYs 116 through 129.

- $\quad$ SOIL_HEAT_FLUX_HOLLOW_10CM installed on DOY 127 at 1600.

- $\quad$ SENSIBLE_HEAT_FLUX_450CM value is missing on DOYs 116 through 124 at 1430 due to a broken thermocouple wire.

- $\quad$ LATENT_HEAT_FLUX_450CM, H2O_FLUX_450CM and SPECIFIC_HUMIDITY_450CM are missing on DOY 116 at 1330 through DOY 118 at 1530.

- $\quad$ LATENT_HEAT_FLUX_450CM,H2O_FLUX_450CM and SPECIFIC_HUMIDITY_450CM are missing on DOY 130 from 230-430 due to ice on the hygrometer. 
Data Period: May 10 - May 23/95 (DOY 130-143)

- DRY_BULB_TEMP_250CM, DRY_BULB_TEMP_325CM, DRY_BULB_TEMP_400CM, DRY_BULB_TEMP_500CM, DRY_BULB_TEMP_600CM, DRY_BULB_TEMP_750CM, WET_BULB_TEMP_250CM, WET_BULB_TEMP_325CM, WET_BULB_TEMP_400CM, WET_BULB_TEMP_500CM, WET_BULB_TEMP_600CM and

WET_BULB_TEMP_750CM sensors are intermittently frozen on DOYs 130 through 138 and 143.

- $\quad$ PPFD_IN_1049CM sensor has intermittent open circuit from DOY 136 through 142.

- $\quad$ PPFD_IN_1033CM sensor has open circuit on DOY 143.

- $\quad$ LATENT_HEAT_FLUX_450CM, H2O_FLUX_450CM and

SPECIFIC_HUMIDITY_450CM are missing on DOY 130 from 830 through 1300 due to ice on the hygrometer.

- $\quad$ LATENT_HEAT_FLUX_450CM, SENSIBLE_HEAT_FLUX_450CM and

H2O_FLUX_450CM are missing on DOY 130 at 1330 to 131 at 1830 due to weather.

- $\quad$ LATENT_HEAT_FLUX_450CM, SENSIBLE_HEAT_FLUX_450CM, H2O_FLUX_450CM, SPECIFIC_HUMIDITY_450CM and

SPEC̄IFIC_HUMIDITY_STDEV_450CM readings end on DOY 132 at 1930.

\section{Data Period: May 24 - June 6/95 (DOY 144-157)}

- DRY_BULB_TEMP_250CM, DRY_BULB_TEMP_325CM, DRY_BULB_TEMP_400CM, DRY_BULB_TEMP_500CM, DRY_BULB_TEMP_600CM, DRY_BULB_TEMP_750CM, WET_BULB_TEMP_250CM, WET_BULB_TEMP_325CM, WET_BULB_TEMP_400CM, WET_BULB_TEMP_500CM, WET_BULB_TEMP_600CM and

WET_BULB_TEMP_750CM sensors are intermittently frozen on DOY 144 through 145 and on DOY 147.

- PPFD_IN_1049CM sensor has open circuit on from DOY 144 through 157.

Data Period: June 7 - June 14/95 (DOY 158-165)

- DRY_BULB_TEMP_250CM, DRY_BULB_TEMP_325CM, DRY_BULB_TEMP_400CM, DRY_BULB_TEMP_500CM, DRY_BULB_TEMP_600CM, DRY_BULB_TEMP_750CM, WET_BULB_TEMP_250CM, WET_BULB_TEMP_325CM, WET_BULB_TEMP_400CM, WET_BULB_TEMP_500CM,WET_BULB_TEMP_600CM and WET_BULB_TEMP_750CM sensors are intermittently frozen on DOY 158 through 161.

- $\quad$ PPFD_IN_1049CM sensor has open circuit on from DOY 158 through 165.

Data Period: April 29 - May $8 \backslash 96$ (DOY 120-129)

- SOIL_HEAT_FLUX_HOLLOW_10CM sensor not installed until DOY 133 at 2230 due to

- frozen ground conditions.

- WIND_SPEED_400CM not available until DOY 189 at 0630.

- $\quad$ SOIL_TEMPERATURE_HUMMOCK_50CM not available from DOY 123(1430) to DOY 132(1730).

- HEAT_STORAGE_TOTAL, and HEAT_STORAGE_LATENT_AIR not available until 134(1700).

- $\quad$ HEAT_STORAGE_SENSIBLE_AIR not available until DOY 133(0630).

- $\quad$ DOY 120(1600) CO2_EDDY_FLUX_450CM and CO2_CONC_450CM were linearly interpolated.

- DOY 122 CO2_EDDY_FLUX_450CM(2000), and CO2_CONC_450CM(1730) were linearly interpolated.

- DOY 123(1700-1900,2030) CO2_CONC_450CM(1700-1900), and CO2_EDDY_FLUX_450CM

- were linearly interpolated.

- $\quad$ DOY 126(1700) and 129(1500-1530) CO2_CONC_450CM and CO2_EDDY_FLUX_450CM were linearly interpolated. 
- DOY 120 (0630-1600) LATENT_HEAT_FLUX_450CM,

SENSIBLE_HEAT_FLUX 450 $\overline{\mathrm{C}} \mathrm{M}, \mathrm{H} 2 \overline{\mathrm{O}}$ FLUX $450 \mathrm{CM}$,

CO2_STORAGE_FLUX_450CM, SPECIFIC_HUMIDITY_450CM,

SPECIFIC_HUMIDITY_STDEV_450CM, and VAPOUR_PRESSURE_400CM are not available.

- DOY 126(2130) to 129(1500) LATENT_HEAT_FLUX_450CM,

SENSIBLE_HEAT_FLUX_450CM, H2O_FLUX_450CM, CO2_EDDY_FLUX_450CM, and CO2_TOTAL_FLUX_450CM not available.

- $\quad$ SPECIFIC_HUMIDITY_450CM, and SPECIFIC_HUMIDITY_STDEV_450CM missing DOY $127(1800-2300)$.

\section{SPECIAL NOTES: 1996}

All data were averaged over thirty-minute intervals, starting on the hour or half-hour, and ending thirty minutes later. Sampling was continous, and each day's data is from 0600 UTC to 0600 UTC the next day.

- $\quad$ LONGWAVE_IN_1033CM was calculated as a residual.

- Small nighttime values for SOLAR RAD IN 1047CM, SOLAR RAD OUT 1023CM, PPFD_IN_1049CM, and PPFD_OUT_1031CM were set to zero to account for very slight zero depressions and elevations in the radiometers.

- $\quad$ Negative values of NET_SOLAR_RAD_1035CM were set to zero, as were corresponding values of SOLAR_RAD_IN_1047CM, SOLAR_RAD_OUT_1023CM, and SURFACE ALBEDO.

- Corresponding changes were also made in the calculations of LONGWAVE_IN_1033CM, TOTAL_RAD_IN_1041CM, and TOTAL_RAD_OUT_1028CM.

- $\quad$ R_NET_1035CM_CORRECTED was calculated from day and night time equations developed by Hodges and Smith(1997) (see documentation for details).

- $\quad$ LATENT_HEAT_FLUX_450CM is flagged if $<-50.00 \mathrm{~W} / \mathrm{m}^{\wedge} 2$.

- $\quad$ SENSIBLE_HEAT_FLUX_450CM is flagged if $<-70.00 \mathrm{~W} / \mathrm{m}^{\wedge} 2$.

- HEAT_STORAGE_TOTAL is the sum of HEAT_STORAGE_SENSIBLE_AIR, HEAT_STORAGE_LATENT_AIR, and SOIL_HEAT_FLUX_HOLLOW_10CM.

- CO2_TOTAL_FLUX_450CM is the sum of CŌ2_EDDY_FLUX_450CM, and CO2_STORAGE_FLUX_450CM.

- Where only CO2_STORAGE_FLUX_450CM is missing, CO2_TOTAL_FLUX_450CM is based on CO2_EDDY_FLUX_450CM only.

- When SOLAR_RAD_IN_1047CM is zero, any negative CO2_TOTAL_FLUX_450CM values are set to zero as well.

Data Period: May 9 - May 22\96 (DOY 130-143)

- $\quad$ SOIL_HEAT_FLUX_HOLLOW_10CM sensor not installed until DOY 133 at 2230 due to frozen ground conditions.

- WIND_SPEED_400CM not available until DOY 189 at 0630.

- $\quad$ SOIL_TEMPERATURE_HUMMOCK_50CM not available from DOY 123(1430) to DOY 132(1730).

- HEAT_STORAGE_TOTAL, and HEAT_STORAGE_LATENT_AIR not available until $134(1700)$.

- $\quad$ HEAT STORAGE SENSIBLE_AIR not available until DOY 133(0630).

- DOY 135(1430-1500) and 136(1930-2000) CO2_EDDY_FLUX_450CM and CO2_CONC_450CM are linearly interpolated.

- DOY 132 (1600-1730) SOLAR_RAD_IN_1047CM, SOLAR_RAD_OUT_1023CM, NET_SOLAR_RAD_1035CM, LONGWĀVE_IN_1033CM, LONGWAVE_OUT_1028CM, TOTAL_RAD_IN_1041CM, TOTAL_RAD_OUT_1028CM, R_NET_1035CM, R_NET_1035CM_CORRECTED,PPFD_IN_1049CM,PPFD_OUT_1031CM, SURFACE_ALBEDO, all soil temperatures in the hummock and hollow, DRY_BULB_TEMP_250CM, DRY_BULB_TEMP_600CM, WIND_DIR_600CM, and WIND_DIR_STDEV_600CM missing due to processing problems. 
- $\quad$ DOY 132(1830) to 134(1630) LATENT_HEAT_FLUX_450CM, SENSIBLE_HEAT_FLUX_450CM, H2O_FLUX_450CM, CO2_EDDY_FLUX_450CM, CO2_STORAGE_FLUX_450CM, CO2_TOTAL_FLUX_450CM, SPECIIFIC_HUMIDITY_450CM, SPECIFIC_HUMIDITY_STDEV_450CM, VAPOUR_PRESSURE $400 \mathrm{CM}, \mathrm{W}$ MEAN $450 \mathrm{CM}, \mathrm{W}$ STDEV $450 \mathrm{CM}$, RELATIVE_HUMIDITY_400CM, ĀIR_PRESSSURE, and CO2_CONC_450CM missing due to processing malfunctions.

- $\quad$ LATENT_HEAT_FLUX_450CM, and H2O_FLUX_450CM (137 1600-152 0500), SENSIBLE_HEAT_FLUX_450CM (137 1600-152 2000), CO2_EDDY_FLUX_450CM, CO2_STORAGE_FLUX_450CM, and CO2_TOTAL_FLUX_450CM (137 1300-155 1800)are missing.

- $\quad$ DOY 132(1800), 134(1700), and 137(1300) CO2_STORAGE_FLUX_450CM are missing.

- SPECIFIC_HUMIDITY_450CM, and SPECIFIC_HUMIDITY_STDEV_450CM is unavailable from DOY $1 \overline{3} 9(1030-1400)$ and DOY $139(1730)$ to $142(1300)$.

Data Period: May 23 - June $5 \backslash 96$ (DOY 144-157)

- WIND_SPEED_400CM not available until DOY 189 at 0630.

- $\quad$ LATENT HEAT FLUX 450CM, and H2O FLUX 450CM (137 1600-152 0500), SENSIBLE_HEAT_FLUX_450CM (137 1600-152 2000), CO2_EDDY_FLUX_450CM, CO2_STORAGE_FLUX_450CM, and CO2_TOTAL_FLUX_450CM (137 1300-155 1800) are missing.

- $\quad$ DOY 155(1800-1830) sign of CO2_TOTAL_FLUX_450CM is corrected.

- $\quad$ SPECIFIC_HUMIDITY_450CM, and SPECIFIC_HUMIDITY_STDEV_450CM unavailable DOY $152(1200-1400), 152(1700)$ to $153(1700), 153(0700)$ to $154(1830)$, and $156(0500)$ to $157(1330)$.

- $\quad$ LATENT_HEAT_FLUX_450CM and H2O_FLUX_450CM unavailable DOY 153(0700) to $154(0830)$, and $1 \overline{5} 6(0500)$ to $157(1330)$.

- DOY 158(2100)-160(0630) CO2_CONC_450CM is missing.

Data Period: June 6 - June 19\96 (DOY 158-171)

- WIND_SPEED_400CM not available until DOY 189 at 0630 .

- $\quad$ LATENT_HEAT_FLUX_450CM, and H2O_FLUX_450CM unavailable DOY $158(2100)-159(1830), 161(0400-1400), 162(1530-1900), 164(0730-1500)$, 165(1700-1900), 166(0500)-167(2130), and 167(0400)-168(1130).

- $\quad$ SENSIBLE_HEAT_FLUX_450CM unavailable DOY 158(2100)-159(1830), and 165(1700-1900).

- CO2_EDDY_FLUX_450CM, CO2_STORAGE_FLUX_450CM, and CO2_TOTAL_FLUX_450CM are unavailable DOY 158(2100)-160(0630), and 165(1700-1900).

- CO2_STORAGE_FLUX_450CM is missing DOY 158(2030), 160(0630), and $165(1630,1930)$.

- SPECIFIC_HUMIDITY_450CM, and SPECIFIC_HUMIDITY_STDEV_450CM unavailable DOY 160(0400)-161(1400), 162(1530-1900), 164(0730-1500), 166(0500)-167(2130), $167(0400)-168(1130)$.

Data Period: June 20 - July 3\96 (DOY 172-185)

- WIND_SPEED_400CM not available until DOY 189 at 0630.

- DOY 180(1530)-189(0630) SOIL_TEMPERATURE_HUMMOCK_50CM is unavailable.

- Linear interpolation of CO2_CONC_450CM occurred DOY 176(1800-1930), 177(1900), 179(1730-1800), and 185(1530) and CO2_TOTAL_FLUX_450CM DOY 176(1800-2030), 177(1900), 179(1730-1800), and 185(1530).

- DOY 172 (0900-2230) SENSIBLE_HEAT_FLUX_450CM, CO2_EDDY_FLUX_450CM, and CO2_TOTAL_FLUX_450CM are unavailable. 
- $\quad$ LATENT_HEAT_FLUX_450CM, H2O_FLUX_450CM, SPECIFIC_HUMIDITY_450CM, and SPECIFIC_HUMIDITY STDEV_450CM missing at following times: DOY 171(0430)-173(1800), 174(1100-1400), 181(0230)-182(1430), 182(0400)-183(1500), 185(0730-1230), 185(0430)-186(1630).

- DOY 180 HEAT_STORAGE_TOTAL, HEAT_STORAGE_SENSIBLE_AIR, and HEAT_STORAGE_LATENT_AIR is unavailable.

- DOY 180 (0030-0600) SOLAR RAD IN 1047CM, SOLAR RAD OUT 1023CM, NET_SOLAR_RAD_1035CM, LONGWĀVE_IN_1033CM, LONGWAVE_OUT_1033CM, TOTAL_RAD_IN_1041CM, TOTAL_RAD_OUT_1028CM, R_NET_1035CM, R_NET_1035CM_CORRECTED,PPF̄D_IN_1049CM,PPFD_OUT_1031CM, SÜRFACE_ALBEDO,SOIL_HEAT_FLUX_HOLLOW_10CM, all hummock and hollow temperatures, DRY_BULB_TEMP_250CM, DRY_BULB_TEMP_600CM, WIND SPEED 250 CM, WIND SPEED 600CM, WIND_DIR_600CM,WIND_DIR_STDEV_600CM, and RAINFALL_100CM are unavailable.

\section{Data Period: July 4 - July 17\96 (DOY 186-199)}

- WIND_SPEED_400CM not available until DOY 189 at 0630.

- DOY 180(1530)-189(0630) SOIL_TEMPERATURE_HUMMOCK_50CM is unavailable.

- DOY 185(0430)-186(1630) LATENT HEAT_FLUX 450CM, H2O FLUX 450CM, SPECIFIC_HUMIDITY_450CM, and SPECIFIC_HUMIDITY_STDEV_450CM are missing.

- SOLAR_RAD_IN_1047CM, SOLAR_RAD_OUT_1023CM, NET_SOLAR_RAD_1035CM, LONGWAVE_IN_1033CM, LONGWAVE_OUT_1033CM, TOTAL_RAD_IN_1041CM, TOTAL_RAD_OUT_1028CM, R_NET_1035CM, R_NET_1035C̄M_CORRECTED,PPFD_IN_1049CM,PPFD_OUT_1031CM, SÜRFACE_ALBEDO, SOIL_HEAT_FLUX_HUMMOCK_10 $\bar{C}$, SOIL_HEAT_FLUX_HOLLOW_10 $\bar{C} M$, all soil temperatures for both hummock and hollow, DRY_BULB_TEMP_250CM, DRY_BULB_TEMP_600CM, WIND_SPEED_250CM, WIND_SPEED_400C̄M, WIND_SPEED_600CM, WIND_DIR_600CM, WIND_DIR_STDEV_600CM, and RAINFALL_100CM unavailable DOY 189(1530-1700),189(0500)-190(1200), and 190(1630-1830) and linearly interpolated DOY 189 (1800-1830, 2300-2330, 0030,0130,0300,0400), DOY 190(1300 - except for RAINFALL_100CM, WIND_DIR_600CM, and WIND_DIR_STDEV_600CM).

- $\quad$ SOIL_TEMPERTURE_HUMMOCK_1CM linearly interpolated DOY 193(2000).

- Linear interpolation of $\overline{C O} 2$ _CONC_450CM and CO2_TOTAL_FLUX_450CM occurred DOY 187(1800), 193(1730-1800,1930),196(1800), and 199(2100).

- LATENT_HEAT_FLUX_450CM, H2O_FLUX_450CM, SPECIFIC_HUMIDITY 450CM,

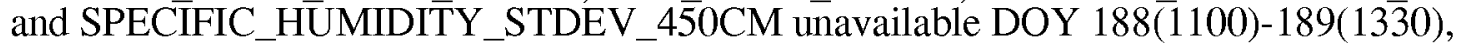
198(1930-2200), 198(2330-0630).

Data Period: July 18 - July $31 \backslash 96$ (DOY 200-213)

- SOIL_TEMPERATURE_HUMMOCK_1CM linearly interpolated DOY 202(2200), 209(2030,2100), 212(2000, 2030).

- Linear interpolation of CO2_CONC_450CM DOY 202(2100-2200), 207(1730-1930), 209(1930) and 212(2130) and CO2_TOTAL_FLUX_450CM DOY 202(2000-2200), 207(1930), 209(1930), and 212(2130).

- $\quad$ AIR_PRESSURE linearly interpolated DOY 202(2100, 2130), 207(1730-1900).

- $\quad$ LATENT_HEAT_FLUX_450CM,H2O_FLUX_450CM, SPECIFIC_HUMIDITY_450CM, and SPECIFIC_HUMIDITY_STDEV_450CM missing on the following days: DOY 201(0730-1130), 202(0630-1630), and 203(0730-1300).

- $\quad$ DOY 202(1900-2130) LATENT_HEAT_FLUX_450CM, and H2O_FLUX_450CM is missing.

- $\quad$ SOIL_TEMPERATURE_HUMMOCK_50CM is missing DOY 203(1830)-209(2100), 212(2100)-217(2000). 
Data Period: August 1 - August $14 \backslash 96$ (DOY 214-227)

- $\quad$ DOY 214(2000) AIR PRESSURE linearly interpolated.

- $\quad$ DOY 214(2000), 217(2100), 221(1830-1930), 226(2030) CO2_CONC_450CM is linearly interpolated.

- $\quad$ DOY 220 SOIL TEMPERATURE HUMMOCK 1CM (1830-2030) and SOIL_TEMPERATURE_HOLLOW_10CM (2000) linearly interpolated.

- DOY 224(1530) linearly interpolated SOLAR_RAD_IN_1047CM, SOLAR_RAD_OUT_1023CM, NET_SOLAR_RAD_1035CM,LONGWAVE_IN_1033CM, LONGWAVE_OUT_1033CM, TOTAL_RAD_IN_1041CM, TOTAL_RAD_OUT_1028CM, R_NET_1035CM, PPDF_IN_1049CM, PPFD_OUT_1031CM, SURFACE_ALBEDO, SOIL_HEAT_FLUX_HUMMOCK_10CM, SOIL_HEAT_FLUX_HOLLOW_10CM, all soil temperatures for both hummock and hollow, DRY_BULB_TEMP_250CM, DRY_BULB_TEMP_600CM, WIND_SPEED_250CM, WIND_SPEED_400CM, WIND_SPEED_600C̄M, WIND_DIR_600CM, WIND_DIR_STDEV_600CM, and RAINFALL_100CM. These variables are also missing DOY 224(1830-2100).

- DOY 226(2030)AIR_PRESSURE and RELATIVE_HUMIDITY_400CM is linearly interpolated.

- DOY 226(1930-2030) CO2_TOTAL_FLUX_450CM is linearly interpolated.

- DOY 214(630)-224(2130) WIND_SPEED_400CM is missing.

- $\quad$ DOY 214(1800-2130) LATENT_HEAT_FLUX_450CM, and H2O_FLUX_450CM are missing.

- DOY 214(1800-2030) SENSIBLE_HEAT_FLUX_450CM, CO2_EDDY_FLUX_450CM, and CO2_TOTAL_FLUX_450CM are missing.

- $\quad$ LATENT_HEAT_FLUX_450CM, H2O_FLUX_450CM, SPECIFIC_HUMIDITY_450CM, and SPECIFIC_HUMIDITY_STDEV_450CM are unavailable DOY 215(1000-1330) 218(2030-2300), 219(1300-2230), 219(0200-0700), 220(1000-1300, 1600-1830), 220(0400)-221(1530), 222(1430-2100), 223(0930-1530), 223(0200)-224(1400).

- $\quad$ DOY 226(2030)-233(1300) LATENT_HEAT_FLUX_450CM is missing.

- DOY 226(2030)-233(0630) SENSIBLE_HEAT_FLUX_450CM is missing.

- $\quad$ SOIL_TEMPERATURE_HUMMOCK_50CM is missing 214(0630)-217(2000), 220(2200)-221(2100)

- SOIL_TEMPERATURE_HOLLOW_5CM is missing DOY217(2000)-218(2000), 218(1930)-220(2000)

- DOY 223(1800-2330) WIND_DIR_600CM, WIND_DIR_STDEV_600CM are missing.

- HEAT_STORAGE_TOTAL,HEAT_STORAGE_SSENSIBLE_AIR, and HEAT_STORAGE_LATENT_AIR are missing DOY 224

- H2O_FLUX_450CM unavailable DOY 227(0630-1200), 227(0230-0530).

Data Period: August 15 - August $28 \backslash 96$ (DOY 228-241)

- $\quad$ DOY 226(2030)-233(1300) LATENT_HEAT_FLUX_450CM is missing.

- DOY 226(2030)-233(0630) SENSIBLE_HEAT_FLUX_450CM is missing.

- CO2_EDDY_FLUX_450CM, and CO2_CONC_450CM are linearly interpolated on DOY $238(1830), 239(1930)$, and 241(1930).

- $\quad$ DOY 236(1930-2000) CO2_CONC_450CM is linearly interpolated.

- $\quad$ LATENT_HEAT_FLUX_450CM, H2O_FLUX_450CM, CO2_EDDY_FLUX_450CM, CO2_TOTAL_FLUX_450CM unavailable DOY 233(0530)-234(1200), 237(900-1330), 237(2000)-238(1500), 238(0530)-239(1300).

- H2O_FLUX_450CM unavailable 227(0630-1200), 227(0230-0530), 228(0370-1200), 228(0100)-22 $9(1830), 229(0100)-233(1300)$

- DOYs 230, 231, and 232 CO2_STORAGE_FLUX_450CM, CO2_CONC_450CM, HEAT_STORAGE_TOTAL, HEAT_STORAGE_LATENT_AIR, VAPOUR_PRESSÜRE_400CM, W_MEAN_450CM, W_STDEV_450CM, RELATIVE_HUMIDITY, AND AIR_PRESSURE are unavailable. 
- DOY 236(1830-2100) CO2_EDDY_FLUX_450CM, CO2_STORAGE_FLUX_450CM, and CO2 TOTAL_FLUX 450CM is unavailable.

- $\quad$ SPECIFIC_HUMIDITY and SPECIFIC_HUMIDITY_STDEV are missing DOY 228(0100)-229(1800), 230(0630)-233(1300), 233(0530)-234(1200), 237(0900-1330), 237(2000)-238(1500), 238(0530)-239(1300)

- WIND_DIR_600CM, and WIND_DIR_STDEV_600CM are missing DOY 223(1800-2330), $228(2000-2300), 233(1900-2130), 234(0130)-242(1830)$.

Data Period: August 29 - September $11 \backslash 96$ (DOY 242-255)

- DOY 244(1130-2000) LATENT_HEAT_FLUX_450CM, and H2O_FLUX_450CM, are unavailable.

- $\quad$ DOY 249(1830)-255(1600) LATENT_HEAT_FLUX_450CM, SENSIBLE_HEAT_FLUX_450CM, and H2O_FLUX_450CM are unavailable.

- $\quad$ DOY 249(1830)-258(1800) CO2_EDDY_FLUX_450CM, CO2_STORAGE_FLUX_450CM, CO2_TOTAL_FLUX_450CM, and CO2_CONC_450CM are unavailable.

- DOY 248(1600)-248(0230) WIND_DIR_600CM, and WIND_DIR_STDEV_600CM are unavailable

- $\quad$ SPECIFIC_HUMIDITY_450CM, and SPECIFIC_HUMIDITY_STDEV_450CM are unavailable DOY 244(1130-2000), 249(0430-0800), 250(0930-0100), 251(0500)-252(1330), 253(1200-1500, 1600-2030), 253(0100)-255(1530).

- Due to power supply problems, SOLAR_RAD_IN_1047CM, SOLAR_RAD_OUT_1023CM, NET_SOLAR_RAD_1023CM, LONGWAVE_IN_1033CM, LONGWAVE_OUT_1033CM, TOTAL_RAD_IN_1041CM, TOTAL_RAD_OUT_1028CM, R_NET_1035CM, PPFD_IN_1049 $\overline{C M}, \bar{M}$ PPD_OUT_1031CM, SURFACE_ALBEDO unavailable DOY 250(0230)-258(1800), and SOIL_HEAT_FLUX_HUMMOCK_10CM, SOIL_HEAT_FLUX_HOLLOW_10CM, all soil hummock and hollow temperatures, DRY_BULB_TEMP_250CM, DRY_BULB_TEMP_600CM, WIND_SPEED_250CM, WIND_SPEED_400CM, WIND_SPEED_600CM, WIND_DIR_600CM, WIND_DIR_STDEV_600CM, and RAINFALL_100CM are unavailable DOY 250(0230)-259(0630), and HEAT_STORAGE_TOTAL, HEAT_STORAGE_LATENT_AIR, and HEAT_STORAGE_SENSIBLE_AIR are unavailable DOYs 250 to 258.

\section{Data Period: September 12 - September $25 \backslash 96$ (DOY 256-269)}

- DOY 261(1830), and 264(1930-2000) CO2_TOTAL_FLUX_450CM and CO2_CONC_450CM are linearly interpolated.

- $\quad$ DOY 267(1730) CO2_CONC_450CM is linearly interpolated.

Data Period: September 26 - October $9 \backslash 96$ (DOY 270-282)

- CO2_TOTAL_FLUX_450CM and CO2_CONC_450CM are linearly interpolated on the following days: 270(2000), 273(1930), 276(1730), 278(1730-1800), 279(1730), 281(0800-0900), and 282(0630-0700).

- $\quad$ LATENT_HEAT_FLUX_450CM,H2O_FLUX_450CM, SPECIFIC_HUMIDITY_450CM, and SPECIFIC_HUMIDITY_STDEV_450CM are unavailable at the following times: DOY270(0130)-271(0800), 271(0930-1330), 271(2300-0400), 272(1600-1900), 281(2230)-282(1830).

Data Period: October 10 - October $23 \backslash 96$ (DOY 283-297)

- CO2_EDDY_FLUX_450CM, and CO2_CONC_450CM are linearly interpolated DOY 283(2130), 289(1730-1800), 291(1730), 292(2000), 293(0500-0530), 295(1630), 297(1830).

- CO2_EDDY_FLUX_450CM is linearly interpolated DOY294(0730, 1230, 1530-1830).

- CO2_EDDY_FLUX_450CM, and CO2_TOTAL_FLUX_450CM are missing DOY 286(2130-2200), 287(0700-1800, 0130-0530), 28990700-1500), 289(1630-1730), 
296(0900-1100).

- DOY 286(0900-1530) CO2_EDDY_FLUX_450CM, CO2_STORAGE_FLUX_450CM, and CO2_TOTAL_FLUX_450CM is unavailable.

- $\quad$ LATENT_HEAT_FLUX_450CM, H2O_FLUX_450CM, SPECIFIC_HUMIDITY_450CM, and SPECIFIC_HUMIDITY_STDEV_450CM are unavailable DOY 284(1600)-285(1100), 286(0900-1930), 286(0130)-287(1800), 287(0130)-288(0100), 288(0250)-289(2130), 293(0330-1630), 296(2100-2330).

- $\quad$ SENSIBLE_HEAT_FLUX_450CM is unavailable DOY 286(0900-1530), 287(0700-1800), 287(0130-0530), 289(0700-1500).

- WIND_DIR_600CM, and WIND_DIR_STDEV_450CM are unavailable DOY 290(0700-1130), 291(0030)-292(1630), 293(2200)-294(1730), 294(0200-0500), 295(0630-1700), 296(2330)-297(1500).

- W_MEAN_450CM, and W_MEAN_STDEV_450CM are missing DOy 287(0700-1800), and 287 $(0130-0430)$.

- $\quad$ RAINFALL_100CM is missing DOY 283(2230)-310(0600).

Data Period: October 24 - November $5 \backslash 96$ (DOY 298-310)

- DOY 300(2000), 303(1700) CO2_TOTAL_FLUX_450CM is linearly interpolated.

- $\quad$ RAINFALL_100CM is missing DOY 283(2230)-310(0600).

- $\quad$ LATENT_HEAT_FLUX_450CM, H2O_FLUX_450CM, are unavailable DOY 298(0230)-301(1900), 301(0200)-303(1400),303(1830-0300), 306(1730)-307(1600), 308(2330)-309(1800), and 309(0330)-310(0600).

- $\quad$ SENSIBLE_HEAT_FLUX_450CM is unavailable DOY 303(2000-0300), 306(1730)-307(1600), 308(2330)-309(1800).

- CO2_EDDY_FLUX_450CM and CO2_TOTAL_FLUX_450CM are missing DOY $302(1730-1800,2230-2300), 303(2000-0300), 306(1730)-307(1600), 307(0330-0430)$, and 308(2330)-309(1800).

- CO2_EDDY_FLUX_450CM,CO2_STORAGE_FLUX_450CM, and CO2_TOTAL_FLUX_450CM are missing DOY 305(1830-1930).

- $\quad$ SPECIFIC_HUMIDITY_450CM and SPECIFIC_HUMIDITY_STDEV_450CM are unavailable DOY 298(0230)-299(1900), 299(2100)-301(1900), 301(0200)-303(1430), 306(0330)-307(0730), 309(0830-1530), 309(0330)-310(0600).

- WIND_SPEED_250CM, and WIND_SPEED_600CM are unavailable DOY 301(0800-1630).

- WIND_DIR_600CM and WIND_DIR_STDEV_600CM are unavailable DOY 301(0830-1500), 302(0930-1530), 302(0230)-303(1830), 306(1700)-308(1100), 309(0730-1930), 310(1100-0600).

- W_MEAN_450CM, and W_MEAN_STDEV_450CM are unavailable DOY 303(2300-0300), 306(1730)-307(1330), 308(2330)-309(1800)

- All variables are missing DOY 310(1730-0600) due to the shut-down of power.

\section{Data Description}

\subsection{Spatial Characteristics}

\subsubsection{Spatial Coverage}

All data were collected at the BOREAS NSA fen site. North American Datum of 1983 (NAD83) coordinates for the site are latitude $55.91481^{\circ} \mathrm{N}$, longitude $98.42072{ }^{\circ} \mathrm{W}$, and elevation of $211.33 \mathrm{~m}$.

The fen site is located along Hwy. 391 west of Thompson, Manitoba. The fen site is located approximately $9 \mathrm{~km}$ to the west of the YJP site. The fen is located in a natural depression, and the fetch is limited to the east of the tower, where the forested shore is located $150 \mathrm{~m}$ from the tower. Cold-air drainage at night could be a factor at this site.

Most of the micrometeorological data were collected on the flux towers at the fen. The soil heat flux, biomass temperatures, and rainfall data were collected in the immediate vicinity of the flux 
towers. All of the micrometeorological data not collected on the towers were measured more than $30 \mathrm{~m}$ away from the towers. Global Positioning System (GPS) location coordinates are available for all sample locations on each site.

\subsubsection{Spatial Coverage Map}

Not applicable.

\subsubsection{Spatial Resolution}

The data collected from towers are usually thought of as point data. However, they actually represent an integrated response to the surface/atmosphere interaction, especially in terms of the eddy flux data, which are considered to represent an integrated upwind surface source region (Leclerc and Thurtell, 1990; Schmid and Oke, 1990). In general, at the YJP the fluxes apply to the surface between 20 to 400 meters upwind. At the fen, where fetch in certain wind directions is limited, data uncertainties may occur (see Section 10.1).

\subsubsection{Projection}

Not applicable.

\subsubsection{Grid Description}

Not applicable.

\subsection{Temporal Characteristics}

\subsubsection{Temporal Coverage}

The start and stop times for the experiments were as follows:

15-AUG-1993 to 31-AUG-1993

10-APR-1994 to 19-SEP-1994

15-APR-1995 to 10-JUN-1995

25-APR-1996 to 10-NOV-1996

\subsubsection{Temporal Coverage Map}

Not applicable.

\subsubsection{Temporal Resolution}

With one exception, the data values submitted to BORIS were integrations of the conditions for the 30-minute reporting periods.

Meteorological data were output at 15- and 30-minute intervals depending upon the variable. The 15-minute data included only absolute wet- and dry-bulb air temperatures and soil temperatures, which were used for heat storage calculations (described below). All signals, except temperature differences, were averaged over 30-minute periods. Only the 30-minute data were reported to BORIS. Eddy covariance data were output every 30 minutes.

\subsection{Data Characteristics}




\subsubsection{Parameter/Variable}

The parameters contained in the data files on the CD-ROM are:

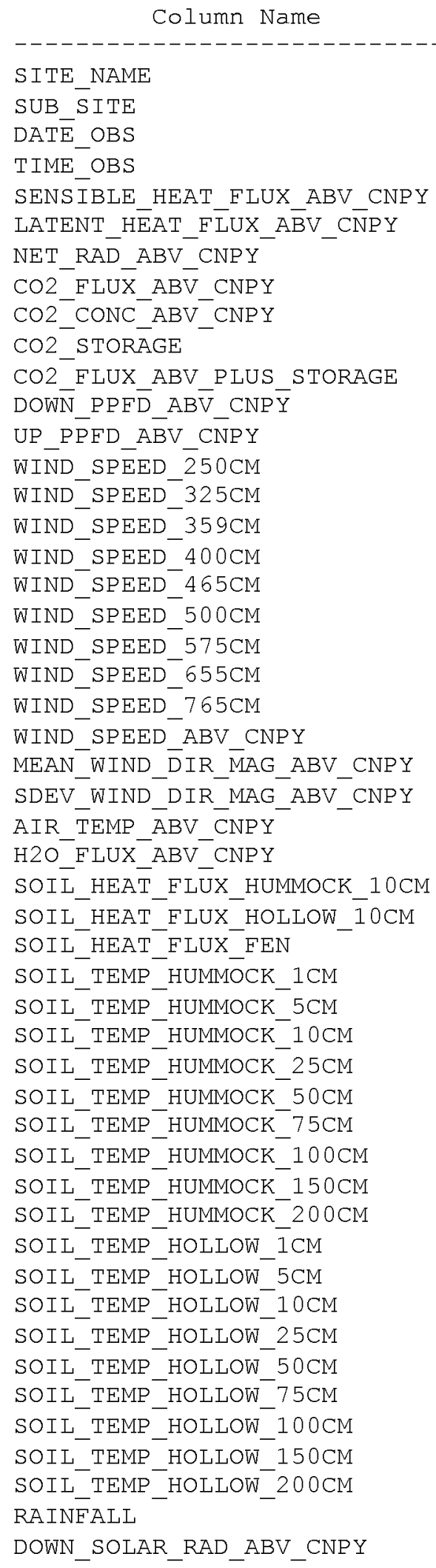


UP SOLAR RAD ABV CNPY

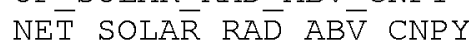

UP TOTAL_RAD_ABV CNPY

AIR TEMP $250 \overline{\mathrm{CM}}$

AIR_TEMP_257CM

AIR_TEMP_325CM

AIR_TEMP_359CM

AIR_TEMP_400CM

AIR TEMP $465 \mathrm{CM}$

AIR TEMP $500 \mathrm{CM}$

AIR TEMP $575 \mathrm{CM}$

AIR TEMP $600 \mathrm{CM}$

AIR TEMP $655 \mathrm{CM}$

AIR_TEMP_ $765 \mathrm{CM}$

WET_BULB_TEMP_250CM

WET_BULB_TEMP_257CM

WET ${ }^{-}$BULB ${ }^{-}$TEMP $-325 \mathrm{CM}$

WET BULB TEMP $359 \mathrm{CM}$

WET BULB TEMP $400 \mathrm{CM}$

WET_BULB_TEMP_ $465 \mathrm{CM}$

WET_BULB_TEMP_500CM

WET_BULB_TEMP_ $575 \mathrm{CM}$

WET_BULB_TEMP_600CM

WET_BULB_TEMP_ $655 \mathrm{cM}$

WET BULB TEMP $765 \mathrm{CM}$

WET ${ }^{-}$BULB ${ }^{-}$TEMP ${ }^{-}$ABV CNPY

VAPOR PRESS $2 \overline{5} 0 \mathrm{CM}$

VAPOR PRESS $257 \mathrm{CM}$

VAPOR_PRESS_325CM

VAPOR_PRESS_359CM

VAPOR PRESS $400 \mathrm{CM}$

VAPOR PRESS $465 \mathrm{CM}$

VAPOR PRESS $500 \mathrm{CM}$

VAPOR PRESS $575 \mathrm{CM}$

VAPOR PRESS $-600 \mathrm{CM}$

VAPOR_PRESS_655CM

VAPOR_PRESS $765 \mathrm{CM}$

VAPOR_PRESS_ABV_CNPY

SURF_PRESS

WATER TABLE HGT

DOWN LONGWAVEE RAD ABV CNPY

UP LONGWAVE RAD ABBV CNNPY

DOWNN TOTAL $\overline{R A D} \overline{A B V} \overline{C N P Y}$

CORR_NET_RAD_ABV_CNPY

ALBEDO

TOTAL_HEAT STORAGE

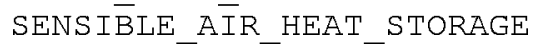

LATENT_AIR_HEAT_STORAGE

MEAN SPECIFIC HUM ABV CNPY

$\mathrm{SDEV}^{-} \mathrm{SPECIFIC}{ }^{-} \mathrm{HUM}^{-} \mathrm{ABV}^{-} \mathrm{CNPY}$

MEAN_W_WIND_SPEED_ABV_CNPY

SDEV $W$ WIND SPEED ABV CNPY

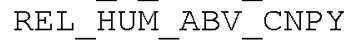

CRTFCN CODE

REVISION_DATE

Page 39 


\subsubsection{Variable Description/Definition}

The descriptions of the parameters contained in the data files on the CD-ROM are:

\begin{tabular}{|c|c|}
\hline Column Name & Description \\
\hline SITE_NAME & $\begin{array}{l}\text { The identifier assigned to the site by BOREAS, } \\
\text { in the format SSS-TTT-CCCCC, where SSS identifies } \\
\text { the portion of the study area: NSA, SSA, REG, } \\
\text { TRN, and TTT identifies the cover type for the } \\
\text { site, } 999 \text { if unknown, and CCCCC is the identifier } \\
\text { for site, exactly what it means will vary with } \\
\text { site type. }\end{array}$ \\
\hline SUB_SITE & $\begin{array}{l}\text { The identifier assigned to the sub-site by } \\
\text { BOREAS, in the format GGGGG-IIIII, where GGGGG is } \\
\text { the group associated with the sub-site } \\
\text { instrument, e.g. HYDO6 or STAFF, and IIIII is the } \\
\text { identifier for sub-site, often this will refer to } \\
\text { an instrument. }\end{array}$ \\
\hline DATE_OBS & The date on which the data were collected. \\
\hline TIME_OBS & $\begin{array}{l}\text { The Greenwich Mean Time (GMT) of the start of the } \\
\text { data collection. }\end{array}$ \\
\hline SENSIBLE_HEAT_FLUX_ABV_CNPY & $\begin{array}{l}\text { The sensible heat flux measured above the canopy. } \\
\text { Instrument heights: in } 1993 \text { at } 6 \mathrm{~m}, 1994 \text { and } 1996 \\
\text { at } 4.5 \mathrm{~m} \text {. }\end{array}$ \\
\hline LATENT_HEAT_FLUX_ABV_CNPY & $\begin{array}{l}\text { The latent heat flux measured above the canopy. } \\
\text { Instrument heights: in } 1993 \text { at } 6 \mathrm{~m}, 1994 \text { and } 1996 \\
\text { at } 4.5 \mathrm{~m} \text {. }\end{array}$ \\
\hline NET_RAD_ABV_CNPY & $\begin{array}{l}\text { The net radiation measured above the canopy, } \\
\text { in 1993, } 1994 \text {, and } 1996 \text { at } 10.35 \mathrm{~m} \text { height. }\end{array}$ \\
\hline CO2_FLUX_ABV_CNPY & $\begin{array}{l}\text { The carbon dioxide flux measured above the canopy } \\
\text { Instrument heights: in } 1994 \text { and } 1996 \text { at } 4.5 \mathrm{~m}\end{array}$ \\
\hline $\mathrm{CO} 2$ CONC_ABV_CNPY & $\begin{array}{l}\text { The carbon dioxide concentration measured above } \\
\text { the canopy. Instrument heights: in } 1994 \text { and } 1996 \\
\text { at } 4.5 \mathrm{~m} \text {. }\end{array}$ \\
\hline CO2_STORAGE & $\begin{array}{l}\text { The storage term of carbon dioxide under the eddy } \\
\text { flux system. }\end{array}$ \\
\hline CO2_FLUX_ABV_PLUS_STORAGE & $\begin{array}{l}\text { The sum of the above canopy carbon dioxide flux } \\
\text { and the under flux instrument storage term. }\end{array}$ \\
\hline DOWN_PPED_ABV_CNPY & $\begin{array}{l}\text { The downward (incoming) photosynthetic photon } \\
\text { flux density measured above the canopy. In 1993, } \\
1994 \text {, and } 1996 \text { at } 10.49 \mathrm{~m} \text { height }\end{array}$ \\
\hline UP_PPFD_ABV_CNPY & $\begin{array}{l}\text { The reflected photosynthetic photon flux density } \\
\text { measured above the canopy. In 1993, 1994, and } \\
1996 \text { at } 10.31 \mathrm{~m} \text { height }\end{array}$ \\
\hline WIND_SPEED_250CM & The wind speed measured $2.5 \mathrm{~m}$ above the ground. \\
\hline WIND_SPEED_325CM & The wind speed measured $3.25 \mathrm{~m}$ above the ground. \\
\hline WIND_SPEED_359CM & The wind speed measured $3.59 \mathrm{~m}$ above the ground. \\
\hline WIND_SPEED_400CM & The wind speed measured $4 \mathrm{~m}$ above the ground. \\
\hline WIND_SPEED_465CM & The wind speed measured $4.65 \mathrm{~m}$ above the ground. \\
\hline WIND_SPEED_500CM & The wind speed measured $5 \mathrm{~m}$ above the ground. \\
\hline WIND_SPEED_575CM & The wind speed measured $5.75 \mathrm{~m}$ above the ground. \\
\hline WIND_SPEED_65 $65 \mathrm{CM}$ & The wind speed measured $6.55 \mathrm{~m}$ above the ground. \\
\hline WIND_SPEED_765CM & The wind speed measured $7.65 \mathrm{~m}$ above the ground. \\
\hline WIND_SPEED_ABV_CNPY & The wind speed measured above the canopy, in \\
\hline
\end{tabular}

Page 40 


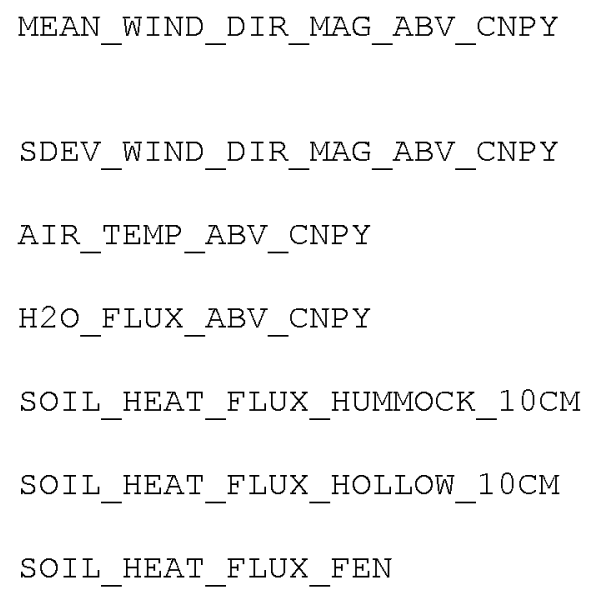

1994 and 1996 at $6 \mathrm{~m}$ height.

The average wind direction over 30 minutes measured above the canopy, in 1993 at $7.65 \mathrm{~m}$, in 1994 and 1996 at $6 \mathrm{~m}$ height

The standard deviation of the wind direction over 30 minutes measured above the canopy.

The air temperature measured above the canopy, in 1994 at $7.5 \mathrm{~m}$ and 1996 at $6 \mathrm{~m}$ height.

The water vapor flux measured above the canopy, in 1993 at $6 \mathrm{~m}$, in 1994 and 1996 at $4.5 \mathrm{~m}$ height. The soil heat flux in a hummock measured at 10 $\mathrm{cm}$ depth.

The soil heat flux in a hollow measured at $10 \mathrm{~cm}$ depth.

The soil heat flux for the whole fen surface, calculated as the product of the measured flux at the hollow and a factor (3.04 in 1994). Soil temperature in a hummock at $1 \mathrm{~cm}$ depth. Soil temperature in a hummock at $5 \mathrm{~cm}$ depth. Soil temperature in a hummock at $10 \mathrm{~cm}$ depth. Soil temperature in a hummock at $25 \mathrm{~cm}$ depth. Soil temperature in a hummock at $50 \mathrm{~cm}$ depth. Soil temperature in a hummock at $75 \mathrm{~cm}$ depth. Soil temperature in a hummock at $1 \mathrm{~m}$ depth. Soil temperature in a hummock at $1.5 \mathrm{~m}$ depth. Soil temperature in a hummock at $2 \mathrm{~m}$ depth. Soil temperature in a hollow at $1 \mathrm{~cm}$ depth. Soil temperature in a hollow at $5 \mathrm{~cm}$ depth. Soil temperature in a hollow at $10 \mathrm{~cm}$ depth. soil temperature in a hollow at $25 \mathrm{~cm}$ depth. Soil temperature in a hollow at $50 \mathrm{~cm}$ depth. Soil temperature in a hollow at $75 \mathrm{~cm}$ depth. Soil temperature in a hollow at $1 \mathrm{~m}$ depth. Soil temperature in a hollow at $1.5 \mathrm{~m}$ depth. Soil temperature in a hollow at $2 \mathrm{~m}$ depth. The amount of rainfall measured above the canopy in the 30 minute period following the time of observation, measured at $1 \mathrm{~m}$ height all years. The downward (incoming) solar radiation measured above the canopy, measured at $10.47 \mathrm{~m}$ height in all years.

The reflected (outgoing) solar radiation measured above the canopy, measured at $10.23 \mathrm{~m}$ height in all years.

The net solar radiation measured above the canopy, measured at $10.35 \mathrm{~m}$ height in all years. The total upward (outgoing) radiation measured above the canopy, in 1993 at $10.28 \mathrm{~m}$, in 1994 at $10.23 \mathrm{~m}$, and in 1996 at $10.28 \mathrm{~m}$ height.

The air temperature measured at 2.5 meters above the ground.

The air temperature measured at 2.57 meters above the ground.

The air temperature measured at 3.25 meters above 


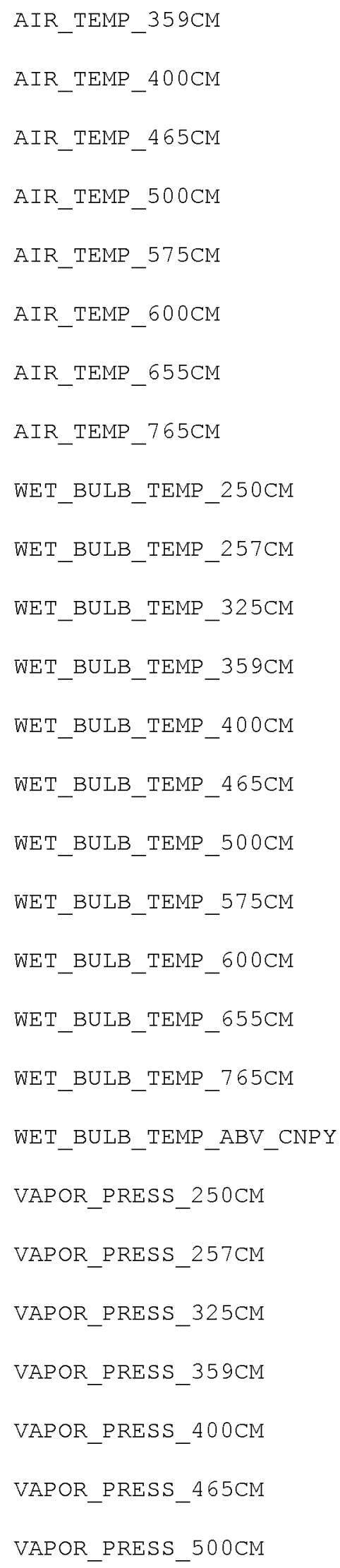

the ground.

The air temperature measured at 3.59 meters above the ground.

The air temperature measured at 4 meters above the ground.

The air temperature measured at 4.65 meters above the ground.

The air temperature measured at 5 meters above the ground.

The air temperature measured at 5.75 meters above the ground.

The air temperature measured at 6 meters above the ground.

The air temperature measured at 6.55 meters above the ground.

The air temperature measured at 7.65 meters above the ground.

The wet bulb temperature measured at 2.5 meters above the ground.

The wet bulb temperature measured at 2.57 meters above the ground.

The wet bulb temperature measured at 3.25 meters above the ground.

The wet bulb temperature measured at 3.59 meters above the ground.

The wet bulb temperature measured at 4 meters above the ground.

The wet bulb temperature measured at 4.65 meters above the ground.

The wet bulb temperature measured at 5 meters above the ground.

The wet bulb temperature measured at 5.75 meters above the ground.

The wet bulb temperature measured at 6 meters above the ground.

The wet bulb temperature measured at 6.55 meters above the ground.

The wet bulb temperature measured at 7.65 meters above the ground.

The wet bulb temperature measured above the canopy, in 1994 at $7.5 \mathrm{~m}$ height.

The vapor pressure measured at 2.5 meters above the ground.

The vapor pressure measured at 2.57 meters above the ground.

The vapor pressure measured at 3.25 meters above the ground.

The vapor pressure measured at 3.59 meters above the ground.

The vapor pressure measured at 4 meters above the ground.

The vapor pressure measured at 4.65 meters above the ground.

The vapor pressure measured at 5 meters above 


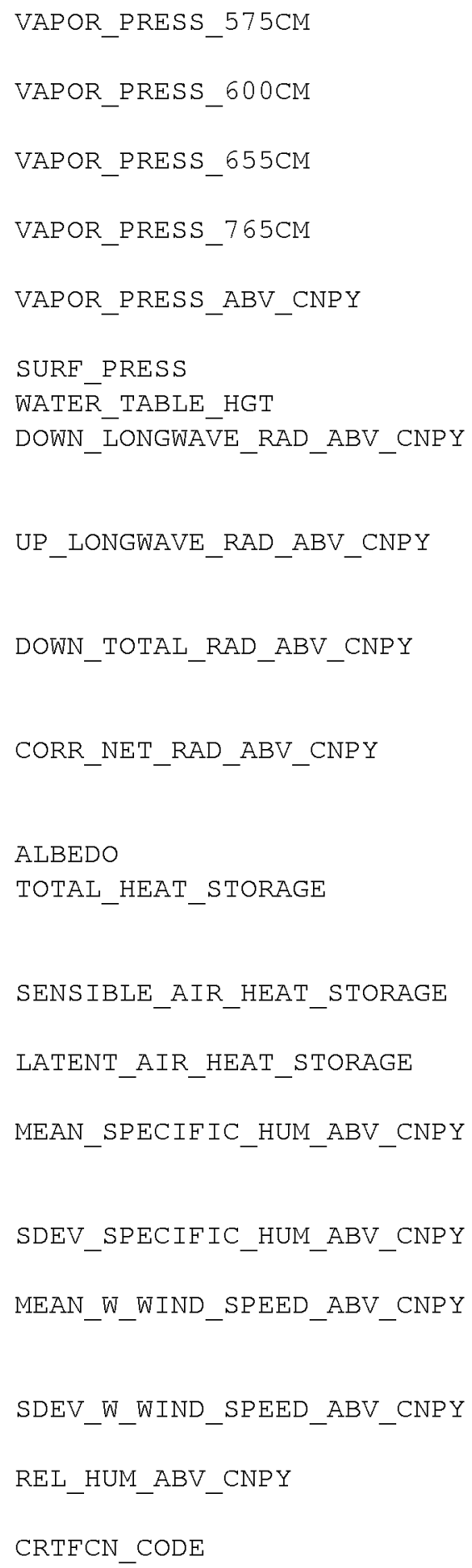

the ground.

The vapor pressure measured at 5.75 meters above the ground.

The vapor pressure measured at 6 meters above the ground.

The vapor pressure measured at 6.55 meters above the ground.

The vapor pressure measured at 7.65 meters above the ground.

The vapor pressure measured above the canopy, in 1994 at $7.5 \mathrm{~m}$ and in 1996 at $4.5 \mathrm{~m}$ height.

The atmospheric pressure measured at the station Water table height above a reference surface.

The downward (incoming) longwave radiation measured above the canopy, in all years measured at $10.33 \mathrm{~m}$ height

The upward (outgoing) longwave radiation measured above the canopy, in all years measured at 10.33 m height

The total downward (incoming) radiation measured above the canopy, in all years measured at 10.41 m height

The corrected net radiation measured above the canopy, using equations developed by Hodges and Smith (1997).

Surface solar albedo.

Total of minor heat storage terms including soil heat flux and sensible and latent heat storage in the air.

Sensible heat storage in air column between the surface and net pyrradiometer.

Latent heat storage in air column between the surface and net pyrradiometer.

The 30 minute mean specific humidity measured above the canopy, in 1994 and 1996 at $4.5 \mathrm{~m}$ height.

The 30 minute standard deviation of specific humidity measured above the canopy.

The 30 minute mean of the vertical wind speed measured above the canopy, in 1994 and 1996 at $4.5 \mathrm{~m}$ height.

The 30 minute standard deviation of the vertical wind speed measured above the canopy.

The relative humidity measured above the canopy, in 1996 at $4 \mathrm{~m}$ height.

The BOREAS certification level of the data.

Examples are CPI (Checked by PI), CGR (Certified by Group), PRE (Preliminary), and CPI-??? (CPI but questionable).

The most recent date when the information in the referenced data base table record was revised

\section{Page 43}




\subsubsection{Unit of Measurement}

The measurement units for the parameters contained in the data files on the CD-ROM are:

\begin{tabular}{|c|c|}
\hline Column Name & Units \\
\hline SITE NAME & [none ] \\
\hline SUB_SITE & [none] \\
\hline DATE_OBS & {$[\mathrm{DD}-\mathrm{MON}-\mathrm{YY}]$} \\
\hline TIME_OBS & {$[$ HHMM GMT] } \\
\hline SENSIBLLE HEAT FLUX ABV CNPY & [Watts] [meter $\left.{ }^{\wedge}-2\right]$ \\
\hline 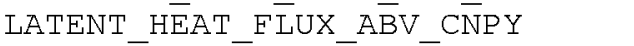 & [Watts ] [meter^-2] \\
\hline NET_RAD_ABV_CNPY ${ }^{-}$ & {$[$Watts $]\left[\right.$meter $\left.{ }^{\wedge}-2\right]$} \\
\hline CO2_ELUX ABV CNPY & [micromoles] [meter $\left.{ }^{\wedge}-2\right]\left[\right.$ second $\left.d^{\wedge}-1\right]$ \\
\hline $\mathrm{CO}_{2}^{-} \mathrm{CONC}{ }_{-}^{-} \mathrm{ABV} \_\mathrm{CNPY}$ & [parts per million] \\
\hline $\mathrm{CO}^{-}{ }^{-} \mathrm{STORA} G E{ }^{-}$ & [micromoles] [meter $\left.{ }^{\wedge}-2\right]\left[\right.$ second $\left.d^{\wedge}-1\right]$ \\
\hline CO2_FLUX_ABV_PLUS_STORAGE & [micromoles] [meter^-2] [second^-1] \\
\hline DOW' $\bar{N} \_P P E \bar{D} \_A B \bar{V} \_C N P \bar{Y}$ & [micromoles $]\left[\right.$ meter $\left.r^{\wedge}-2\right]\left[\operatorname{second}^{\wedge}-1\right]$ \\
\hline $\mathrm{UP} \_\mathrm{PPFD} \overline{\mathrm{ABV}} \_\mathrm{CNPY}$ & [micromoles] [meter^-2] [ second^-1] \\
\hline WIND_SPEED_250CM & [meters] [second^-1] \\
\hline WIND_SPEED_325CM & [meters ] [second $\left.{ }^{\wedge}-1\right]$ \\
\hline WIND_SPEED_359CM & [meters] [second^-1] \\
\hline WIND SPEED $400 \mathrm{CM}$ & [meters] [second^-1] \\
\hline WIND_SPEED_465CM & {$[$ meters $]\left[\operatorname{second} d^{\wedge}-1\right]$} \\
\hline WIND_SPEED_500CM & [meters] [ second^-1] \\
\hline WIND_SPEED_575CM & [meters] [second^-1] \\
\hline WIND_SPEED_65 $65 \mathrm{CM}$ & [meters] [second^-1] \\
\hline WIND_SPEED_765CM & [meters] [ second^-1] \\
\hline WIND_SPEED_ABV_CNPY & {$[$ meters $]\left[\right.$ second $\left.{ }^{\wedge}-1\right]$} \\
\hline MEAN_WIND_DIR_MAG_ABV_CNPY & [degrees from magnetic north] \\
\hline SDEV_WIND_DIR_MAG_ABV_CNPY & [degrees from magnetic north] \\
\hline AIR_TEMP_ĀBAV_CNPY & [degrees Celsius] \\
\hline H2O_ELUX_ABV_CNPY & [millimoles] [meter^-2] [second^-1] \\
\hline 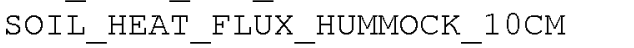 & {$[$ Watts $]\left[\right.$ meter $\left.{ }^{\wedge}-2\right]$} \\
\hline SOIL_HEAT_FLUX_HOLLOW_ $10 \mathrm{CM}$ & [Watts] [meter^-2] \\
\hline SOIL_HEAT_FLUX_FEN & [Watts] [meter^-2] \\
\hline SOIL_TEMP_HUMMOCK_1CM & [degrees Celsius] \\
\hline SOIL_TEMP_HUMMOCK_5CM & [degrees Celsius] \\
\hline SOIL_TEMP_HUMMOCK_- $10 \mathrm{CM}$ & [degrees Celsius] \\
\hline SOIL_TEMP_HUMMOCK_25CM & [degrees Celsius] \\
\hline SOIL_TEMP_HUMMOCK_50CM & [degrees Celsius] \\
\hline SOIL_TEMP_HUMMOCK ${ }^{-}$- $75 \mathrm{CM}$ & [degrees Celsius] \\
\hline SOIL_TEMP_HUMMOCK_100CM & [degrees Celsius] \\
\hline SOIL_TEMP_HUMMOCK_150CM & [degrees Celsius] \\
\hline SOIL_TEMP_HUMMOCK_200CM & [degrees Celsius] \\
\hline SOIL_TEMP_HOLLOW_ICM & [degrees Celsius] \\
\hline SOIL_TEMP_HOLLOW_5CM & [degrees Celsius] \\
\hline SOIL_TEMP_HOLLOW_10 $10 \mathrm{CM}$ & [degrees Celsius] \\
\hline SOIL_TEMP_HOLLOW_25CM & [degrees Celsius] \\
\hline SOIL_TEMP_HOLLOW_50CM & [degrees Celsius] \\
\hline SOIL_TEMP_HOLLOW ${ }^{-} 75 \mathrm{CM}$ & [degrees Celsius] \\
\hline SOIL_TEMP_HOLLOW_100CM & [degrees Celsius] \\
\hline SOIL_TEMP_HOLLOW_150CM & [degrees Celsius] \\
\hline SOIL_TEMP_HOLLOW_200CM & [degrees Celsius] \\
\hline RAINFALL & [millimeters] \\
\hline DOWN_SOLAR_RAD_ABV_CNPY & [Watts] [meter^-2] \\
\hline
\end{tabular}


UP_SOLAR_RAD_ABV_CNPY

NET SOLA $\bar{T}$ RAD ABV CNPY

UP_TOTAL_RAD_ABV_CNPY

AIR TEMP $250 \overline{\mathrm{CM}}$

AIR_TEMP_ $257 \mathrm{CM}$

AIR_TEMP_325CM

AIR TEMP $359 \mathrm{CM}$

AIR_TEMP_400CM

AIR TEMP $465 \mathrm{CM}$

AIR TEMP $500 \mathrm{CM}$

AIR TEMP $575 \mathrm{CM}$

AIR TEMP $600 \mathrm{CM}$

AIR TEMP $655 \mathrm{CM}$

AIR_TEMP_765CM

WET_BULB_TEMP_250CM

WET BULB TEMP $257 \mathrm{CM}$

WET_BULB TEMP $325 \mathrm{CM}$

WET BULB TEMP $359 \mathrm{cM}$

WET BULB TEMP $400 \mathrm{CM}$

WET_BULB_TEMP_ $465 \mathrm{CM}$

WET_BULB TEMP $500 \mathrm{CM}$

WET BULB TEMP $575 \mathrm{CM}$

WET BULB TEMP $600 \mathrm{CM}$

WET_BULB_TEMP_ $655 \mathrm{cM}$

WET BULB TEMP $765 \mathrm{CM}$

WET BULB TEMP ABV CNPY

VAPOR PRESS $2 \overline{5} 0 \mathrm{CM}$

VAPOR PRESS $257 \mathrm{CM}$

VAPOR_PRESS_ $325 \mathrm{CM}$

VAPOR_PRESS_359cM

VAPOR PRESS $400 \mathrm{CM}$

VAPOR PRESS ${ }^{-465 \mathrm{CM}}$

VAPOR PRESS $500 \mathrm{CM}$

VAPOR PRESS $575 \mathrm{CM}$

VAPOR_PRESS $600 \mathrm{CM}$

VAPOR_PRESS_655CM

VAPOR_PRESS_ $765 \mathrm{CM}$

VAPOR_PRESS_ABV_CNPY

SURF_- PRESS

WATER TABLE HGT

DOWN LONGWAVEE RAD ABV CNPY

UP_LONGWAVE_RAD_ABBV_CNPY

DOWN TOTAL RAD A ABV $\bar{C} N P Y$

CORR_NET_RĀD_A $\bar{B} V$ CN $\bar{N} P Y$

ALBEDO

TOTAL_HEAT STORAGE

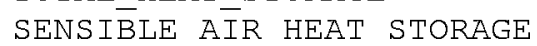

LATENT_AIR_HEAT_STORAGE

MEAN SPECIFIC HUM ABV CNPY

SDEV ${ }^{-} \mathrm{SPECIFIC}{ }^{-} \mathrm{HUM}^{-} \mathrm{ABV}^{-} \mathrm{CNPY}$

MEAN_W_WIND_SPEED_ABV_CNPY

SDEV_W_WIND_SPEED_ABV_CNPY

REL_ĒUM $\bar{M}$ ABV_CNPY

CRTËCN_CODE

REVISION_DATE
[Watts] [meter ${ }^{\wedge}-2$ ]

[Watts ] [meter ${ }^{\wedge}-2$ ]

[Watts ] [meter^-2]

[degrees Celsius]

[degrees Celsius]

[degrees Celsius]

[degrees Celsius]

[degrees Celsius]

[degrees Celsius]

[degrees Celsius]

[degrees Celsius]

[degrees Celsius]

[degrees Celsius]

[degrees Celsius]

[degrees Celsius]

[degrees Celsius]

[degrees Celsius]

[degrees Celsius]

[degrees Celsius]

[degrees Celsius]

[degrees Celsius]

[degrees Celsius]

[degrees Celsius]

[degrees Celsius]

[degrees Celsius]

[degrees Celsius]

[kilopascals]

[kiloPascals]

[kiloPascals]

[kilopascals]

[kilopascals]

[kilopascals]

[kilopascals]

[kiloPascals]

[kilopascals]

[kilopascals]

[kilopascals]

[kilopascals]

[kilopascals]

[millimeters]

[Watts ] [meter ${ }^{\wedge}-2$ ]

[Watts ] [meter ${ }^{\wedge}-2$ ]

[Watts ] [meter ${ }^{\wedge}-2$ ]

[Watts ] [meter ${ }^{\wedge}-2$ ]

[unitless]

[Watts] [meter ${ }^{\wedge}-2$ ]

[Watts ] [meter ${ }^{\wedge}-2$ ]

[Watts] [meter ${ }^{\wedge}-2$ ]

[grams] [kilogram^-1]

[grams] [kilogram^-1]

[meters] [second ${ }^{\wedge}-1$ ]

[meters ] [ second ${ }^{\wedge}-1$ ]

[percent]

[none]

[DD-MON-YY] 


\subsubsection{Data Source}

The sources of the parameter values contained in the data files on the CD-ROM are:

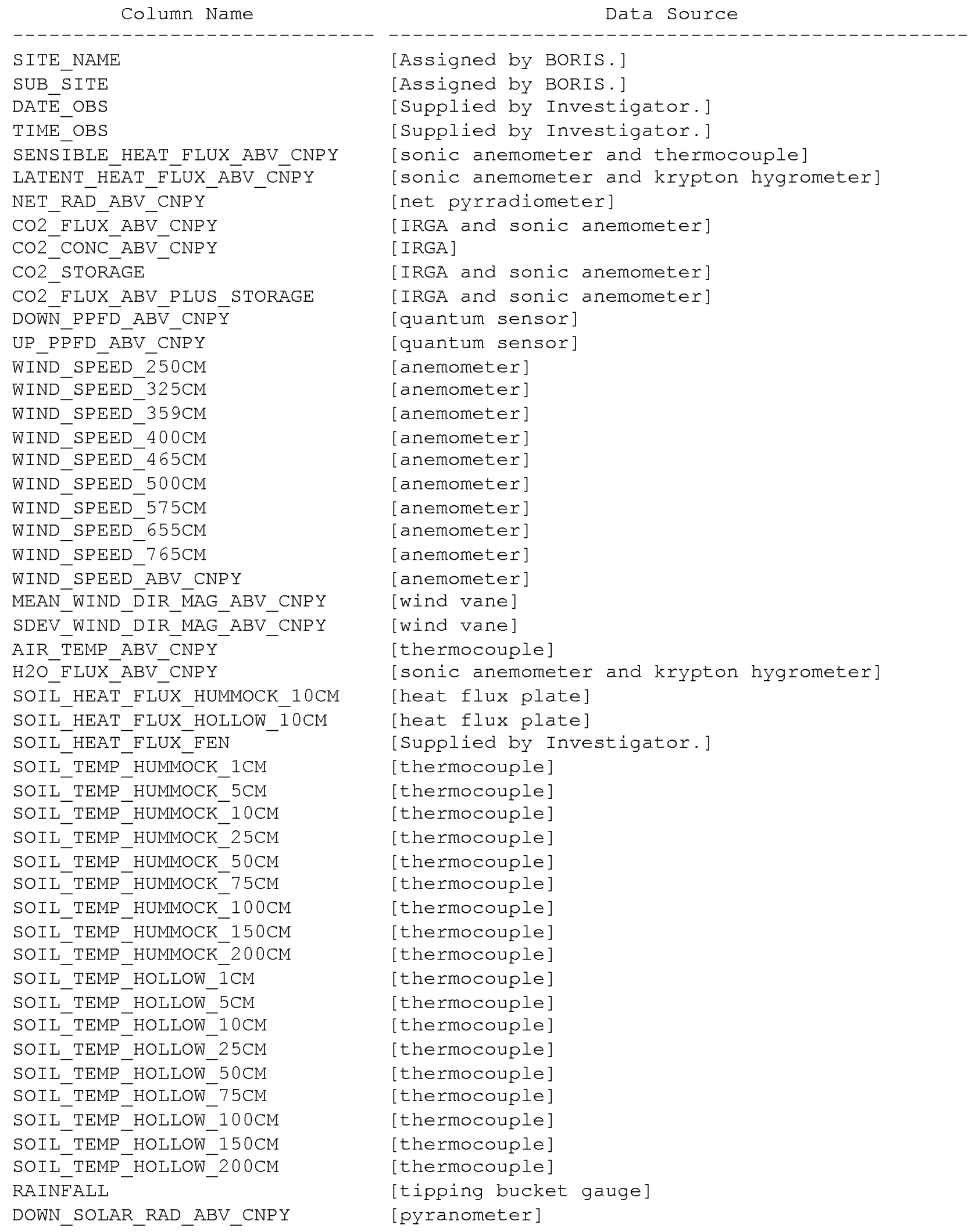


UP_SOLAR_RAD_ABV_CNPY

NET SOLA $\bar{R}$ RAD ABV CNPY

UP_TOTAL_RAD_ABV_CNPY

AIR TEMP $250 \overline{\mathrm{CM}}$

AIR_TEMP_257CM

AIR TEMP $325 \mathrm{CM}$

AIR TEMP $359 \mathrm{CM}$

AIR_TEMP_ $400 \mathrm{CM}$

AIR TEMP $465 \mathrm{CM}$

AIR TEMP $500 \mathrm{CM}$

AIR TEMP $575 \mathrm{CM}$

AIR TEMP $600 \mathrm{CM}$

AIR TEMP $655 \mathrm{CM}$

AIR_TEMP_765CM

WET_BULB_TEMP_250CM

WET BULB TEMP $257 \mathrm{CM}$

WET_BULB ${ }^{-}$TEMP_ $325 \mathrm{CM}$

WET_BULB TEMP_ $359 \mathrm{cM}$

WET BULB TEMP $400 \mathrm{CM}$

WET_BULB_TEMP_ $465 \mathrm{CM}$

WET_BULB TEMP $500 \mathrm{CM}$

WET BULB TEMP $575 \mathrm{CM}$

WET BULB TEMP $600 \mathrm{CM}$

WET_BULB_TEMP_ $655 \mathrm{cM}$

WET BULB TEMP $765 \mathrm{CM}$

WET BULB TEMP ABV CNPY

VAPOR PRESS $2 \overline{5} 0 \mathrm{CM}$

VAPOR PRESS $257 \mathrm{CM}$

VAPOR_PRESS $325 \mathrm{CM}$

VAPOR_PRESS_ $359 \mathrm{CM}$

VAPOR PRESS $400 \mathrm{CM}$

VAPOR_PRESS_465CM

VAPOR PRESS $500 \mathrm{CM}$

VAPOR PRESS $575 \mathrm{CM}$

VAPOR PRESS $-600 \mathrm{CM}$

VAPOR_PRESS_655CM

VAPOR_PRESS_ $765 \mathrm{CM}$

VAPOR_PRESS_ABV_CNPY

SURF_- PRESS

WATER TABLE HGT

DOWN LONGWAVEE RAD ABV CNPY

UP_LONGWAVE_RAD_ABBV_CNPY

DOWN TOTAL RAD A ABV $\bar{C} N P Y$

CORR_NET_RĀD_A $\bar{B} V$ CN $\bar{N} P Y$

ALBEDO

TOTAL_HEAT STORAGE

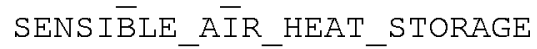

LATENT_AIR_HEAT_STORAGE

MEAN SPECIFIC HUM ABV CNPY

SDEV_SPECIFIC_HUM ${ }^{-}{ }^{-} \mathrm{HBV}^{-} \mathrm{CNPY}$

MEAN_W_WIND_SPEED_ABV_CNPY

SDEV_W_WIND_SPEED_ABV_CNPY

REL_E

CRTFCN_CODE

REVISION_DATE [pyranometer]

[Supplied by Investigator.]

[Supplied by Investigator.]

[thermocouple]

[thermocouple]

[thermocouple]

[thermocouple]

[thermocouple]

[thermocouple]

[thermocouple]

[thermocouple]

[thermocouple]

[thermocouple]

[thermocouple]

[thermocouple]

[thermocouple]

[thermocouple]

[thermocouple]

[thermocouple]

[thermocouple]

[thermocouple]

[thermocouple]

[thermocouple]

[thermocouple]

[thermocouple]

[thermocouple]

[temperature/relative humidity sensor]

[temperature/relative humidity sensor]

[temperature/relative humidity sensor]

[temperature/relative humidity sensor]

[temperature/relative humidity sensor]

[temperature/relative humidity sensor]

[temperature/relative humidity sensor]

[temperature/relative humidity sensor]

[temperature/relative humidity sensor]

[temperature/relative humidity sensor]

[temperature/relative humidity sensor]

[temperature/relative humidity sensor]

[pressure sensor]

[water level recorder]

[pyrgeometer]

[pyrgeometer]

[Supplied by Investigator.]

[Supplied by Investigator.]

[Supplied by Investigator.]

[Supplied by Investigator.]

[Supplied by Investigator.]

[Supplied by Investigator.]

[krypton hygrometer]

[krypton hygrometer]

[sonic anemometer]

[sonic anemometer]

[temperature/relative humidity sensor]

[Assigned by BORIS.]

[Assigned by BORIS.] 
7.3.5 Data Range

The following table gives information about the parameter values found in the flux data files on the CD-ROM.

\begin{tabular}{|c|c|c|c|c|c|c|}
\hline Column Name & $\begin{array}{l}\text { Minimum } \\
\text { Data } \\
\text { Value }\end{array}$ & $\begin{array}{l}\text { Maximum } \\
\text { Data } \\
\text { Value }\end{array}$ & $\begin{array}{l}\text { Missng } \\
\text { Data } \\
\text { Value }\end{array}$ & $\begin{array}{l}\text { Unrel } \\
\text { Data } \\
\text { Value }\end{array}$ & $\begin{array}{l}\text { Below } \\
\text { Detect } \\
\text { Limit }\end{array}$ & $\begin{array}{l}\text { Data } \\
\text { Not } \\
\text { Cllctd }\end{array}$ \\
\hline \multicolumn{7}{|c|}{-- - - - - - - - - - - - - - - - - - - - - - - - - - - - - - - - - - - - - - - - - - - - - - - - - - - - - - - - - - - - - - - - - - - - - - - - - - - - } \\
\hline SITE_NAME & NSA-FEN-FLXTR & NSA-FEN-FLXTR & None & None & None & None \\
\hline SUB_S $I T E$ & $9 \mathrm{TF} 10-\mathrm{FLX} 01$ & $9 \mathrm{TF} 10-\mathrm{FLX} 01$ & None & None & None & None \\
\hline DATE_OBS & $15-A U G-93$ & $06-N O V-96$ & None & None & None & None \\
\hline TIME_OBS & 0 & 2330 & None & None & None & None \\
\hline $\begin{array}{l}\text { SENSI IBLE_HEAT_FLUX } \\
\text { ABV_CNPY }\end{array}$ & -69.58 & 431.78 & -999 & None & None & None \\
\hline $\begin{array}{l}\text { LATENT_HEAT_FLUX_ABV } \\
\text { CNPY }\end{array}$ & -49.08 & 351.22 & -999 & None & None & None \\
\hline NET_RAD_ABV_CNPY & -95.93 & 746.88 & -999 & None & None & None \\
\hline $\mathrm{CO}{ }^{-} \mathrm{FLUX}$ ABV $\mathrm{CNPY}$ & -18.984 & 22.981 & -999 & None & None & Blank \\
\hline $\mathrm{CO} 2$ CONC_ABV_CNPY & 287.4 & 647 & -999 & None & None & Blank \\
\hline $\mathrm{CO} 2^{-} \mathrm{STOR} \overline{\mathrm{A}} \mathrm{GE}$ & -9.46 & 6.5 & -999 & None & None & Blank \\
\hline $\begin{array}{l}\text { CO2_FLUX_ABV_PLUS_- } \\
\text { STORAGE }\end{array}$ & -20.341 & 21.233 & -999 & None & None & Blank \\
\hline DOWN_PPFD_ABV_CNPY & 0 & 2035 & -999 & None & None & None \\
\hline 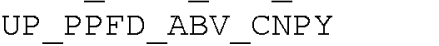 & 0 & 1085 & -999 & None & None & None \\
\hline$W I \overline{N D}$ SPEED $\overline{2} 50 \mathrm{CM}$ & .197 & 8.48 & -999 & None & None & Blank \\
\hline WIND_SPEED_325CM & .198 & 9.38 & -999 & None & None & Blank \\
\hline WIND_SPEED_359CM & .198 & 5.331 & -999 & None & None & Blank \\
\hline WIND_SPEED_400CM & .198 & 10 & -999 & None & None & Blank \\
\hline WIND_SPEED_465CM & .198 & 5.647 & -999 & None & None & Blank \\
\hline WIND_SPEED_500CM & .198 & 10.35 & -999 & None & None & Blank \\
\hline WIND_SPEED_575CM & .198 & 5.917 & -999 & None & None & Blank \\
\hline WIND_SPEED_655CM & .197 & 6.052 & -999 & None & None & Blank \\
\hline WIND_SPEED_765CM & .194 & 6.063 & -999 & None & None & Blank \\
\hline WIND_SPEED_ABV_CNPY & .194 & 10.33 & -999 & None & None & Blank \\
\hline $\begin{array}{l}\text { MEAN_WIND_DIR_MAG } \\
\text { ABV_CNPY }\end{array}$ & .031 & 360 & -999 & None & None & Blank \\
\hline $\begin{array}{l}\text { SDEV__WIND_DIR_MAG_ } \\
\text { ABV_CNPY }\end{array}$ & 0 & 194.6 & -999 & None & None & Blank \\
\hline AIR_TEMP_ABV_CNPY & -26.63 & 30.46 & -999 & None & None & Blank \\
\hline H2O_FLUX_ABV_CNPY & -1.4033 & 8.0233 & -999 & None & None & None \\
\hline 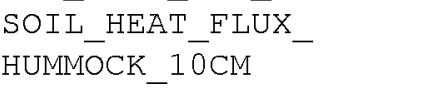 & -94.12 & 169.65 & -999 & None & None & None \\
\hline $\begin{array}{l}\text { SOIL_HEATT_FLUX_- } \\
\text { HOLLOW_10CM }\end{array}$ & -52.86 & 207.5 & -999 & None & None & None \\
\hline SOIL_HEAT_FLUX_FEN & -137.4 & 315.2 & -999 & None & None & Blank \\
\hline $\begin{array}{l}\text { SOIL_TEMP_HUMMOCK_ } \\
1 \mathrm{CM}\end{array}$ & -18.14 & 33.19 & -999 & None & None & None \\
\hline $\begin{array}{l}\text { SOIL_TEMP_HUMMOCK_ } \\
5 \mathrm{CM}\end{array}$ & -12.43 & 29.44 & -999 & None & None & None \\
\hline $\begin{array}{l}\text { SOIL_TEMP_HUMMOCK_ } \\
10 \mathrm{CM}\end{array}$ & -8.18 & 24.94 & -999 & None & None & None \\
\hline $\begin{array}{l}\text { SOIL_TEMP_HUMMOCK_ } \\
25 \mathrm{CM}\end{array}$ & -3.379 & 22.29 & -999 & None & None & None \\
\hline $\begin{array}{l}\text { SOIL_TEMP_HUMMOCK_ } \\
50 \mathrm{CM}\end{array}$ & -.949 & 15.78 & -999 & None & None & None \\
\hline
\end{tabular}




\begin{tabular}{|c|c|c|c|c|c|c|}
\hline $\begin{array}{l}\text { SOIL_TEMP_HUMMOCK_ } \\
75 \mathrm{CM}\end{array}$ & .05 & 12.87 & -999 & None & None & None \\
\hline $\begin{array}{l}\text { SOIL_TEMP_HUMMOCK_ } \\
100 \mathrm{CM}\end{array}$ & .42 & 11.1 & -999 & None & None & None \\
\hline $\begin{array}{l}\text { SOIL_TEMP_HUMMOCK_ } \\
150 \mathrm{CM}\end{array}$ & 1.28 & 8.94 & -999 & None & None & None \\
\hline $\begin{array}{l}\text { SOIL_TEMP_HUMMOCK_ } \\
200 \mathrm{CM}\end{array}$ & 2.04 & 7.49 & -999 & None & None & None \\
\hline SOIL_TEMP_HOLLOW_1CM & -8.76 & 34.52 & -999 & None & None & None \\
\hline SOIL_TEMP_HOLLOW_5CM & -5.11 & 31.25 & -999 & None & None & None \\
\hline $\begin{array}{l}\text { SOIL_TEMP_HOLLOW_ } \\
10 \mathrm{CM}\end{array}$ & -2.19 & 24.19 & -999 & None & None & None \\
\hline $\begin{array}{l}\text { SOIL_TEMP_HOLLOW_ } \\
25 \mathrm{CM}\end{array}$ & -1.032 & 17.77 & -999 & None & None & None \\
\hline $\begin{array}{l}\text { SOIL_TEMP_HOLLOW_ } \\
50 \mathrm{CM}\end{array}$ & -.172 & 13.85 & -999 & None & None & None \\
\hline $\begin{array}{l}\text { SOIL_TEMP_HOLLOW_ } \\
75 \mathrm{CM}\end{array}$ & .31 & 11.76 & -999 & None & None & None \\
\hline $\begin{array}{l}\text { SOIL_TEMP_HOLLOW_ } \\
100 \mathrm{CM}\end{array}$ & .77 & 9.94 & -999 & None & None & None \\
\hline $\begin{array}{l}\text { SOIL_TEMP_HOLLOW_ } \\
150 \mathrm{CM}\end{array}$ & 1.57 & 7.48 & -999 & None & None & None \\
\hline $\begin{array}{l}\text { SOIL_TEMP_HOLLOW_ } \\
200 \mathrm{CM}\end{array}$ & 2.32 & 6.23 & -999 & None & None & None \\
\hline RAINEALL & 0 & 11.2 & -999 & None & None & Blank \\
\hline $\begin{array}{l}\text { DOWN_SOLAR_RAD_ABV } \\
\text { CNPY }\end{array}$ & 0 & 975 & -999 & None & None & None \\
\hline $\begin{array}{l}\text { UP_SOLAR_RAD_ABV } \\
\text { CNPY }\end{array}$ & 0 & 536.5 & -999 & None & None & None \\
\hline $\begin{array}{l}\text { NET_SOLAR_RAD_ABV } \\
\text { CNPY }\end{array}$ & 0 & 854.9 & -999 & None & None & None \\
\hline $\begin{array}{l}\text { UP_TOTAL_RAD_ABV_- } \\
\text { CNPY }\end{array}$ & 202.6 & 775.8 & -999 & None & None & None \\
\hline AIR_TEMP_250CM & -28.22 & 30.46 & -999 & None & None & Blank \\
\hline AIR_TEMP_257CM & -2.283 & 26.74 & -999 & None & None & Blank \\
\hline AIR TEMP $325 \mathrm{CM}$ & -27.57 & 29.66 & -999 & None & None & Blank \\
\hline AIR_TEMP_ $359 \mathrm{CM}$ & -2.227 & 26.66 & -999 & None & None & Blank \\
\hline AIR_TEMP_400CM & -27.44 & 29.31 & -999 & None & None & Blank \\
\hline AIR_TEMP_465CM & -2.211 & 26.56 & -999 & None & None & Blank \\
\hline AIR_TEMP_500 5 CM & -26.81 & 29.83 & -999 & None & None & Blank \\
\hline AIR_TEMP_575CM & -2.238 & 26.42 & -999 & None & None & Blank \\
\hline AIR_TEMP_600CM & -27.2 & 29.84 & -999 & None & None & Blank \\
\hline $\mathrm{AIR}^{-}{ }^{-} \mathrm{TEMP}{ }^{-} 655 \mathrm{CM}$ & -2.234 & 26.46 & -999 & None & None & Blank \\
\hline AIR_TEMP_765CM & -2.207 & 26.34 & -999 & None & None & Blank \\
\hline WET_BULB_TEMP_250CM & -5.504 & 19.35 & -999 & None & None & Blank \\
\hline WET_BULB_TEMP_ $257 \mathrm{CM}$ & -2.373 & 19.24 & -999 & None & None & Blank \\
\hline WET_BULB_TEMP_325cM & -5.506 & 19.42 & -999 & None & None & Blank \\
\hline WET_BULB_TEMP_359CM & -2.296 & 19.12 & -999 & None & None & Blank \\
\hline WET_BULB_TEMP_400CM & -5.556 & 19.04 & -999 & None & None & Blank \\
\hline WET_BULB_TEMP_465CM & -2.215 & 19.1 & -999 & None & None & Blank \\
\hline WET_BULB_TEMP_500CM & -5.512 & 19.03 & -999 & None & None & Blank \\
\hline WET_BULB_TEMP_575CM & -2.165 & 18.88 & -999 & None & None & Blank \\
\hline WET_BULB_TEMP_ $600 \mathrm{CM}$ & -5.514 & 19.01 & -999 & None & None & Blank \\
\hline WET_BULB_TEMP_655CM & -2.268 & 19.13 & -999 & None & None & Blank \\
\hline
\end{tabular}




\begin{tabular}{|c|c|c|c|c|c|c|}
\hline WET BULB TEMP $765 \mathrm{CM}$ & -2.165 & 18.88 & -999 & None & None & Blank \\
\hline $\begin{array}{l}\text { WET_BULB_TEMP_ABV } \\
\text { CNPY }\end{array}$ & -5.437 & 18.84 & -999 & None & None & Blank \\
\hline VAPOR_PRESS_250CM & .2806 & 2.0161 & -999 & None & None & Blank \\
\hline VAPOR_PRESS_257CM & .5071 & 2.0547 & -999 & None & None & Blank \\
\hline VAPOR_PRESS_325CM & .3295 & 1.9958 & -999 & None & None & Blank \\
\hline VAPOR_PRESS_359CM & .51 & 2.0302 & -999 & None & None & Blank \\
\hline VAPOR_PRESS_400CM & .2968 & 1.9958 & -999 & None & None & Blank \\
\hline VAPOR_PRESS_465CM & .5173 & 2.0225 & -999 & None & None & Blank \\
\hline VAPOR_PRESS_500CM & .2865 & 1.9925 & -999 & None & None & Blank \\
\hline VAPOR_PRESS_575CM & .5236 & 2.0413 & -999 & None & None & Blank \\
\hline VAPOR_PRESS_600CM & .3273 & 1.9918 & -999 & None & None & Blank \\
\hline VAPOR_PRESS_655CM & .5148 & 2.0275 & -999 & None & None & Blank \\
\hline VAPOR_PRESS_765CM & .5222 & 2.0096 & -999 & None & None & Blank \\
\hline VAPOR_PRESS_ABV_CNPY & .0809 & 2.2266 & -999 & None & None & Blank \\
\hline SURF_PRESS & 96 & 99.9 & -999 & None & None & Blank \\
\hline WATER_TABLE_HGT & -110.7 & 87.33 & -999 & None & None & Blank \\
\hline $\begin{array}{l}\text { DOWN_LONGWAVE_RAD_ } \\
\text { ABV_CNPY }\end{array}$ & 118.78 & 433.6 & -999 & None & None & None \\
\hline $\begin{array}{l}\text { UP_LONONGWAVE_RAD_ABV } \\
\text { CNPY }\end{array}$ & 202.6 & 513.8 & -999 & None & None & None \\
\hline $\begin{array}{l}\text { DOWN_TOTAL_RAD_ABV } \\
\text { CNPY }\end{array}$ & 139.39 & 1295.8 & -999 & None & None & None \\
\hline $\begin{array}{l}\text { CORR_NET_RAD_ABV } \\
\text { CNPY }\end{array}$ & -92.41 & 717.96 & -999 & None & None & Blank \\
\hline ALBEDO & 0 & .9177 & -999 & None & None & None \\
\hline TOTAL_HEAT_STORAGE & -137.8 & 317.7 & -999 & None & None & None \\
\hline $\begin{array}{l}\text { SENSIBLE_AIR_HEAT_- } \\
\text { STORAGE }\end{array}$ & -32.2 & 38 & -999 & None & None & None \\
\hline $\begin{array}{l}\text { LATENT_AIR_HEAT__ } \\
\text { STORAGE }\end{array}$ & -39.5 & 36 & -999 & None & None & None \\
\hline $\begin{array}{l}\text { MEAN_SPECIFIC_HUM } \\
\text { ABV_CNPY }\end{array}$ & 1.57 & 26.23 & -999 & None & None & Blank \\
\hline $\begin{array}{l}\text { SDEV } \bar{Z} \text { SPECIFIC_HUM } \\
\text { ABV_CNPY }\end{array}$ & 0 & 56.297 & -999 & None & None & Blank \\
\hline 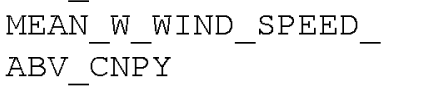 & -1.998 & 3.28 & -999 & None & None & Blank \\
\hline $\begin{array}{l}\text { SDEV } \bar{W} \text { WININD_SPEED_ } \\
\text { ABV_CNPY }\end{array}$ & 0 & 3.815 & -999 & None & None & Blank \\
\hline REL_HUM_ABV_CNPY & 15.2 & 107 & -999 & None & None & Blank \\
\hline CRTFCN_CODE & CP I & $\mathrm{CPI}$ & None & None & None & None \\
\hline REVISION_DATE & $07-\mathrm{DEC}-98$ & $08-\mathrm{DEC}-98$ & None & None & None & None \\
\hline Minimum Data Value - & \multirow{5}{*}{\multicolumn{6}{|c|}{$\begin{array}{l}\text { The minimum value found in the column. } \\
\text { - The maximum value found in the column. } \\
\text { - The value that indicates missing data. This is used } \\
\text { indicate that an attempt was made to determine the } \\
\text { parameter value, but the attempt was unsuccessful. } \\
\text { - The value that indicates unreliable data. This is }\end{array}$}} \\
\hline Maximum Data Value - & & & & & & \\
\hline Missng Data Value & & & & & & \\
\hline Unrel Data Value & & & & & & \\
\hline Below Detect Limit & & & & & & \\
\hline
\end{tabular}

Page 50 
indicate that an attempt was made to determine the parameter value, but the analysis personnel determined that the parameter value was below the detection limit of the instrumentation.

Data Not Cllctd - - This value indicates that no attempt was made to determine the parameter value. This usually indicates that BORIS combined several similar but not identical data sets into the same data base table but this particular science team did not measure that parameter.

Blank -- Indicates that blank spaces are used to denote that type of value. N/A -- Indicates that the value is not applicable to the respective column. None -- Indicates that no values of that sort were found in the column.

\subsection{Sample Data Record}

The following are wrapped versions of data record from a sample flux data file on the CD-ROM.

SITE NAME, SUB SITE, DATE OBS, TIME OBS, SENSIBLE HEAT FLUX ABV CNPY, LATENTT_HEAT_FLUX_ABV_CNPY,NET_RAD_ABV_CNPY, CO $\overline{2} \_$FLUX_ABV_CNPY, CO2_CONC_ABV_CNPY, CO2_STORAGE, CO2 FLUX_ABV_PLUS_STORAGE, DOWN_PPFD_ABV_CNPY, UP_PPFD_ABV_ $\overline{\mathrm{CNPY}}$,

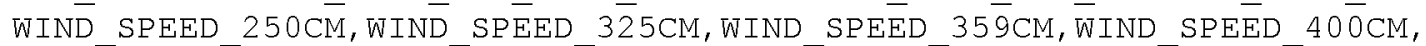
WIND_SPEED_465CM,WIND_SPEED_500CM,WIND_SPEED_575CM,WIND_SPEED_655CM, WIND_SPEED_765CM,WIND_SPEED_ABV_CNPY,MEAN_WIND_DIR_MAG_ABV_CNPY, SDEV_WIND_DIR_MAG_ABV_CNPY, AIR_TEMP_ABV_CNPY, H2O_FLUX_ĀBV_CNPY, SOIL_HEAT_FLUX_HUMMOCK_ $10 \mathrm{CM}$, SOIL_HEAT_ELUX_HOLLOW $\overline{-} 10 \mathrm{CM}$, SOIL_HEAT_FLUX_FEN, SOIL_TEMP_HUMMOCK_1CM, SOIL_TEMP_HUMMOCK_5CM, SOIL_TEMP_HUMMOCK_10CM,

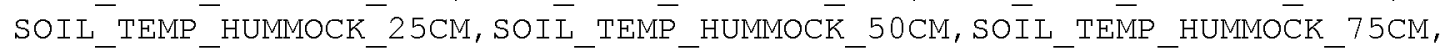
SOIL TEMP HUMMOCK $100 \mathrm{CM}$, SOI $\bar{L}$ TEMP HUMMOCK $150 \mathrm{CM}$, SOIL TEMP HUMMOCK_200CM, SOIL_TEMP_HOLLOW_- $1 \mathrm{CM}$, SOIL_TEMP_HOLLOW_5CM, SOIL_TEMP_HOLLOW_ $10 \mathrm{CM}$,

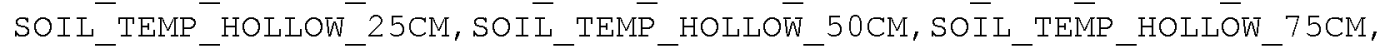
SOIL_TEMP HOLLOW_100CM, SOI $\bar{L}$ TEMP HOLLOW $150 \mathrm{CM}$, SOIL_TEMP HOLLOW_200CM, RAINFALL, DOWN_SOLAR_RAD_ABV_CNPY, UP_SOLAR_RAD_ABV_CNPY, NET_SOLAR_RAD_ABV_CNPY,

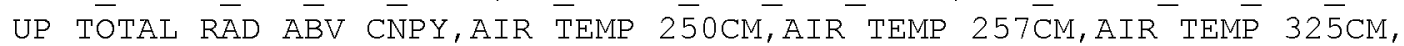
AI $\bar{R}$ TEMP $359 \overline{\mathrm{CM}}, \overline{\mathrm{A}} \bar{I} \mathrm{R}$ TEMP $4 \overline{0} 0 \mathrm{CM}, \overline{\mathrm{A}} I \mathrm{R}$ TEMP $4 \overline{6} 5 \mathrm{CM}, \overline{\mathrm{A}} I \mathrm{I}$ TEMP $5 \overline{0} 0 \mathrm{CM}, \overline{\mathrm{A}} I \mathrm{R}$ TEMP $575 \mathrm{CM}$, AIR_TEMP_600CM,AIR_TEMP_655CM,AIR_TEMP_765CM, WET_BULB_TEMP_250CM, WET_BULB_TEMP_257CM, WET_BULB_TEMP_325CM, WET_BULB_TEMP_359CM, WET_BULB_TEMP_400CM, WET_BULB_TEMP_465CM,WET_BULB_TEMP_500CM, WET_BULB_TEMP_575CM, WET_BULB_TEMP_600CM, WET BULB TEMP $655 \mathrm{CM}, W E T$ BULB TEMP $765 \mathrm{CM}, W E T$ BULB TEMP ABV CNPY, VAPOR_PRESS_250CM, VAPOR_PRESS_257CM, VAPOR_PRESS_325CM,VAPOR_PRESS_359CM, VAPOR_PRESS_400CM, VAPOR_PRESS_465CM,VAPOR_PRESS_500CM, VAPOR_PRESS_575CM, VAPOR_PRESS_600CM, VAPOR_PRESS_655CM,VAPOR_PRESS_765CM, VAPOR_PRESS_ABV_CNPY,

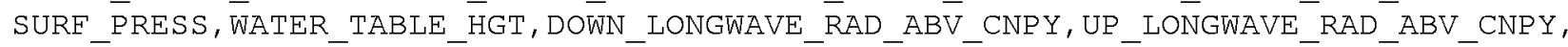

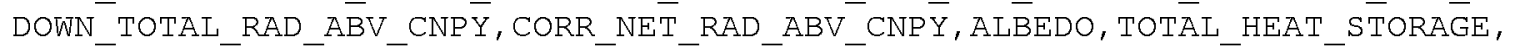

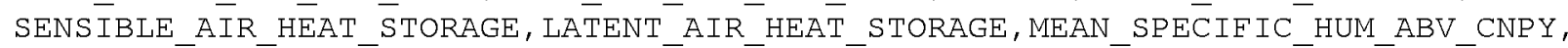

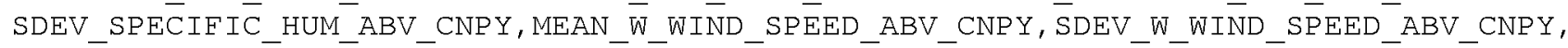
REL_HUM ABV_CNPY, $\bar{C} R T F \bar{C}$ CODE, REVIISION_DATE

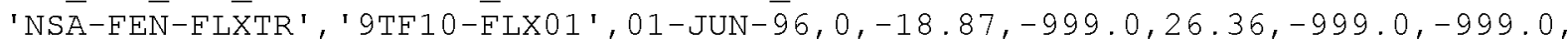
$-999.0,-999.0,0.0,0.0,3.129,1,-999.0,1,1,3.576,65.29,19.19,3.38,-999.0, .5$, $-.2,4.4,4.83,5.43,5.84, .28, .4, .81,1.63,2.42,5.57,5.72,5.54,2.5, .29, .72,1.16$,

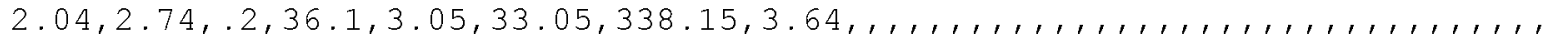
$.7545,98.6,328.41,335.1,364.51,28.43, .085,-.5,-.2,-.1,-999.0,-999.0,-.018$, $.585,98.2,{ }^{\prime} \mathrm{CPI}, 08-\mathrm{DEC}-98$ 


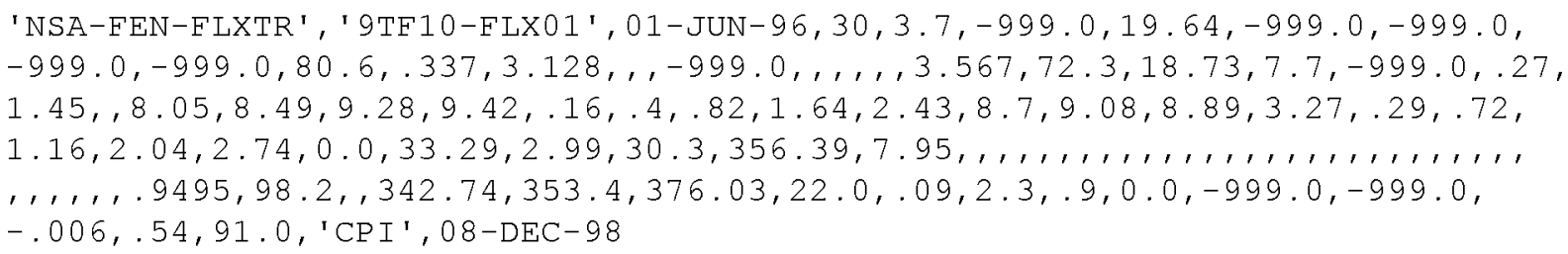

\section{Data Organization}

\subsection{Data Granularity}

The smallest unit of data tracked by BORIS was data collected at a given site on a given date.

\subsection{Data Format}

The Compact Disk-Read-Only Memory (CD-ROM) files contain American Standard Code for Information Interchange (ASCII) numerical and character fields of varying length separated by commas. The character fields are enclosed with single apostrophe marks. There are no spaces between the fields.

Each data file on the CD-ROM has four header lines of Hyper-Text Markup Language (HTML) code at the top. When viewed with a Web browser, this code displays header information (data set title, location, date, acknowledgments, etc.) and a series of HTML links to associated data files and related data sets. Line 5 of each data file is a list of the column names, and line 6 and following lines contain the actual data.

\section{Data Manipulations}

\subsection{Formulae}

Net Solar Radiation $\left(\mathrm{W} / \mathrm{m}^{2}\right)$

Net solar radiation $\left(\mathrm{K}^{*}\right)$ is the difference between incoming solar radiation $(\mathrm{Kd})$ and reflected solar radiation $(\mathrm{Ku})$ :

$$
\mathrm{K}^{*}=\mathrm{Kd}-\mathrm{Ku}
$$

\section{Incoming Longwave Radiation (W/m²)}

Incoming longwave radiation (Ld) is calculated as a residual from the net radiation balance, where net radiation $\left(\mathrm{Q}^{*}\right)$ is the sum of net solar radiation $\left(\mathrm{K}^{*}\right.$, see e.g. 9.1) and net longwave radiation $\left(\mathrm{L}^{*}\right)$. $\mathrm{L}^{*}$ is the difference between incoming longwave radiation $(\mathrm{Ld})$ and outgoing longwave radiation $(\mathrm{Lu})$.

$$
\mathrm{Q}^{*}=\mathrm{Kd}-\mathrm{Ku}+\mathrm{Ld}-\mathrm{Lu}
$$

\section{Total Incoming Radiation (W/m²)}

Total incoming radiation (Qd) is the sum of all incoming radiation:

$$
\mathrm{Qd}=\mathrm{Kd}+\mathrm{Ld}
$$

\section{Total Outgoing Radiation (W/m²)}

Total outgoing radiation $(\mathrm{Qu})$ is the sum of all outgoing radiation:

$$
\mathrm{Qu}=\mathrm{Ku}+\mathrm{Lu}
$$




\section{Net Radiation corrected $\left(\mathrm{W} / \mathrm{m}^{2}\right)$}

Measured net radiation $\left(\mathrm{Q}^{*}\right.$ ) was corrected using a set of site-specific day- and night-time equations developed by Hodges and Smith (1997). These equations (shown below) were used for all years of data, excluding data collected in 1993 at both fen and YJP. The use of the day or night equation is based on measured incoming solar radiation. When $\mathrm{Kd}>5.00 \mathrm{~W} / \mathrm{m}^{2}$, daytime equations are used. The relevant equations are:

Time of day Correction equation

$$
\begin{array}{lll}
\text { DAY } & Q^{*} \text { corr }=0.957\left(\mathrm{Q}^{*}\right)+3.2 & (9.5) \\
\text { NIGHT } & \mathrm{Q}^{*} \text { corr }=1.079\left(\mathrm{Q}^{*}\right)+11.1 & (9.6)
\end{array}
$$

\section{Surface Albedo (dimensionless)}

Surface albedo (a) is the ratio of the amount of radiation reflected by a body to the amount incident upon it:

$$
\mathrm{a}=\mathrm{Ku} / \mathrm{Kd}
$$

Total $\mathrm{CO}_{2}$ Flux $\left(\mu \mathrm{mol} / \mathrm{m}^{2} / \mathrm{s}\right)$

The total $\mathrm{CO}_{2}$ flux $\left(\mathrm{Fe}_{\mathrm{CO} 2}\right)$ is the sum of the eddy flux $\left(\mathrm{Fe}_{\mathrm{CO} 2}\right)$ and the storage flux $\left(\mathrm{Fs}_{\mathrm{CO} 2}\right)$ :

$$
\mathrm{F}_{\mathrm{CO} 2}=\mathrm{Fe}_{\mathrm{CO} 2}+\mathrm{Fs}_{\mathrm{CO} 2}
$$

\section{Heat Storage $\left(\mathrm{W} / \mathrm{m}^{2}\right)$}

Total heat storage (G_total) is based on the sum of heat storage from several environmental compartments:

$$
\text { G_total }=\mathrm{G}+\mathrm{Ga}+\mathrm{Ge}+\mathrm{Gveg}
$$

where: $G=$ soil heat flux

$\mathrm{Ga}=$ sensible heat storage in the air

$\mathrm{Ge}=$ latent heat storage in the air

Gveg $=$ heat storage in the vegetation

Only $\mathrm{G}$ is measured, and the remaining variables are calculated using the formulae given by Thom (1975):

$$
\begin{array}{ll}
\mathrm{Ga}(\mathrm{T})=0.33 \mathrm{zrdTa}(\mathrm{t}) & (9.10) \\
\mathrm{Ge}(\mathrm{T})=0.5 \mathrm{zrde}(\mathrm{t}) & (9.11) \\
\operatorname{Gveg}(\mathrm{T})=0.8 \mathrm{Mv} \mathrm{dTb}(\mathrm{t}) & (9.12)
\end{array}
$$

where $\mathrm{zr}$ is the reference height (in this case the height of the net pyrradiometer)(m); dTa, de, and dTb are the rates of change in air temperature $\left({ }^{\circ} \mathrm{C} / \mathrm{s}\right)$, vapor pressure $(\mathrm{kPa} / \mathrm{s})$, and biomass temperature $\left({ }^{\circ} \mathrm{C} / \mathrm{s}\right)$, respectively, for time step $\mathrm{t}$; and $\mathrm{Mv}$ is the standing green mass of vegetation over unit area $\left(\mathrm{kg} / \mathrm{m}^{2}\right)$. Theoretically, $\mathrm{Ga}$ and $\mathrm{Ge}$ are integrated over the height interval between the surface and $\mathrm{zr}$. In this study, the calculations were performed for discrete layers represented by the profile psychrometer heights and summed to get the totals. The calculation of all minor heat storage terms in the energy balance were calculated with the Fortran program called STORAG. An explanation of this program is given in Section 9.1.1, and a description of the command files used to process the data is given in Section 9.2.1.

Ground heat flux at the fen in 1994 only (Gfen) was computed by adjusting the heat flux plate readings from the hollow (Ghol) with a correction factor determined from calorimetric methods. In the 
following explanation, Gpla is equal to Ghol. Hence,

$$
\mathrm{G}=\mathrm{G}(\mathrm{z}) \mathrm{CF}
$$

where $\mathrm{CF}=\mathrm{Gcal} / \mathrm{Gpla}$

in which CF is a correction factor (3.04) determined from calorimetric calculations of heat storage in the soil profile (Gcal) and the time integrated flux measured by the heat flux plates (Gpla). Gpla is calculated by summing the 30 -minute average heat flux plate readings multiplied by 1800 seconds over a specified time interval (usually 10-14 days). Gcal is the total heat storage in the soil profile calculated from individual soil layers represented by the measured temperature profile(s), plus the heat flux out the bottom of the soil profile (GB).

Heat storage in the individual layers, $\mathrm{S}$ (i) is computed as:

$$
\mathrm{S}(\mathrm{i})=\mathrm{CdT}(\mathrm{t}) \mathrm{z}
$$

where symbols are defined as above. $\mathrm{C}$ varies between $3.48 \times 10^{6} \mathrm{~J} / \mathrm{m}^{3} /{ }^{\circ} \mathrm{C}$ for saturated peat soil and $0.58 \times 10<\mathrm{SUP}>6</ \mathrm{SUP}>\mathrm{J} / \mathrm{m}^{3} /{ }^{\circ} \mathrm{C}$ for dry peat soil. The flux out the base of the soil profile is calculated as:

$$
\mathrm{GB}=-\mathrm{Ks} \mathrm{dT} / \mathrm{dz}
$$

where $-\mathrm{Ks}$ is the thermal conductivity of saturated peat soil $\left(0.5 \mathrm{~W} / \mathrm{m} /{ }^{\circ} \mathrm{C}\right)$ and $\mathrm{dT} / \mathrm{dz}$ is the temperature gradient at the base of the soil profile.

In 1993, 1995, and 1996, no correction factor was applied to the fen's soil heat flux data (see Section 10.2.2). In these years, the soil heat flux from the hollow ( $\mathrm{Ghol}$ ) was used in the calculations of G_total.

\section{Specific Humidity $(\mathrm{g} / \mathrm{kg})$}

Specific humidity $(\mathrm{SH})$ and the standard deviation of specific humidity ( $\mathrm{sSH}$ ) were calculated using measured air temperature (T_air), vapor density (q), and the standard deviation of $\ln \mathrm{q}(\sin \mathrm{q})$.

Air density (rho) is found as a function of T_air, where:

$$
\begin{aligned}
& \text { if T_air>30 then rho }=1.149-0.0036 \text { (T_air }-30.01) \text { (9.17) } \\
& \text { if 25>T_air>30 then rho }=1.168-0.0038 \text { (T_air }-25.01 \text { ) (9.18) } \\
& \text { if } 20>\bar{T} \text { air }>25 \text { then rho }=1.188-0.0040 \text { (T-air - 20.01) (9.19) } \\
& \text { if 15>T_air>20 then rho }=1.209-0.0042 \text { (T_air - 15.01) (9.20) } \\
& \text { if 10>T_air>15 then rho }=1.230-0.0042 \text { (T_air }-10.01 \text { ) (9.21) } \\
& \text { if 5>T_air>10 then rho }=1.252-0.0044 \text { (T_air - 5.01) (9.22) } \\
& \text { if } 0>\text { T_air>5 then rho }=1.275-0.0045 \text { (T_air - 0.01) (9.23) } \\
& \text { if }-5>\text { T_air }>0 \text { then } r h o=1.229-0.0048 \text { (T_air }+4.99) \quad(9.24) \\
& \text { if -10>T_air>-5 then rho }=1.324-0.0050\left(\mathrm{~T}_{-} \text {air }+9.99\right) \quad \text { (9.25) } \\
& \text { if -15>T_air>-10 then rho }=1.350-0.0050\left(T_{-} \text {air }+14.99\right) \quad \text { (9.26) } \\
& \text { if }-20>\text { T_air }>-15 \text { then } r h o=1.376-0.0054(\text { T_air }+19.99) \quad(9.27)
\end{aligned}
$$

The specific humidity is found from the vapor density $\left(\mathrm{g} / \mathrm{m}^{3}\right)$, measured by the krypton hygrometer at each site, and

$$
\mathrm{q}=(\ln \mathrm{s}-\ln \mathrm{v}) / \mathrm{kx}
$$

where $\mathrm{s}=$ the signal voltage from the hygrometer $(\mathrm{mv}), \mathrm{v}$ is the intercept of the hygrometer's calibration ( $4054 \mathrm{mv}$ for the fen and $4528 \mathrm{mv}$ for the YJP), $\mathrm{k}$ is absorption coefficient for water vapor $\left(-0.141 \mathrm{~m}^{3} / \mathrm{g} / \mathrm{cm}\right.$ for the fen and $-0.133 \mathrm{~m}^{3} / \mathrm{g} / \mathrm{cm}$ for the YJP), and $\mathrm{x}$ is the path length of the hygrometer $(1.542 \mathrm{~cm}$ for the fen and $1.400 \mathrm{~cm}$ for the YJP). Then, 


$$
\begin{array}{ll}
\mathrm{SH}=\mathrm{q} / \text { rho } & (9.29) \text { and } \\
\mathrm{sSH}=\left(\mathrm{e}^{\mid \sin } \mathrm{q} \mid\right) / \text { rho } & (9.30)
\end{array}
$$

where $s$ indicates the standard deviation.

\section{Convective Heat Fluxes (H and LE)}

The sensible heat flux was found from equation 3.2 which states that

$$
\mathrm{H}=\text { rho } \mathrm{Cp}<\mathrm{w}^{\prime} \mathrm{T}^{\prime}>\quad(9.31)
$$

where the variables have their usual meanings. Webb (1982) showed that the air density and specific heat of air are functions of both the air's temperature and vapor pressure, and that air temperature had the largest control. Thus, in our calculations, the rho Cp term was corrected for changing temperature and air pressure as follows:

$$
\text { rho } \mathrm{Cp}=\mathrm{Cp}(\mathrm{d})(\mathrm{P} \mathrm{M} / \mathrm{R} \mathrm{T}) \quad(9.32)
$$

where $C p(d)$ is the specific heat of dry air, $P$ is the atmospheric pressure, $M$ is the molecular weight of dry air, $\mathrm{R}$ is the universal gas constant, and $\mathrm{T}$ is the air temperature. In the 1994 experiments, $\mathrm{P}$ was obtained from Thompson airport and read into the data logger once a day, usually about 1500 UTC, when the site was first visited. In 1996, analog pressure sensors at the YJP and fen were recorded P every half-hour. The air temperature that was used was the average value from the previous half-hour, which was updated on a continuous basis automatically by the data logger. The precision of this correction was improved in 1996 because we incorporated air pressure sensors into the measurement packages at each site, and this allowed the use of the previous half-hour's air pressure as well as temperature in equation 9.41.

The value of $L$, the latent heat of vaporization, in the eddy covariance measurement of latent heat flux (equation 3.1) was found as a function of air temperature from the equation

$$
\mathrm{L}=2501+(-2.363) \mathrm{T}+(-0.00023) \mathrm{T}^{2}
$$

where $\mathrm{T}$ is the air temperature averaged over the previous half-hour. Equation 9.42 was part of the online calculations.

The krypton lamp in the hygrometer has two emission lines, a major line at $123.58 \mathrm{~nm}$, and a minor line at $116.49 \mathrm{~nm}$. Both lines are absorbed by both water vapor and oxygen. It is necessary to account for the effect of absorption by oxygen on the value of vapor density in order to correct the latent heat flux. The oxygen correction is a function of atmospheric pressure and temperature, and Tanner, et al. (1993) provide the appropriate equations to find the oxygen correction. At standard atmospheric pressure $(101.3 \mathrm{kP})$ and temperature $(305 \mathrm{~K})$, the pressure correction is small in comparison to that caused by temperature, and it is usual to correct for oxygen absorption based only on temperature. This procedure was followed in this experiment.

Webb et al. (1980) described the influence of sensible heat and vapor fluxes that cause changes in the density of atmospheric constituents, and the necessary corrections to the flux associated with these fluctuations. These corrections are usually termed the Webb, Pearman, and Leuning (WPL) corrections, and they were applied to the latent heat flux in this experiment (Joiner, 1994). The WPL correction due to the sensible heat flux is approximately five times larger than that due to the vapor flux itself (Tanner et al., 1993).

\section{Carbon Dioxide Flux}

Because we used a closed-path IRGA and the air sample was delivered to the instrument through a sample tube, there is a time delay, or lag, in the concentration of $\mathrm{CO}_{2}$, measured in the IRGA, and the measured vertical wind in the free atmosphere around the sonic. If the $\mathrm{CO}_{2}$ concentration data were not corrected for lag, we would not calculate the correct covariance, and the flux of $\mathrm{CO}_{2}$ would be 
incorrect. We found the lag for our $\mathrm{CO}_{2}$ systems at fen and YJP empirically. While continuously monitoring the output of $\mathrm{CO}_{2}$ and vertical wind, we introduced a bubble of nitrogen in the vicinity of the sample tube intake. The arrival of the nitrogen in the sample cell of the IRGA caused a discernable spike in the $\mathrm{CO}_{2}$ time series. We identified formally the time of occurrence of the spike by lag correlation analysis of $\mathrm{CO}_{2}$ concentration and vertical wind. The lag was where the correlation coefficient between $\mathrm{CO}_{2}$ and vertical wind was a maximum. Site-specific lag times were programmed into the data loggers at each site, and these lags allowed us to compute a covariance using the correct values of $\mathrm{CO}_{2}$ and vertical wind.

The concentration of $\mathrm{CO}_{2}$ measured by an IRGA is dependent on pressure. Changing pressure changes the calibration of the instrument (span/voltage difference) by changing the span. The span is the difference in concentration between the high and low span gases; in our case approximately 30 to 40 ppmv. The effect of changing pressure on the IRGA's calibration was corrected online.

Changes in the air's temperature and water vapor density, which in turn are related to the sensible and latent heat fluxes, affect the concentration of $\mathrm{CO}_{2}$ and hence the flux of $\mathrm{CO}_{2}$ (Webb et al., 1980). In postprocessing, the $\mathrm{CO}_{2}$ flux was corrected for changing density and vapor flux (Joiner, 1994). The correction includes a correction for the cross-sensitivity of the IRGA to water vapor and carbon dioxide (Leuning and Moncrieff, 1990; Leuning and King, 1992).

\subsubsection{Derivation Techniques and Algorithms}

STORAG is the general name for a Fortran program that calculates the minor heat storage terms in the energy balance. There are several operational versions of the program that differ depending upon the available data (see Section 9.2.1). Also, ENBAL, a Fortran program to solve for the terms of the radiation balance, was used in the analysis. Both STORAG and ENBAL work on the principle of GET commands that read input data into memory from various files, and when sufficient variables are read to solve the control equations, the calculations get done and are stored in output tables that can be delivered to spreadsheets or plotting packages for further processing and plotting. An example of the operation of STORAG is given in Section 9.2.1 that illustrates not only the specific features of STORAG but also the general nature of both programs.

\subsection{Data Processing Sequence}

\subsubsection{Processing Steps}

Two versions of STORAG were used in the calculations of heat storage depending on what data were available: STORY94.exe and STORY96.exe. STORY94.exe, used on 1993, 1994, and 1995 data, calculated heat storage variables from wet-bulb and dry-bulb temperatures, net radiation, soil heat flux, and soil temperatures. STORY96.exe was used on the 1996 data where relative humidity (RH) was an input measured variable, which replaced its calculation using wet-bulb temperatures.

A command file is used to run the STORAG program. It comprises a list of GET statements that select variables from a specified column in a specified file. The last two numbers in the GET statement are the slope and intercept of the equation to be used with those data. This is useful if the input data are in the wrong units, because a linear calibration can then be applied. Other variables are set using SET statements. Variables used in the STORY94 program are:

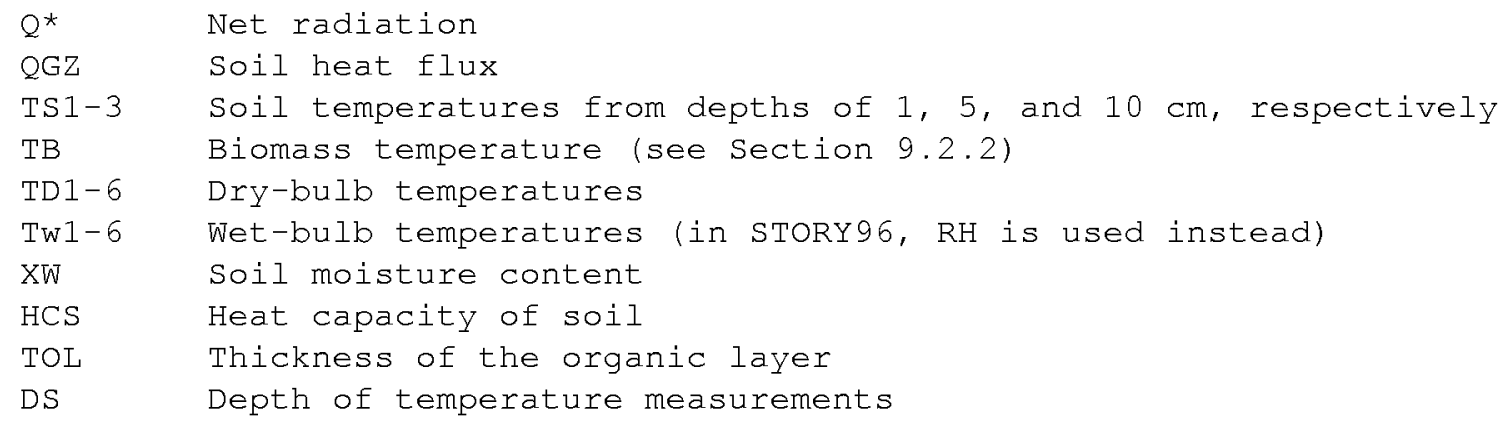


$\begin{array}{ll}\text { ZR } & \text { Height of the net radiation measurement } \\ \text { ZCQ } & \text { Height of canopy, height of net pyrradiometer } \\ \text { MV } & \text { Green mass of vegetation } \\ \text { CON } & \text { Constant used in equations determining Ga, Ge, and Gveg }\end{array}$

An example of the command file used to run STORAG is listed in Table 14 for one day. All commands must be in capital letters, $\mathrm{Q}^{*}$ and QGZ data must

be 30 -minute averages, and the remaining temperatures are 15 -minute averages.

Table 14. Example command file for STORAG, a program to find the minor heat storage terms in the surface energy balance.

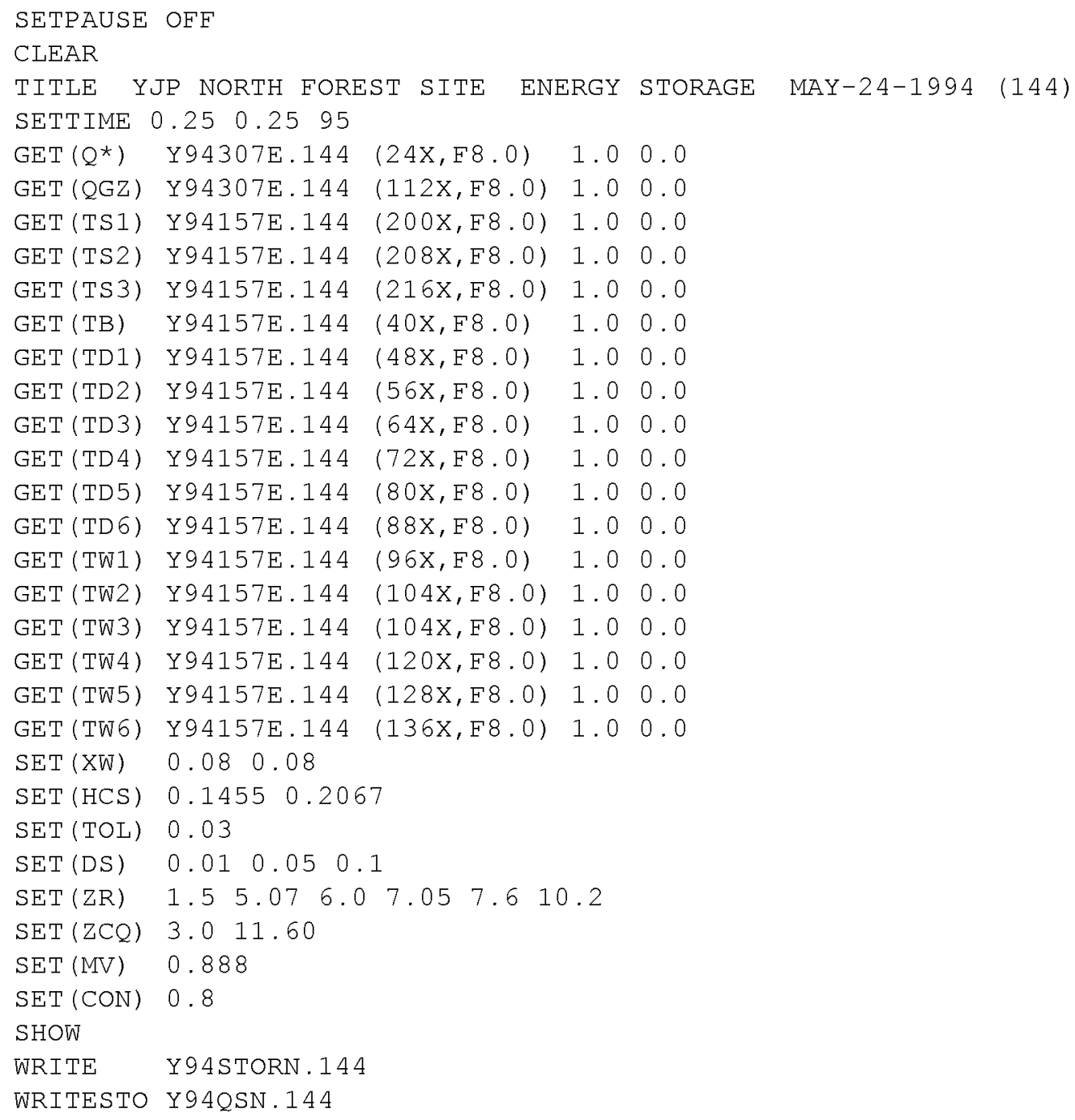

\subsubsection{Processing Changes}

Where one level of air temperature was missing from a file used in STORAG, the GET statement was changed to read the value from the nearest level. For example, if the third level of temperature is missing, the value from the fourth level could be used instead.

Mass of vegetation (MV) is zero in the fen calculations. For heat storage calculations at YJP in the west site, $\mathrm{MV}=2.22$. Because there were only small trees in the north site, MV was equal to 0.888 for this site. Biomass temperature (TB) is zero in the fen calculations, whereas it is based on the stem temperatures at YJP. In the north site, TB = Tbsn. In the west site, the following weighted average, based on the percentage occurrence of small, medium, and large trees, was used to determine TB: 
$\mathrm{TB}=0.4 \mathrm{Tbsw}+0.486 \mathrm{Tbmw}+0.114 \mathrm{Tblw}$

The STORAG program does not accept zero in the command file; therefore, the TB multiplier, the thickness of the organic layer (TOL), the height of the canopy, and MV were set to 0.000001 in the fen calculations, creating insignificant values in the calculated heat storage.

\subsection{Calculations}

\subsubsection{Special Corrections/Adjustments}

The following rules were followed in preparing the data files:

- Any small negative values of $\mathrm{Kd}$ and $\mathrm{Ku}\left(<1 \mathrm{~W} / \mathrm{m}^{2}\right)$ were changed to zero, and $\mathrm{Ld}, \mathrm{Qd}, \mathrm{Qu}$, and the albedo were recalculated accordingly; negative values occur as a result of zero depression on the instruments.

- $\quad$ All negative values of incoming and reflected PPFD (PPFDd and PPFDu) were changed to zero; as is the case with pyranometers, small negative values result from zero depression.

- When $\mathrm{FsCO}_{2}$ was missing and $\mathrm{Kd}>0$, then $\mathrm{F}_{\mathrm{CO} 2}=\mathrm{Fe}_{\mathrm{CO} 2}$.

- When $\mathrm{FsCO}_{2}$ was missing and $\mathrm{Kd}=0$, then $\mathrm{F}_{\mathrm{CO} 2}=\mathrm{CO}_{2}$ night.

- $\quad$ Latent heat flux (LE) was flagged (i.e., changed to -6999) when $\mathrm{LE}<-50 \mathrm{~W} / \mathrm{m}^{2}$.

- $\quad$ Sensible heat flux $(\mathrm{H})$ was flagged when $\mathrm{H}<-70 \mathrm{~W} / \mathrm{m}^{2}$.

- $\quad$ All negative wind speeds were flagged.

- Where LE was flagged and vertical wind speed (w) was $>2$ or $<-2 \mathrm{~m} / \mathrm{s}$, w was flagged.

- Where between one and three half-hourly average values of a variable were missing, a linear interpolation was done, assuming that the meteorological conditions were steady and a clear temporal trend was present before and after the data gap.

\subsubsection{Calculated Variables}

Formulae for the following list of calculated variables can be found in Section 9.1: $\mathrm{K}^{*}, \mathrm{Ld}, \mathrm{Qd}$, $\mathrm{Qu}, \mathrm{Q}^{*}, \mathrm{Q}^{*}$ corr, a, $\mathrm{F}_{\mathrm{CO} 2}, \mathrm{CO}_{2}$ night, G_total, Ga, Ge, Gveg, G10, SH, and sSH.

\subsection{Graphs and Plots}

Day 260 in 1996 was chosen because it was a clear day and it shows many interesting contrasting features of the radiation, energy, and $\mathrm{CO}_{2}$ balances of the two sites (Figure 4). The time shown in the figure is UTC. The most notable differences in the radiation balances between the two sites (Figure 4A and $4 \mathrm{~B}$ ) occur in the net radiation $\left(\mathrm{Q}^{*}\right)$ and reflected solar radiation $(\mathrm{Ku})$ components: the latter is larger and the former is smaller at the fen as a result of $\mathrm{i}$ ) the larger albedo at the fen and ii) the higher surface temperatures on the jack pine; which increase the outgoing longwave radiation (Lu) from the drier surface; the greatest contrast in Lu occurs early in the day. The incoming solar radiation (Kd) and incoming longwave radiation (Ld) do not indicate substantial differences between the sites.

The fen had started to senesce by day 260; as a result, the majority of the available energy goes into sensible heat flux (average Bowen ratio 2.0) (Figure 4C). The YJP was still actively transpiring (average Bowen ratio 1.0), except for a short period in the middle of the day when the sensible heat flux exceeds the latent heat flux (Figure 4D). The value of the total heat storage (G_total) includes the soil heat storage and biomass storage from the north site.

The impact of senescence is very noticeable in the different net $\mathrm{CO}_{2}$ flux patterns. The fen is either effluxing or in a state of zero net exchange for the majority of the day (Figure 4E), but there is some very weak uptake in the late morning. The jack pine shows vigorous uptake for the whole daylight period and consistent efflux in the nighttime period at the start of the day (Figure 4F). The pattern of efflux breaks down late in the day under the very calm wind speed conditions (Figure 4H).

The pattern of wind at the fen is characterized by very low wind speed or complete calm during the night and maximum values of $5 \mathrm{~m} / \mathrm{s}$ during the daylight period (Figure $4 \mathrm{G}$ ). The increase of wind speed in the morning and the decrease in the evening are very sharp. The pattern at the YJP is quite different early in the day, when the wind speed increases gradually to a maximum of only $3 \mathrm{~m} / \mathrm{s}$ by the evening. The precipitous drop in wind speed at 0000 UTC is the same pattern as at the fen. The 
direction of the wind was steadier at the fen, where it blew from the southeast from 1200 UTC onwards. At the YJP, the direction was more easterly for the majority of the day. It is clear that the fen has its own particular wind climate, and on very calm nights such as the start of day 260 , it is much calmer than the more open YJP site (compare Figures 4G and 4H).

The slightly higher and more gradually declining air temperatures at the YJP in the early part of the day (Figure $4 \mathrm{H}$ ) are consistent with the presence of the higher wind speeds, which would have mixed the lower atmosphere more effectively. The increased mixing would hinder the development of a surface temperature inversion and raise the air temperature. It is important to note that the eddy covariance measurement of $\mathrm{CO}_{2}$ was very successful at this time of the day, when a constant efflux of 1 umole $/ \mathrm{m}^{2} / \mathrm{s}$ was measured (Figure $4 \mathrm{~F}$ ). The same is not true for the fen, where the $\mathrm{CO}_{2}$ series is quite jagged (Figure 4E) as a result of measured negative fluxes that have been set to zero as part of the data management. Clearly, the measurement of the flux was breaking down at the fen under the totally calm wind speed conditions (Figure 4G).
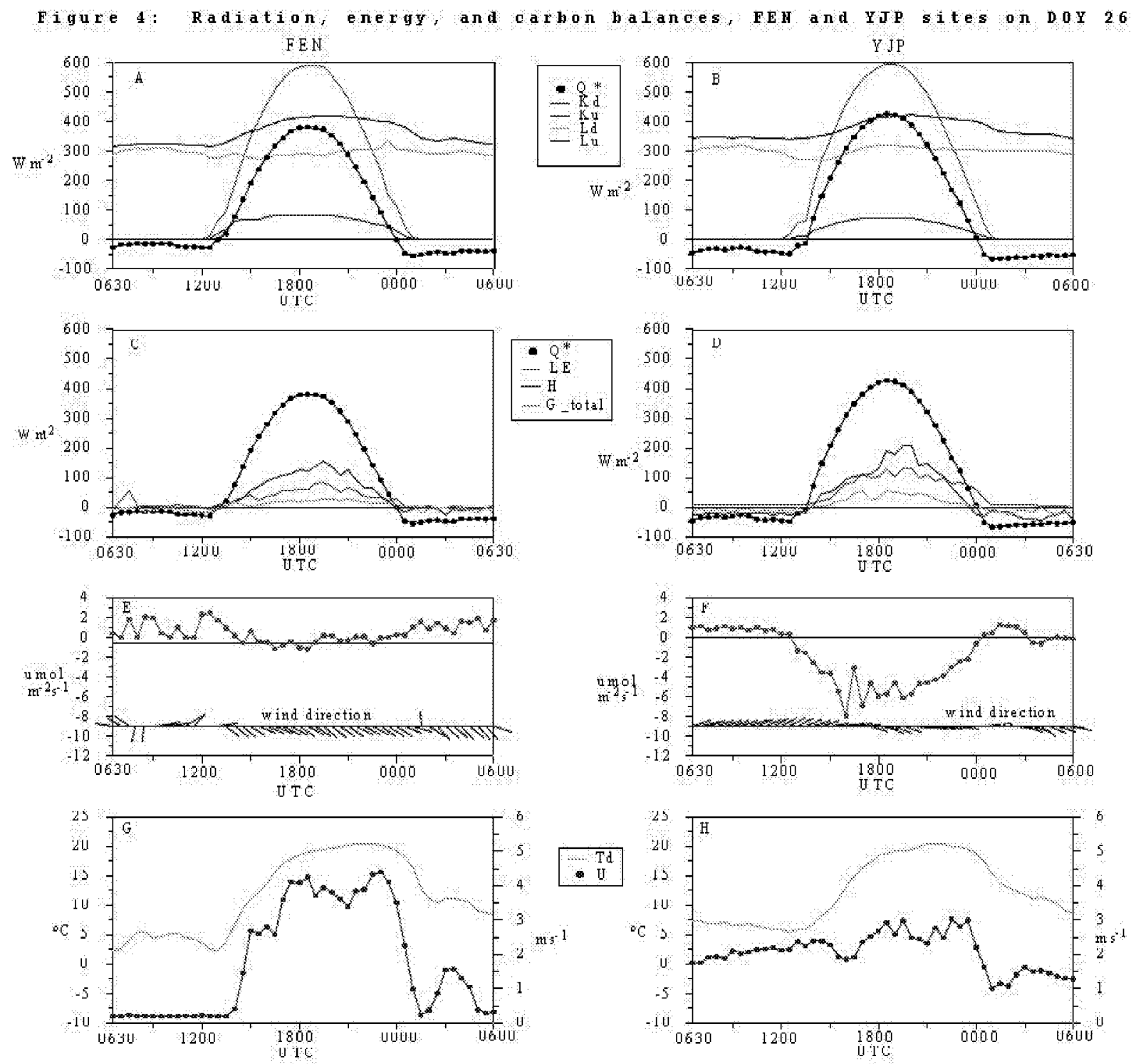

Figure 4: Contrasting Radiation, Energy, and $\mathrm{CO}_{2}$ Balances Between NSA-Fen and NSA-YJP 


\section{Errors}

\subsection{Sources of Error}

There are a number of sources of error in the data. In general, these sources can be identified as:

- instrument error, i.e., the error component from the transducer itself

- a component from the measurement device

- a component dependent upon field placement.

Not all of the components of error are easily evaluated, and the most difficult to evaluate through a formal analysis is that due to field placement. We believe that we minimized field placement error, but we do not have a formal way of verifying this claim. We do claim that all instruments were located according to normal field practice, and a close watch was kept by field staff for any apparent aberrant output from the instruments.

\subsection{Quality Assessment}

All aberrant data occurrences found in the field were noted in the field log and examined in detail during postprocessing. There are a number of reasons for the occurrence of aberrant values. In our particular case, the two most common reasons were i) shutdown of the $\mathrm{CO}_{2}$ system for calibration, which was done once a day and which resulted in the loss of one 30-minute average value, and ii) covering of the sonic anemometer to prevent its damage by heavy rain. There were various other occurrences of apparently aberrant values unrelated to these two causes. In order to try to identify aberrant behavior more formally, during postprocessing all raw time series were scanned for each day and the outliers from the series were identified and examined in detail. In addition, the calculated time series of fluxes were examined for outliers. Typically, when an outlier was found, the field notes were consulted to see if some action on the tower or in the vicinity of the instrument had been recorded that would have caused the outlier to occur. Irrespective of whether we could tie the outlier to a cause, a simple linear interpolation was applied if the outlier was judged aberrant, the period of bad data was short, and steady state conditions applied. If it was clear that the data point was wrong and it could not be corrected or interpolated, it was flagged and a missing value place holder inserted. It is admitted that this process is not totally objective and it does involve some judgments based upon field experience. We do claim that the data acceptance criteria were conservative; i.e., it was normal to reject an apparently aberrant data point unless there was very strong evidence to the contrary.

\subsubsection{Data Validation by Source}

The data set has been checked for internal consistency, and all aberrant values have been either removed or interpolated. Aberrant values that could not be interpolated, along with truly missing values, have been designated in the files as missing data. See Section 10.2 for elaboration.

\subsubsection{Confidence Level/Accuracy Judgment}

The overall best estimate of accuracy of the primary variables are as follows:

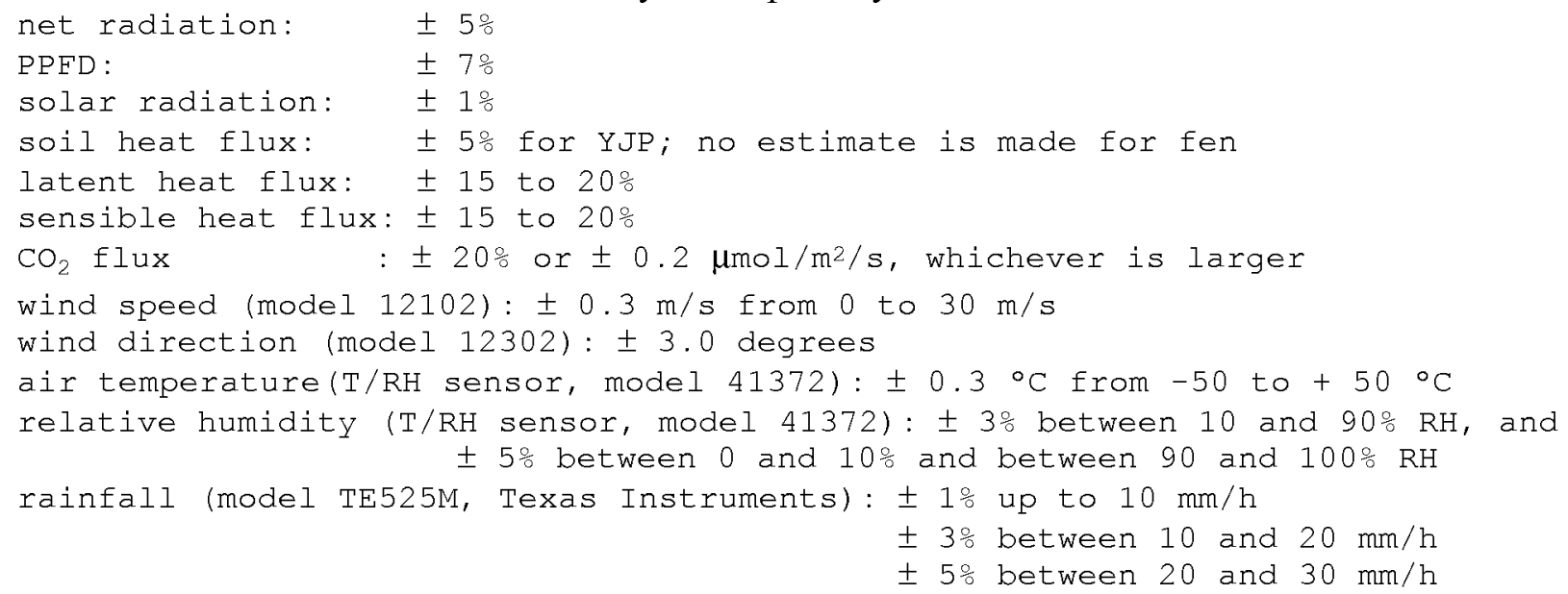


In 1993, 1995, and 1996, no correction factor was applied to the fen's soil heat flux data. Rather, we report the flux values measured by the plate(s). This is a puzzling result, but if the same correction value had been applied as in 1994, totally unreasonable values of flux would have resulted. In fact, the energy balance closures would have consistently been much greater than unity as a result. This points out the difficulty of measuring heat storage in the peat soil. We suggest that our application of different methodologies can be explained in the following way. In 1994, only the plate in the hollow exhibited any diurnal pattern, but the size and amplitude of the measured flux was tiny. The signal from the plate in the hummock showed zero amplitude, and was a flat line during the whole day, we believe as a result of poor thermal contact between the plate and the peat. Such patterns were not observed in the other sample years, when both plates exhibited similar and significant signal sizes and diurnal amplitudes. Furthermore, accepting the measured fluxes in these sample years results in reasonable energy balance closures. However, the measurement of soil heat flux on a fen remains a confounding problem, and it requires further careful assessment in terms of measurement methodology.

Another problem that caused serious questioning of our methodology was the measurement of the $\mathrm{CO}_{2}$ flux at night. This problem was most apparent at the YJP. After examination of the data, it was concluded that the measured fluxes should be replaced with modeled values in order to obtain reasonable diurnal patterns. The issue of how best to measure $\mathrm{CO}_{2}$ fluxes at night under low turbulent mixing conditions remains a priority. In addition, there are outstanding issues on the best way to model the nighttime $\mathrm{CO}_{2}$ flux.

\subsubsection{Measurement Error for Parameters}

See Section 10.2.2.

\subsubsection{Additional Quality Assessments}

None given.

\subsubsection{Data Verification by Data Center}

Data were examined to check for spikes, values that are four standard deviations from the mean, long periods of constant values, and missing data.

\section{Notes}

\subsection{Limitations of the Data}

At this time (June 1998), the data series are not continuous. Where there were measurement problems, e.g., as a result of a sensor failure or a power failure, missing value place holders have been inserted. We are working toward providing robust methods for reconstruction of large data gaps. One method that has been fairly successful is to construct the diurnal patterns of fluxes using ensemble averaging. However, for users who require unbroken time series of 30-minute averages, these data will fall short. In most instances of a small gap, say one or two contiguous half-hours, in a period of steady-state atmospheric conditions, straight linear interpolation should work satisfactorily. If the atmospheric conditions are changing rapidly, or if the gap is large, say half a day, then a rigorous interpolation method will be required. Please consult the PI for progress on the development of interpolation routines for large data gaps.

At this time (June 1998), the eddy covariance flux data (sensible and latent heat and $\mathrm{CO}_{2}$ ) at the YJP site are from the Campbell Scientific single-axis sonic anemometer. A second sonic anemometer (Applied Technologies, Inc., (ATI), Boulder, CO, USA) was operational at the site in 1996, and both were located at the same height and orientation on the flux tower. The final calculation of the fluxes based on the ATI sonic data are not yet complete and are not included in this data set. 


\subsection{Known Problems with the Data}

Where tower flux sites do not have adequate upwind fetch, uncertainties are introduced into the interpretation of the flux data. We believe this may have been a problem at the fen. The eddy covariance instruments were located at a height of $4.5 \mathrm{~m}$ above the surface. Using the standard micrometeorological "rule-of-thumb" for fetch-to-height ratio of 100:1, a 4500-m fetch is required in all directions around the fen tower. The site did not meet this criterion. Fetch was limited along the northeast shore in the azimuth directions (from magnetic north) 350-0-125 degrees. Minimum fetch in this quadrant was approximately $150 \mathrm{~m}$ at a bearing 65 degrees. Similarly, fetch was limited along the south shore in the bearing 160-235 degrees. Minimum fetch in this quadrant was $220 \mathrm{~m}$ at the bearing 205 degrees. Fetch in all other directions exceeded $450 \mathrm{~m}$. Measurements for all wind directions were reported in the data set, and users are cautioned as to this possible source of uncertainty.

\subsection{Usage Guidance}

Data gaps have been filled using linear interpolation. This method applies only to short periods, a few half-hours at best, under steady-state conditions. If the meteorological conditions are changing, linear interpolation fails. It also fails if the data gap is longer than a few half-hours. When we encountered a long data gap, we left the data field blank and assigned a "missing value" place holder. Given that we did have significant gaps in the flux series because of the difficulties of the Campbell sonic anemometer in rainy weather, we have used ensemble averaging to create complete average diurnal curves of fluxes for publications. We recognize that ensemble average data are not necessarily the ideal kind for modelers who prefer unbroken time series for each variable.

\subsection{Other Relevant Information}

None.

\section{Application of the Data Set}

These data can be used for various applications. For example, they will provide meteorological input variables for a wide range of models. Also, for those models that estimate fluxes, the data set provides flux data series for sensible and latent heat and $\mathrm{CO}_{2}$ for model verification.

\section{Future Modifications and Plans}

Once the data processing is complete, we will submit the convective and $\mathrm{CO}_{2}$ flux data for YJP in 1996 based on measurements from the ATI sonic anemometer. Secondly, we are working on a more objective method to fill data gaps.

\section{Software}

\subsection{Software Description}

The measurement of the raw data was principally on Campbell Scientific data loggers, and all of the specific control programs for these data loggers are available.

A variety of software was used in the data assessment and analysis. STORAG, a Fortran program to find the minor heat storage terms in the energy balance, calculated the surface soil heat flux, the biomass heat storage, and the latent and sensible heat storage in the air up to the level of measurement of net radiation, where the surface balance was closed. RADBAL, a Fortran program to solve the terms of the energy balance, was used in the analysis of the radiation balance data, including the calculation of shortwave and PPFD albedos, and the radiative surface temperatures. We developed a number of QuattroPro spreadsheets for the calculation of convective fluxes ( $\mathrm{H}$ and $\mathrm{LE}$ ) and the $\mathrm{CO}_{2}$ flux, including the correction of the fluxes for density effects and ensemble averaging to construct 
average daily flux patterns for the days included in the average. Ensemble averaging was used as a means to find the mean diurnal pattern from often incomplete flux data series on individual days. This methodology was successful and was favored over the development of other means for filling data gaps. However, active research on the issue of how best to fill data gaps continues.

\subsection{Software Access}

All software developed for the analysis of the data is available by contacting J.H. McCaughey (PI).

\section{Data Access}

The NSA-Fen tower flux and meteorological data are available from the Earth Observing System Data and Information System (EOSDIS) Oak Ridge National Laboratory (ORNL) Distributed Active Archive Center (DAAC).

\subsection{Contact Information}

For BOREAS data and documentation please contact:

ORNL DAAC User Services

Oak Ridge National Laboratory

P.O. Box 2008 MS-6407

Oak Ridge, TN 37831-6407

Phone: (423) 241-3952

Fax: (423) 574-4665

E-mail: ornldaac@ornl.gov or ornl@eos.nasa.gov

\subsection{Data Center Identification}

Earth Observing System Data and Information System (EOSDIS) Oak Ridge National Laboratory (ORNL) Distributed Active Archive Center (DAAC) for Biogeochemical Dynamics http://www-eosdis.ornl.gov/.

\subsection{Procedures for Obtaining Data}

Users may obtain data directly through the ORNL DAAC online search and order system [http://www-eosdis.ornl.gov/] and the anonymous FTP site [ftp://www-eosdis.ornl.gov/data/] or by contacting User Services by electronic mail, telephone, fax, letter, or personal visit using the contact information in Section 15.1.

\subsection{Data Center Status/Plans}

The ORNL DAAC is the primary source for BOREAS field measurement, image, GIS, and hardcopy data products. The BOREAS CD-ROM and data referenced or listed in inventories on the CD-ROM are available from the ORNL DAAC.

\section{Output Products and Availability}

\subsection{Tape Products}

None.

\subsection{Film Products}

None.

\subsection{Other Products}

These data are available on the BOREAS CD-ROM series. 


\section{References}

\subsection{Platform/Sensor/Instrument/Data Processing Documentation}

All persons from Queen's University, Kingston, Ontario, who worked on the flux towers received training on tower climbing techniques, tower rescue methods, and the operation of a safe field site. The material is summarized in McCaughey (1993), and a summary of the training materials can be found in the tower safety document.

The data analysis to find the minor heat storage terms in the energy balance was accomplished with the software program titled STORAG, and details of this software are available in McCaughey (1991).

\subsection{Journal Articles and Study Reports}

Alemdag, I.S. 1983. Mass equations and merchantability factors for Ontario softwoods. Inf. Rep. PI-X-23, 27, Natl. For. Inst., Petawawa, Ontario, Canada.

Brand, D.G. 1987. Estimating the surface area of spruce and pine foliage from displaced volume and length. Can. J. For. Res. 17:1305-1308.

Campbell, G.S. and B.D. Tanner. 1985. A krypton hygrometer for measurement of atmospheric water vapor concentration. Moisture and Humidity 1985, Measurement and Control in Science and Industry, Proc. 1985 Intl. Symp. on Moisture and Humidity, Washington, D.C, 609-612.

Campbell, G.S. and M.H. Unsworth. 1979. An inexpensive sonic anemometer for eddy correlation. J. Appl. Meteorol. 18:1072-1077.

Chen, J.M. and T.A. Black. 1992. Foliage area and architecture of plant canopies from sunfleck size distributions. Agric. For. Meteorol. 60:249-266.

Costello, A.M. 1995. Canopy Characteristics and Surface-Atmosphere Interactions of a Young Jack Pine Forest Near Thompson, Manitoba, M.Sc. Thesis, Queen's University, Kingston, Ontario, 125 pp.

Gower, S.T. and J.M. Norman. 1991. Rapid estimation of leaf area index in conifer and broad-leaf plantations. Ecology 72:1896-1900.

Halliwell, D.H. and W.R. Rouse. 1987. Soil heat flux in permafrost: Characteristics and accuracy of measurement. J. Climatol. 7:571-584.

Hodges, G.B. and E.A. Smith. 1997. Intercalibration, objective analysis, intercomparison, and synthesis of BOREAS surface net radiation measurements. Journal of Geophysical Research 102(D24): 28,885-28,900.

Joiner, D.W. 1994. Corrections to TF-10 eddy covariance fluxes. Queen's University internal report, $23 \mathrm{pp}$.

Lafleur, P.M., J.H. McCaughey, D.W. Joiner, P.A. Bartlett, and D.E. Jelinski. 1997. Seasonal trends in energy, water, and carbon dioxide fluxes at a northern boreal wetland. Journal of Geophysical Research 102(D24): 29,009-29,020.

Leclerc, M.Y. and G.W. Thurtell. 1990. Footprint prediction of scalar fluxes using a Markovian analysis. Boundary-Layer Meteorol. 52:247-258.

Leuning, R. and J. Moncrieff. 1990. Eddy-covariance $\mathrm{CO}_{2}$ flux measurement using open- and closed-path $\mathrm{CO}_{2}$ analyzers: Corrections for analyzer water vapor sensitivity and damping of fluctuations in air sampling tubes. Boundary-Layer Meteorol. 53:63-76. 
Leuning, R. and K.M. King. 1992. Comparison of eddy-covariance measurements of $\mathrm{CO}_{2}$ fluxes by open- and closed-path $\mathrm{CO}_{2}$ analyzers. Boundary-Layer Meteorol. 59:297-311.

McCaughey, J.H. 1991. Safety in Climatology: a Seminar on Tower Climbing. 7 pp., 1987, last revision in 1993.

McCaughey, J.H. RTDMS Program Manual, Second Edition, Delta T Documents, 50 pp..

McCaughey, J.H. and W.L. Saxton. 1988. Energy balance storage terms in a mixed forest. Agric. For. Meteorol. 44:1-18.

McCaughey, J.H., P.M. Lafleur, D.W. Joiner, P.A. Bartlett, A.M. Costello, D.E. Jelinski, and M.G. Ryan. 1997. Magnitudes and seasonal patterns of energy, water, and carbon exchanges at a boreal young jack pine forest in the BOREAS northern study area. Journal of Geophysical Research 102(D24):28,997-29,007.

Mueller-Dombois, D. and H. Ellenberg. 1974. Aims and Methods of Vegetation Ecology. J. Wiley \& Sons, New York, 547 pp.

Newcomer, J., D. Landis, S. Conrad, S. Curd, K. Huemmrich, D. Knapp, A. Morrell, J. Nickeson, A. Papagno, D. Rinker, R. Strub, T. Twine, F. Hall, and P. Sellers, eds. 2000. Collected Data of The Boreal Ecosystem-Atmosphere Study. NASA. CD-ROM.

Saxton, W.L. and J.H. McCaughey. 1988. Measurement considerations and trends in biomass heat storage of a mixed forest. Can. J. For. Res. 18:143-149.

Schmid, H.P. and T.R. Oke. 1990. A model to estimate the source area contributing to turbulent exchange in the surface layer over patchy terrain. Quart. J. Roy. Meteorol. Soc. 116:965-988.

Sellers, P. and F. Hall. 1994. Boreal Ecosystem-Atmosphere Study: Experiment Plan. Version 1994-3.0, NASA BOREAS Report (EXPLAN 94).

Sellers, P. and F. Hall. 1996. Boreal Ecosystem-Atmosphere Study: Experiment Plan. Version 1996-2.0, NASA BOREAS Report (EXPLAN 96).

Sellers, P., F. Hall, and K.F. Huemmrich. 1996. Boreal Ecosystem-Atmosphere Study: 1994 Operations. NASA BOREAS Report (OPS DOC 94).

Sellers, P., F. Hall, and K.F. Huemmrich. 1997. Boreal Ecosystem-Atmosphere Study: 1996 Operations. NASA BOREAS Report (OPS DOC 96).

Sellers, P., F. Hall, H. Margolis, B. Kelly, D. Baldocchi, G. den Hartog, J. Cihlar, M.G. Ryan, B. Goodison, P. Crill, K.J. Ranson, D. Lettenmaier, and D.E. Wickland. 1995. The boreal ecosystem-atmosphere study (BOREAS): an overview and early results from the 1994 field year. Bulletin of the American Meteorological Society. 76(9):1549-1577.

Sellers, P.J., F.G. Hall, R.D. Kelly, A. Black, D. Baldocchi, J. Berry, M. Ryan, K.J. Ranson, P.M. Crill, D.P. Lettenmaier, H. Margolis, J. Cihlar, J. Newcomer, D. Fitzjarrald, P.G. Jarvis, S.T. Gower, D. Halliwell, D. Williams, B. Goodison, D.E. Wickland, and F.E. Guertin. 1997. BOREAS in 1997: Experiment Overview, Scientific Results and Future Directions. Journal of Geophysical Research 102(D24): 28,731-28,770. 
Smith, E.A., G.B. Hodges, M. Bacrania, H.J. Cooper, M.A. Owens, R. Chappell, and W. Kincannon. 1997. Final Report NASA Grant NAG5-2447, BOREAS Net Radiometer Engineering Study. Goddard Space Flight Center, Greenbelt, Maryland. 51 pp.

Smith, N.J., J.M. Chen, and T.A. Black. 1993. Effects of clumping on estimates of stand leaf area index using the LI-COR LAI 2000. Can. J. For. Res. 23:1940-1943.

Tanner, B.T., E. Swiatek, and J.P. Greene. 1993. Density fluctuations and use of the krypton hygrometer in surface flux measurements. Proceedings of the 1993 National Conference on Irrigation and Drainage Engineering, American Society of Civil Engineers, Park City, Utah.

Thom, A.S. 1975. Momentum, mass and heat exchange of plant communities. In: Vegetation and the Atmosphere, Vol. 1 (Ed. J. L. Monteith), Academic Press, London. pp. 57-109.

Webb, E.K. 1982. On the correction of flux measurements for effects of heat and water vapor transfer. Boundary-Layer Meteorol. 23:251-254.

Webb, E.K., G.I. Pearman, and R. Leuning. 1980. Correction of flux measurements for density effects due to heat and water vapor transfer. Quart. J. Roy. Meteorol. Soc. 106:85-100.

\subsection{Archive/DBMS Usage Documentation}

None.

\section{Glossary of Terms}

\begin{tabular}{|c|c|c|}
\hline Symbol & Quantity & Units \\
\hline------------- & --------------------------------------------------- & ------ \\
\hline a & Albedo & dim. \\
\hline $\mathrm{AT}$ & Total needle area & $\mathrm{cm} 2$ \\
\hline $\mathrm{C}$ & Volumetric heat capacity of soil & $\mathrm{J} / \mathrm{m} 3 /{ }^{\circ} \mathrm{C}$ \\
\hline$C^{\prime}$ & CO2 concentration per volume fluctuation & ppmv \\
\hline $\mathrm{CF}$ & Correction factor & dim. \\
\hline $\mathrm{Cm}$ & Heat capacity of mineral fraction & $\mathrm{J} / \mathrm{m} 3 /{ }^{\circ} \mathrm{C}$ \\
\hline Co & Heat capacity of organic soil & $\mathrm{J} / \mathrm{m} 3 /{ }^{\circ} \mathrm{C}$ \\
\hline Co2night & Net $\mathrm{CO} 2 \mathrm{flux}$ from model when $\mathrm{Kd}<5 \mathrm{~W} / \mathrm{m} 2$ & $\mu \mathrm{mol} / \mathrm{m} 2 / \mathrm{s}$ \\
\hline CON & $\begin{array}{l}\text { Constant used in STORAG to find heat storage in } \\
\text { air, soil, and vegetation }\end{array}$ & $\mathrm{J} / \mathrm{m} 3 /{ }^{\circ} \mathrm{C} / \mathrm{s}$ \\
\hline $\mathrm{Cp}$ & Specific heat of air at constant pressure & $\mathrm{J} / \mathrm{kg} /{ }^{\circ} \mathrm{C}$ \\
\hline $\mathrm{CW}$ & Heat capacity of water & $\mathrm{J} / \mathrm{m} 3 /{ }^{\circ} \mathrm{C}$ \\
\hline $\mathrm{dbh}$ & Diameter at breast height & $\mathrm{cm}$ \\
\hline de & Rate of change in vapor pressure & $\mathrm{kPa} / \mathrm{s}$ \\
\hline dim. & Dimensionless number & dim. \\
\hline DS & Depth of temperature measurements & $\mathrm{m}$ \\
\hline $\mathrm{dTa}$ & Rate of change in air temperature & ${ }^{\circ} \mathrm{C} / \mathrm{s}$ \\
\hline $\mathrm{dTb}$ & Rate of change in biomass temperature & ${ }^{\circ} \mathrm{C} / \mathrm{s}$ \\
\hline dTs & Rate of change in soil temperature & ${ }^{\circ} \mathrm{C} / \mathrm{s}$ \\
\hline $\mathrm{FeCO} 2$ & $\begin{array}{l}\text { Eddy flux of CO2 (equivalent to net flux at height } \\
\text { of measurement) }\end{array}$ & $\begin{array}{l}\mu \mathrm{mol} / \mathrm{m} 2 / \mathrm{s} \text { or } \\
\mathrm{mg} / \mathrm{m} 2 / \mathrm{s}\end{array}$ \\
\hline $\mathrm{EsCO} 2$ & Storage flux of $\mathrm{CO} 2$ & $\mu \mathrm{mol} / \mathrm{m} 2 / \mathrm{s}$ \\
\hline $\mathrm{FCO} 2$ & Total Co2 flux & $\mu \mathrm{mol} / \mathrm{m} 2 / \mathrm{s}$ \\
\hline G & Soil heat flux at surface & $\mathrm{W} / \mathrm{m} 2$ \\
\hline$G(z)$ & Soil heat flux measured at depth $\mathrm{z}$ & $\mathrm{W} / \mathrm{m} 2$ \\
\hline G10 & Heat storage in the soil volume above $10-\mathrm{cm}$ depth & $\mathrm{W} / \mathrm{m} 2$ \\
\hline
\end{tabular}

Page 66 


\begin{tabular}{|c|c|c|}
\hline $\mathrm{Ga}$ & Sensible heat storage in air & $\mathrm{W} / \mathrm{m} 2$ \\
\hline GB & $\begin{array}{l}\text { Heat flux out the bottom of the soil profile at } \\
\text { the fen }\end{array}$ & $\mathrm{W} / \mathrm{m} 2$ \\
\hline Gcal & Total heat storage in the soil profile at fen & $\mathrm{W} / \mathrm{m} 2$ \\
\hline $\mathrm{Ge}$ & Latent heat storage in air & $\mathrm{W} / \mathrm{m} 2$ \\
\hline Gfen & Ground heat flux at the fen in 1994 & $\mathrm{~W} / \mathrm{m} 2$ \\
\hline Ghol & Ground heat flux in hollow at the fen & $\mathrm{W} / \mathrm{m} 2$ \\
\hline$G(z) n$ & Soil heat flux at YJP (north site) & $\mathrm{W} / \mathrm{m} 2$ \\
\hline Gpla & Time-integrated soil flux from plate at fen & $\mathrm{W} / \mathrm{m} 2$ \\
\hline$G(z) w$ & Soil heat flux at YJP (west site) & $\mathrm{W} / \mathrm{m} 2$ \\
\hline G_total & Total heat storage & $\mathrm{W} / \mathrm{m} 2$ \\
\hline G totaln & Total heat storage at YJP (north site) & $\mathrm{W} / \mathrm{m} 2$ \\
\hline G_totalw & Total heat storage at YJP (west site) & $\mathrm{W} / \mathrm{m} 2$ \\
\hline Gveg & Heat storage in biomass at YJP & $\mathrm{W} / \mathrm{m} 2$ \\
\hline Gvegn & Heat storage in biomass at YJP (north site) & $\mathrm{W} / \mathrm{m} 2$ \\
\hline Gvegw & Heat storage in biomass at YJP (west site) & $\mathrm{W} / \mathrm{m} 2$ \\
\hline h & Tree height & $\mathrm{m}$ \\
\hline $\mathrm{H}$ & Sensible heat flux & $\mathrm{W} / \mathrm{m} 2$ \\
\hline HCS & Heat capacity of soil in STORAG & $\mathrm{J} / \mathrm{m} 3 /{ }^{\circ} \mathrm{C}$ \\
\hline $\mathrm{Kd}$ & Incoming solar radiation & $\mathrm{W} / \mathrm{m} 2$ \\
\hline Ku & Reflected solar radiation & $\mathrm{W} / \mathrm{m} 2$ \\
\hline Ks & Thermal conductivity of saturated peat soil & $\mathrm{W} / \mathrm{m} / \mathrm{K}$ \\
\hline $\mathrm{k}$ & Instrument $\mathrm{H} 20$ vapor absorption coefficient & $\mathrm{m} 3 / \mathrm{kg} / \mathrm{cm}$ \\
\hline $\mathrm{K}^{*}$ & Total shortwave radiation & $\mathrm{W} / \mathrm{m} 2$ \\
\hline L & Latent heat of vaporization of water & $\mathrm{J} / \mathrm{kg}$ \\
\hline LE & Latent heat flux & $\mathrm{W} / \mathrm{m} 2$ \\
\hline $\mathrm{Ld}$ & Incoming longwave radiation & $\mathrm{W} / \mathrm{m} 2$ \\
\hline Lu & Outgoing longwave radiation & $\mathrm{W} / \mathrm{m} 2$ \\
\hline $\mathrm{L} *$ & Net longwave radiation & $\mathrm{W} / \mathrm{m} 2$ \\
\hline M & Molecular weight of dry air & Mole \\
\hline mis. & Missing value & dim. \\
\hline MV & Standing green biomass & $\mathrm{kg} / \mathrm{m} 2$ \\
\hline $\mathrm{P}$ & Atmospheric pressure & $\mathrm{kPa}$ \\
\hline $\mathrm{PA}$ & Total projected needle area & $\mathrm{cm} 2$ \\
\hline $\mathrm{PA}(\mathrm{S})$ & Shoot projected area & $\operatorname{cm} 2$ \\
\hline PPFDd & Incoming PPFD & $\mu \mathrm{mol} / \mathrm{m} 2 / \mathrm{s}$ \\
\hline PPFDu & Reflected PPFD & $\mu \mathrm{mol} / \mathrm{m} 2 / \mathrm{s}$ \\
\hline Qd & Total incoming radiation & $\mathrm{W} / \mathrm{m} 2$ \\
\hline$Q G Z$ & Soil heat flux from flux plate (for STORAG only) & $\mathrm{W} / \mathrm{m} 2$ \\
\hline Qu & Total outgoing radiation & $\mathrm{W} / \mathrm{m} 2$ \\
\hline$Q^{*}$ & Net radiation & $\mathrm{W} / \mathrm{m} 2$ \\
\hline$Q^{*} \operatorname{cor} r$ & $\begin{array}{l}\text { Corrected net radiation (following Hodges and } \\
\text { Smith (1997)) }\end{array}$ & $\mathrm{W} / \mathrm{m} 2$ \\
\hline q & Water vapor density & $\mathrm{g} / \mathrm{m} 3$ \\
\hline$q^{\prime}$ & Water vapor density fluctuation & $\mathrm{g} / \mathrm{m} 3$ \\
\hline $\mathrm{R}$ & Universal gas constant & $\mathrm{J} / \mathrm{mol} / \mathrm{K}$ \\
\hline$R^{\prime}$ & Conifer correction factor & dim. \\
\hline rho & Density of air & $\mathrm{kg} / \mathrm{m} 3$ \\
\hline rho (c) & Density of $\mathrm{CO} 2$ & $\mathrm{~kg} / \mathrm{m} 3$ \\
\hline$s$ & Signal voltage from hygrometer & $\mathrm{mv}$ \\
\hline $\mathrm{S}$ & $\begin{array}{l}\text { Flux equivalent to the heat stored between } \\
\text { individual soil layers }\end{array}$ & $\mathrm{W} / \mathrm{m} 2$ \\
\hline $\mathrm{SH}$ & Specific humidity & $\mathrm{g} / \mathrm{kg}$ \\
\hline sSH & Standard deviation of specific humidity & $\mathrm{g} / \mathrm{kg}$ \\
\hline
\end{tabular}

\section{Page 67}




\begin{tabular}{|c|c|c|}
\hline$T^{\prime}$ & Temperature fluctuation & ${ }^{\circ} \mathrm{C}$ \\
\hline T_air & Air temperature & ${ }^{\circ} \mathrm{C}$ \\
\hline $\mathrm{TB}$ & Biomass temperature in STORAG & ${ }^{\circ} \mathrm{C}$ \\
\hline $\mathrm{Tb} l \mathrm{~W}$ & Stem temperature of large trees (west site) & ${ }^{\circ} \mathrm{C}$ \\
\hline Tbmw & Stem temperature of medium trees (west site) & ${ }^{\circ} \mathrm{C}$ \\
\hline Tbsn & Stem temperature of small trees (north site) & ${ }^{\circ} \mathrm{C}$ \\
\hline Tbsw & Stem temperature of small trees (west site) & ${ }^{\circ} \mathrm{C}$ \\
\hline TD & Dry bulb temperature in STORAG & ${ }^{\circ} \mathrm{C}$ \\
\hline TOL & Thickness of organic layer in STORAG & $\mathrm{m}$ \\
\hline Ts & Soil temperature & ${ }^{\circ} \mathrm{C}$ \\
\hline Tsloavg & Average soil temperature at $10-\mathrm{cm}$ depth & ${ }^{\circ} \mathrm{C}$ \\
\hline Ts75avg & Average soil temperature at $75-\mathrm{cm}$ depth & ${ }^{\circ} \mathrm{C}$ \\
\hline $\mathrm{TW}$ & Wet-bulb temperature & ${ }^{\circ} \mathrm{C}$ \\
\hline $\mathrm{U}$ & Wind speed & $\mathrm{m} / \mathrm{s}$ \\
\hline $\mathrm{v}$ & Intercept of the krypton hygrometer calibration & $\mathrm{mv}$ \\
\hline$w^{\prime}$ & Vertical wind velocity & $\mathrm{m} / \mathrm{s}$ \\
\hline $\mathrm{x}$ & Path length of the hygrometer & $\mathrm{cm}$ \\
\hline $\mathrm{Xm}$ & Soil volumetric mineral fraction & fraction \\
\hline Xo & Soil volumetric organic soil fraction & fraction \\
\hline $\mathrm{XW}$ & Soil volumetric water fraction & fraction \\
\hline$X W$ & Soil moisture content in STORAG & fraction \\
\hline$z$ & Depth to soil heat flux plate & $\mathrm{m}$ \\
\hline ZCQ & $\begin{array}{l}\text { Control variable in STORAG; used to read two } \\
\text { variables: height of canopy and heightof net } \\
\text { pyrradiometer }\end{array}$ & $\mathrm{m}, \mathrm{m}$ \\
\hline $\mathrm{zr}$ & Reference height & $\mathrm{m}$ \\
\hline $\mathrm{ZR}$ & $\begin{array}{l}\text { Height of net radiation measurement in early } \\
\text { version of STORAG }\end{array}$ & $\mathrm{m}$ \\
\hline
\end{tabular}

\section{List of Acronyms}

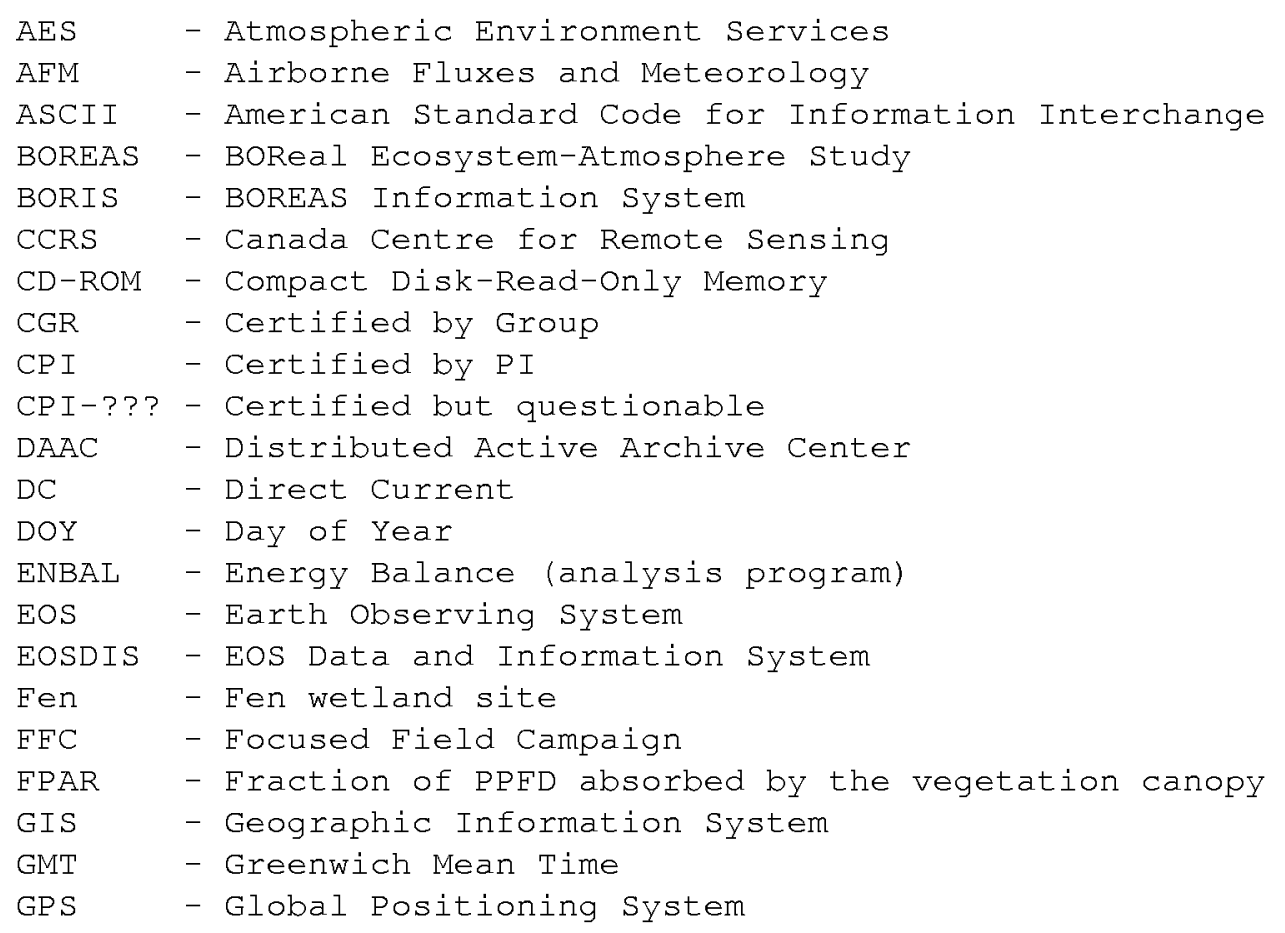






\section{Document Information}

\subsection{Document Revision Date}

Written: 06-Jun-1998

Revised: 20-Dec-1999

\subsection{Document Review Date(s)}

BORIS Review: 03-Dec-1998

Science Review:

\subsection{Document ID}




\subsection{Citation}

These data were provided by BOREAS Team TF-10; the primary consultants include:

Flux and meteorological data (YJP and Fen):

Dr. J. Harry McCaughey, Department of Geography, Queen's University, Kingston, ON, CANADA, K7L 3N6 (PI) and Dr. Peter M. Lafleur, Department of Geography, Trent University, Peterborough, ON, CANADA, K9J 7B8. Both investigators should be acknowledged in all future publications.

Fen biophysical data:

Dr. Dennis E. Jelinski, Department of Geography, Queen's University, Kingston, ON, CANADA, K7L 3N6 (PI).

YJP biophysical data:

Dr. J. Harry McCaughey, Department of Geography, Queen's University, Kingston, ON, CANADA, K7L 3N6 (PI).

In addition, please include citations of relevant papers in Section 17.2.

If using data from the BOREAS CD-ROM series, also reference the data as:

McCaughey, J.H. and D.E. Jelinski, "Surface Energy and Water Balances of Forest and Wetland Subsystems in the Boreal Forest - Surface Atmosphere Links and Ecological Controls." In Collected Data of The Boreal Ecosystem-Atmosphere Study. Eds. J. Newcomer, D. Landis, S. Conrad, S. Curd, K. Huemmrich, D. Knapp, A. Morrell, J. Nickeson, A. Papagno, D. Rinker, R. Strub, T. Twine, F. Hall, and P. Sellers. CD-ROM. NASA, 2000.

Also, cite the BOREAS CD-ROM set as:

Newcomer, J., D. Landis, S. Conrad, S. Curd, K. Huemmrich, D. Knapp, A. Morrell, J.

Nickeson, A. Papagno, D. Rinker, R. Strub, T. Twine, F. Hall, and P. Sellers, eds. Collected Data of The Boreal Ecosystem-Atmosphere Study. NASA. CD-ROM. NASA, 2000.

\subsection{Document Curator}

\subsection{Document URL}



gathering and maintaining the data needed and completing and reviewing the collection of information. Send comments regarding this burden estimate or any other aspect of this collection of information including suggestions for reducing this burden to Washington Headguarters Services, Directorate for Information Operations and Reports 1215 Jefferson Davis Highway, Suite 1204, Arlington, VA 22202-4302, and to the Office of Management and

\begin{tabular}{l|l|l|l}
\hline 1. AGENCY USE ONLY (Leave blank) & $\begin{array}{c}\text { 2. REPORT DATE } \\
\text { November 2000 }\end{array}$ & $\begin{array}{r}\text { 3. REPORT TYPE AND DATES COVERED } \\
\text { Technical Memorandum }\end{array}$ \\
\hline
\end{tabular}

4. TITLE AND SUBTITLE

November 2000

5. FUNDING NUMBERS

Technical Report Series on the Boreal Ecosystem-Atmosphere Study (BOREAS)

BOREAS TF-10 NSA-Fen Tower Flux and Meteorological Data

\section{AUTHOR(S)}

J. Harry McCaughey and Dennis E. Jelinski

Forrest G. Hall and Karl Huemmrich, Editors

7. PERFORMING ORGANIZATION NAME(S) AND ADDRESS (ES)

Goddard Space Flight Center

Greenbelt, Maryland 20771

923

RTOP: $923-462-33-01$

9. SPONSORING / MONITORING AGENCY NAME(S) AND ADDRESS (ES)

10. SPONSORING / MONITORING AGENCY REPORT NUMBER

National Aeronautics and Space Administration

Washington, DC 20546-0001

TM-2000-209891

Vol. 207

\section{SUPPLEMENTARY NOTES}

J.H. McCaughey and D.E. Jelinski: Queen's University, Kingston, Ontario;

K. Huemmrich: University of Maryland, NASA Goddard Space Flight Center, Greenbelt, Maryland

\begin{tabular}{l|l}
\hline 12a. DISTRIBUTION / AVAILABILITY STATEMENT & 12b. DISTRIBUTION CODE \\
Unclassified-Unlimited & \\
Subject Category: 43 & \\
Report available from the NASA Center for AeroSpace Information, \\
7121 Standard Drive, Hanover, MD 21076-1320. (301) $621-0390$.
\end{tabular}

13. ABSTRACT (Maximum 200 words)

The BOREAS TF-10 team collected tower flux and meteorological data at two sites, a fen and a young jack pine forest, near Thompson, Manitoba, Canada, as part of BOREAS. A preliminary data set was assembled in August 1993 while field testing the instrument packages, and at both sites data were collected from 15-Aug to 31-Aug. The main experimental period was in 1994, when continuous data were collected from 08-Apr to 23-Sep at the fen site. A very limited experiment was run in the spring/ summer of 1995, when the fen site tower was operated from 08-Apr to 14-Jun in support of a hydrology experiment in an adjoining feeder basin. Upon examination of the 1994 data set, it became clear that the behavior of the heat, water, and carbon dioxide fluxes throughout the whole growing season was an important scientific question, and that the 1994 data record was not sufficiently long to capture the character of the seasonal behavior of the fluxes. Thus, the fen site was operated in 1996 in order to collect data from spring melt to autumn freeze-up. Data were collected from 29-Apr to 05-Nov at the fen site. All variables are presented as 30-minute averages. The data are stored in tabular ASCII files.

\section{SUBJECT TERMS}

BOREAS, tower flux, meteorological data.
15. NUMBER OF PAGES 70

16. PRICE CODE

\begin{tabular}{l|c|c} 
17. SECURITY CLASSIFICATION & 18. SECURITY CLASSIFICATION & 19. SECURITY CLASSIFICATION \\
OF REPORT & OF THIS PAGE & OF ABSTRACT \\
Unclassified & Unclassified & Unclassified
\end{tabular}

20. LIMITATION OF ABSTRACT

UL 
